\title{
1 A transcriptomic atlas of Aedes aegypti reveals 2 detailed functional organization of major body parts 3 and gut regional specializations in sugar-fed and 4 blood-fed adult females
}

6 Bretta Hixson ${ }^{1}$, Xiao-Li Bing ${ }^{1,2}$, Xiaowei Yang ${ }^{1,3}$, Alessandro Bonfini ${ }^{1}$, Peter Nagy ${ }^{1}$, Nicolas

7 Buchon $^{1^{*}}$

8 Addresses:

9 1: Cornell Institute of Host-Microbe Interactions and Disease, Department of Entomology, 10 Cornell University, Ithaca, NY, 14853, USA

11 2: Current address: Department of Entomology, Nanjing Agricultural University, Nanjing, 12 Jiangsu 210095, China 3: Current address: State Key Laboratory for Biology of Plant Diseases and Insect Pests,

14 Institute for Plant Protection, Chinese Academy of Agricultural Sciences, Beijing 100193, China

15 Keywords:

16 Aedes, Anopheles, mosquito, RNAseq, atlas, gut, transcriptome, blood feeding, proteases,

17 innate immunity, antimicrobial peptides 


\section{Abstract}

24 Mosquito vectors transmit numerous pathogens, but large gaps remain in our understanding of

25 their physiology. To facilitate future explorations of mosquito biology, with specific attention to

26 the major vector Aedes aegypti, we have created Aegypti-Atlas

27 (http://aegyptiatlas.buchonlab.com/), an online resource hosting RNAseq profiles of Ae. aegypti body parts (head, thorax, abdomen, gut, Malpighian tubules, and ovaries), gut regions (crop, proventriculus, anterior and posterior midgut, and hindgut), and a time course of blood meal digestion in the gut. Using Aegypti-Atlas, we provide new insights into the regionalization of gut function, blood feeding response, and immune defenses. We find that the anterior and posterior regions of the mosquito midgut possess clearly delineated digestive specializations which are preserved in the blood-fed state. Blood feeding initiates the sequential transcriptional induction and repression/depletion of multiple cohorts of peptidases throughout blood meal digestion. With respect to defense, immune signaling components, but not recognition or effector molecules, show enrichment in ovaries. Basal expression of antimicrobial peptides is dominated by two genes, holotricin and gambicin, that are expressed in the carcass and the digestive tissues, respectively, in a near mutually exclusive manner. In the midgut, gambicin and other

39 immune effector genes are almost exclusively expressed in the anterior regions, while the posterior midgut exhibits the hallmarks of immune tolerance. Finally, in a cross-species comparison between the midguts of Ae. aegypti and Anopheles gambiae, we observe that regional digestive and immune specializations are closely conserved, indicating that our data may yield inferences that are broadly relevant to multiple mosquito vector species. We further demonstrate that the expression of orthologous genes is highly correlated, with the exception of mosquito biology. 


\section{Introduction}

Hematophagous mosquito vectors contribute substantially to the world's disease burden

51 through the transmission of Plasmodium parasites and arboviruses [1]. With the rise of

52 insecticide resistance [2-4], and the expansion of mosquito species' ranges potentiated by

53 climate change [5], new and more efficient means of vector control are needed, grounded in a

54 solid understanding of mosquito physiology.

The mosquito gut is of special interest to vector control, as it is central to the hematophagous lifestyle and serves as the first interface between a mosquito and the

57 pathogens it transmits. In recent years, many groups have used microarrays and RNAseq to create transcriptomic profiles of different mosquito tissues, especially midguts, in the context of infection [6-13]. Here, we aimed to complement these efforts by (a) contextualizing the adult female gut's transcriptome with additional profiles of the whole body and other major body parts and organs (head, thorax, abdomen, Malpighian tubules, ovaries) (b) exploring regionalization of gut function by profiling the anatomically distinct regions of the adult female gut (crop,

63 proventriculus, anterior midgut, posterior midgut, hindgut) and (c) examining transcriptional responses to blood feeding in the anterior and posterior midgut and at multiple timepoints $(6,24$, and $48 \mathrm{hrs}$ ) after blood meal ingestion. For this project, we opted to profile Aedes aegypti, as it is among the most important insect vectors [14], with an increasing worldwide range [15], and a recently updated genome assembly [16]. All the resulting transcriptional data can be accessed at the Aegypti-Atlas online database we constructed (http://aegyptiatlas.buchonlab.com/).

71 by making it possible to quickly ascertain where in the body, and in what quantity, any gene of

72 interest is transcribed. FlyAtlas also showed how the various contributions of different organs 
added up to constitute the whole fly transcriptome, providing an estimate of the relative transcriptional yield of the parts of the Drosophila body. Similar anatomical datasets have been created for several species of Anopheles [11,19,20], but not for Aedes mosquitoes. While transcriptional profiles have been created for various Ae. aegypti body parts in diverse studies (e.g. head [21], Malpighain tubules [22], midgut [7,9,23-27], ovaries [28,29], carcass [28,30]), the lack of uniformity of strain and methodology between these studies makes direct comparison difficult. We elected to profile the major body parts and organs of female $A e$. aegypti in parallel with the gut with the dual goals of (a) creating an at-a-glance reference for the anatomical distribution of transcripts, genome-wide and (b) facilitating the identification of tissuespecific marker genes which may, in the future, be useful in the construction of tissue-specific expression systems.

Insect guts are highly regionalized organs, with specialized functions differentially distributed along their length [31-34]. The mosquito gut is divided into five anatomically distinct regions: foregut (comprising pharynx, dorsal diverticula, and crop), proventriculus, anterior midgut, posterior midgut, and hindgut. The crop and dorsal diverticula are muscular cuticle-lined sacs which store imbibed sugar for gradual release into the midgut [35]. In Anopheles gambiae, the proventriculus and anterior midgut were found to exhibit an enrichment of transcripts encoding antimicrobial peptides (AMPs) and anti-Plasmodium factors [13] suggesting that these regions serve a special defensive function against orally acquired pathogens. Within the midgut, digestive functions are believed to be divided between the anterior and posterior regions, with the former specializing in the digestion of nectar but playing no direct role in the digestion of the blood meal, which is processed in the posterior midgut [36]. The hindgut receives and eliminates excreta from the midgut and urine from the Malpighian tubules [35]. Genome-wide transcriptomic profiles have the potential to reveal much more detailed information about regionalized function in the mosquito gut. However, to our knowledge, only a single microarraybased study has ever characterized the transcriptomes of individual mosquito midgut regions 
99

\section{0}

\section{1}

[13] and no transcriptomic profiles have been generated for either foregut or hindgut tissues in any mosquito species. To address this lack, we created RNAseq profiles for all five regions of the Ae. aegypti gut. Additionally, to more thoroughly explore the roles of the anterior and posterior midgut in blood meal digestion, we created profiles for the two regions $24 \mathrm{hrs}$ after ingestion of a blood meal.

The Ae. aegypti gut's response to the ingestion of a blood meal has been characterized as a biphasic process. In the first phase mRNAs encoding a cohort of "early" serine endopeptidases, transcribed in response to juvenile hormone $(\mathrm{JH})$ secretion during previtellogenic maturation, are translated [37-42]. In the second, ecdysone signaling mediates the transcription of a "late" cohort of endo and exopeptidases, with the transcripts of key peptidases and overall proteolytic activity typically peaking around $24 \mathrm{hrs}$ post blood meal (pbm) [43-50]. The transcriptional timeline is, however, more complex than a simple early translation/late transcription paradigm might suggest. Several studies have, by RTqPCR and microarray, documented de novo transcription of peptidases and other genes peaking much earlier than $24 \mathrm{hrs} \mathrm{pbm} \mathrm{[51-53].} \mathrm{To} \mathrm{better} \mathrm{characterize} \mathrm{the} \mathrm{transcriptome} \mathrm{of} \mathrm{the} \mathrm{gut,} \mathrm{genome-}$ wide, over the course of the digestion of a blood meal, we created profiles for guts at 6,24 , and $48 \mathrm{hrs} \mathrm{pbm}$ to compare with a sugar-fed baseline.

With RNAseq profiles for body parts, gut regions, and blood-fed guts in hand, we launched a broad investigation into multiple aspects of mosquito biology. Our inquiries were guided by the following questions: What functions are associated with each body part? What are the functional specializations of the gut regions? How does the gut transcriptome change in the context of blood feeding, and how are those changes distributed in the midgut? What can our atlas tell us about the organization of mosquitoes' antimicrobial defenses? Finally, in a cross-species comparison between the midguts of Ae. aegypti and Anopheles gambiae, we asked whether the gut's structure-function relationship is conserved between two hematophagous mosquito vector species. 


\section{The transcriptional landscape of an adult mosquito reflects}

\section{the embryonic origins and functional signatures of its major}

\section{tissues}

In order to develop a transcriptomic atlas of some of the main body parts of Ae. aegypti, we generated RNAseq profiles from the whole bodies and dissected body parts (head, thorax, abdomen, gut, Malpighian tubules, and ovaries) of sucrose-fed adult mated female mosquitoes of a field-derived 'Thai' strain from a region where arbovirus transmission is endemic [54]. For the dissected body parts (but not whole body) we omitted the anterior-most section of the thorax as well as the final segments of the abdomen to exclude transcripts from salivary glands and from sperm in the spermatheca (see S1.1A for diagram). We first evaluated the relative variance between body part and whole-body profiles by Principal Component Analysis (PCA) (Fig 1A). All transcriptomes from the same body part clustered together closely, providing evidence for the replicability of our data. On PC1, body parts were grouped in a manner that accorded with their divergent embryonic origin (primarily mesoderm/ectoderm for head, thorax, and abdomen, endoderm for gut and Malpighian tubules) and whole-body transcriptomes were clustered in

142 between. Ovaries, which contain the germline, strongly separated from the other, exclusively somatic, body parts on PC2. Altogether, PCA indicated that the transcriptomes of body parts are largely defined by their embryonic origin, and that germline tissues possess a highly distinctive transcriptional signature. some of which, we hypothesize, may be exclusive tissue markers. We conducted a census of putative tissue markers (here defined as genes expressed at five or more transcripts per million 
(TPM) in one body part and enriched at least fifty-fold compared to all other body parts). Figure

1B presents a selection of markers from each body part (full census in S1 Table). The quantity of markers ranged from 8 in the abdomen to 391 in the ovaries, which expressed more markers than all other body parts combined; nearly one in fifty of all genes in the genome qualified as an ovary marker. We further noted that ovaries simultaneously expressed the greatest number of highly enriched transcripts relative to other dissected body parts (S1.1B Fig) and the smallest

155 number of highly enriched transcripts relative to whole body (S1.1C Fig). This apparent paradox 156 led us to hypothesize that the ovaries make a disproportionately large contribution to the 157 transcriptome of the whole female mosquito. A gene that is uniquely expressed in the ovaries will not be highly enriched relative to the whole mosquito body if the ovarian transcriptome comprises a large proportion of the whole body's transcriptome. reference gene for our assay over more traditional candidates [55], on the basis of its robust qPCR confirmed the anatomical specificity of each selected marker (S1.2B Fig).

The existence of transcripts specific to each body part allowed us to calculate their relative contribution to the whole body's transcriptome (see methods). Expressed as

167 percentages, the body part contributions we obtained were: head (4.7\%), thorax (19.4\%), 168 abdomen (26.2\%), gut (14.0\%), Malpighian tubules (1.7\%), and ovaries (28.8\%). Collectively, 169 these scaling factors sum to $94.9 \%$. We validated our estimates by using them to predict the 170 whole-body expression of every gene in the genome, then plotting those predictions against 171 observed values from the whole-body transcriptome (S1.3A Fig). Calculated and observed 172 values were highly correlated (slope of $1.00, R^{2}=0.95$ ) after removal of a single outlying gene 173 (AAEL018689, a mitochondrial ribosomal RNA) which was underpredicted by our calculation.

174 This analysis validates our hypothesis that the ovaries contribute a disproportionate number of 
175 transcripts to the whole-body transcriptome. Further, our data demonstrate that, due to the

176 preponderance of ovarian contribution, multiple tissues have only a low representation in the

177 body, severely limiting the ability to detect tissue-specific changes in whole-mosquito

178 experiments.

To examine the biological processes and molecular functions enriched in each body part, we performed a Gene Ontology Enrichment Analysis (GOEA) of genes 5x enriched in each body part (in comparison to whole body, DESeq2 padj <0.05). An extended list of GO categories may be found in S2 Table. We complemented this approach by identifying the twenty highest expressed genes in each body part (pie charts in Fig 1C), reasoning that the highest expressed genes in a transcriptome may also give insight into function. In brief, the head showed enrichment for sensory machinery and neuronal signaling, the thoracic carcass (which houses flight muscle) showed signs of enhanced metabolic activity, and the abdominal carcass (which contains mostly fat body) displayed enrichment for regulatory proteolytic enzymes (CLIPdomain serine endopeptidases), defense, and lipid transport. The gut was enriched with defense-related genes including immune-activating peptidoglycan recognition proteins (PGRPs), AMPs, and immune-modulating amidase PGRPs. It also showed enrichment for digestive enzymes, especially peptidases. Notably, its three most prevalent transcripts were the 192 non-CLIP serine endopeptidases early trypsin $(E T)$, female-specific chymotrypsin $(C H Y M O)$, 193 and juvenile hormone-regulated chymotrypsin (JHA15) which, together, accounted for more 194 than one third of its transcriptome. (Note: Vectorbase gene IDs for all genes named in this text 195 are listed in S3 Table). The Malpighian tubules, which serve a function analogous to mammalian 196 kidneys, expressed large quantities of ion transporters, especially vacuolar ATPases, which 197 may be required to create proton gradients for use in secondary active transport [56]. Because 198 the ovaries did not express many highly enriched genes, we adjusted our analysis to examine 199 genes expressed $2 x$ higher than in the whole body and discovered categories related to cell 
200

201

202

203

204

205

206

207

208

209

210

211

212

213

214

215

216

217

218

219

220

221

222

223

division and germline maintenance. Overall, we concluded that the most prominent functions in each body part were consistent with expectations for the tissues they house. We take these results as a validation of our data set, and as confirmation that the segments of the mosquito carcass (head, thorax, abdomen) perform well as proxies for important tissues (brain/eyes, flight muscle, fat body).

\section{Gut region-specific transcriptomes reveal functional} compartmentalization of the mosquito midgut

To evaluate the regionalization of gut function, we generated RNAseq profiles for the five main regions of the mosquito digestive tract: crop and dorsal diverticula (hereafter referred to as "crop" for brevity), proventriculus, anterior midgut, posterior midgut, and hindgut. A PCA of these profiles (Fig 2A) demonstrated clear segregation between regions, and close clustering of all replicates from the same region, indicating clearly distinct transcriptomes. The anterior and posterior midgut, which are predominantly derived from endoderm, clustered together opposite the crop and hindgut, which are of ectodermal origin. The proventriculus, which is partially derived from both germ layers, was intermediate between these two clusters on PC1. Whole-gut transcriptomes clustered closely with posterior midgut transcriptomes, suggesting that the posterior midgut contributes more to the transcriptome of the whole gut than do the other regions. Accordingly, very few genes in the posterior midgut showed enrichment compared to the whole gut (S2A Fig). GOEA on genes 5x enriched in each region compared to the whole gut (Fig 2B), complemented by an examination of the twenty highest expressed genes in each gut region (Fig $2 \mathrm{C}$ ) revealed that the ectodermally-derived regions of the gut (crop and hindgut) expressed genes involved in chitin metabolism, lipid metabolism, ion transport and numerous CLIP-domain serine endopeptidases. The proventriculus was notably enriched for wingless 
224 signaling and defensive genes (lysozymes, and the highly expressed AMP gambicin, GAM1). In

225 the anterior midgut, carbohydrate metabolism and heme-binding proteins (predominantly 226 cytochrome P450s) were the most prominently enriched categories. The highest expressed

227 gene in this region was a member of the MBF2 family of transcription factors of unknown 228 function in mosquitoes. As the posterior midgut transcriptome closely resembled that of the 229 whole gut, only a handful of genes were enriched $5 x$ in this region relative to whole gut. We also 230 noted that a large proportion of the genome was either unexpressed or little-expressed in the 231 posterior midgut relative to the other gut regions (S2B Fig). To better identify genes enriched in 232 the posterior midgut, we calculated enrichment against an aggregate of the other four gut 233 regions. We found that the posterior midgut is highly enriched for peptidases (especially non234 CLIP serine endopeptidases) and genes involved in translation. Other enriched categories include SRP-dependent targeting, amino acid transport and amino acid metabolism. Together these categories describe a region that is primed to translate and secrete large quantities of peptidases, and to process and absorb the resulting free amino acids. Overall, our data demonstrate that the five gut regions are highly specialized functional units.

The central function of the gut is digestion, a highly sequential process. To better understand how digestion and nutrient absorption are distributed along the gut, we examined 241 the regional cumulative expression of enzymes and transporters putatively involved in the 242 digestion and absorption of lipids, carbohydrates, and proteins/amino acids. We postulated that 243 the cumulative expression of a given set of digestive enzymes/transporters of common function 244 reflects the investment of each region in that function (what fraction of their transcriptome they 245 dedicate to that process). We first assembled lists of lipases, lipid-transporting proteins, 246 amylases/maltases, glucosidases, sugar transporters, peptidases, and amino acid transporters with a probable digestive function (excluding genes with anticipated non-digestive function, e.g., 
proteasome components, etc.). For complete lists and inclusion criteria, see S4 Table. We summed the expression of the genes from each category (in TPM) and calculated their relative expression by region (Fig 2D). The highest investments in different categories of lipases were divided among several regions, with phospholipases receiving the greatest investment from crop and anterior midgut, sphingomyelinases from anterior midgut, and the remainder of lipases modestly more expressed in the posterior midgut and hindgut. The crop was the greatest investor in lipid carrier proteins and fatty acid transporters, while the anterior midgut showed the greatest investment in phospholipid and sterol transporters. The highest investments in sugar digestion/absorption and protein digestion were found in the anterior and posterior midgut, respectively. The hindgut was a disproportionate investor in amino acid transporters, suggesting that many of the products of protein digestion from the midgut are absorbed there. These data demonstrate that distinct gut regions invest different amounts of their respective transcriptomes in the digestion and absorption of different nutrients, hinting at a system of specialization/sequential processing of ingested materials. investment (in TPM) is distinct from output (i.e., the number of transcripts of a given gene or category produced in a region). The five regions do not produce equal numbers of transcripts overall, so their transcriptional investments must be scaled by their total transcriptional yield to 267 achieve an estimate of their relative contributions to specific functions. We measured the RNA content from each region (Fig 2E) and scaled the cumulative expression values from Fig 2D by

269 yield to gain an estimate of the transcriptional output of each region with respect to each 270 digestive category (Fig 2F). We found that the posterior midgut, by virtue of its outsized 271 transcriptional yield, is the dominant contributor not only of peptidases, but of most categories of 272 transcripts with digestive and absorptive functions. However, the proventriculus and anterior 273 midgut together are the source of more than half of all amylases/maltases and glucosidases and 
contribute a sizeable minority of all sugar transporters. These observations cement our conclusion that the anterior midgut specializes in the digestion and absorption of carbohydrates, while the posterior midgut is responsible for most protein and lipid digestion.

\section{Blood feeding initiates a series of transcriptomic shifts over}

\section{the course of digestion}

The gut of the hematophagous mosquito undergoes dramatic changes upon blood feeding. To better understand these changes at a transcriptome-wide level, we generated RNAseq profiles for sugar-fed guts as well as guts at 4-6 hrs (hereafter referred to as 6 hrs for brevity), 24 hrs, and $48 \mathrm{hrs}$ after feeding on a live chicken. PCA (Fig 3A) demonstrates that the transcriptome changes throughout at least the first $24 \mathrm{hrs}$ pbm, before reverting to a near-basal condition by $48 \mathrm{hrs}$ pbm, suggesting that the transcriptional regulation of digestion is a very dynamic process.

To evaluate the functional changes to the blood-fed gut's transcriptome, we performed a GOEA (Fig 3B) comparing the gut at each time-point to its state at the time-point prior. Guts at the final timepoint (48 hrs) were also compared to sugar-fed guts. The analysis was limited to the 400 most responsive genes (DESeq2 padj $<0.05$, minimum fold change of 2). We found that transcripts of $E c R$, the sole gene in the ecdysone signaling GO category, were significantly reduced in the gut at $6 \mathrm{hrs}$ pbm, while at $24 \mathrm{hrs} \mathrm{pbm}$, after the release of ecdysone peaks [57], not only did the level of EcR transcripts rebound but two other steroid receptors, USP (encoding the co-receptor to EcR) and $H R 3$, were enriched. At $24 \mathrm{hrs}$ pbm, multiple categories pertaining to mRNA processing, translation, protein folding, and protein secretion were significantly downregulated. Several of these categories had rebounded by $48 \mathrm{hrs} \mathrm{pbm}$, and it was notable 
297

298

300

301

302

303

304

305

306

307

308

309

310

311

312

313

314

315

that translation was one of very few categories that was significantly enriched in 48-hr blood-fed guts compared to exclusively sugar-fed guts.

Several of the categories regulated by blood feeding appear to reflect necessary adaptations to the changing luminal environment. Six hours following blood meal ingestion, ferric iron-binding proteins (specifically two ferritin subunit precursors, AAEL004335 and AAEL007385) were upregulated and the lysozyme activity and defense response categories (comprising two lysozymes LYSC11, and LYSC4 and the AMPS DEFC, CECD, and CECM) were also induced, in agreement with the previously described increase of ROS and bacterial density pbm [58]. At 24 hrs pbm, two additional defensins (DEFA and DEFD) were enriched, as well as two peptidoglycan-degrading amidases (PGRP-SC1, and PGRPS4), orthologs of which, in Drosophila, modulate the activation of the immune deficiency (IMD) pathway [59]. At 48 hrs pbm, both the ferric iron-binding and defense response categories were downregulated relative to $24 \mathrm{hrs}$, which is unsurprising as most of the luminal content had been evacuated by that time (S3.1A Fig). We also noted a significant induction of genes involved in cellular respiration which could reflect the metabolic expenditure required for the peristaltic evacuation of the blood bolus. GO categories related to the digestion and absorption of macronutrients were nearly all upregulated at $6 \mathrm{hrs}$ pbm and upregulated again at $24 \mathrm{hrs}$ but downregulated to return to baseline by $48 \mathrm{hrs}$. In summary, GOEA indicates that blood feeding regulates the transcription of genes involved in diverse functions, including digestion, absorption, translation, and defense.

To characterize the changes in digestion/absorption in more detail, we calculated the cumulative investment of the gut in each digestive category at each timepoint (Fig 3C). Overall, cumulative transcript analysis echoed the results of our GOEA. Both showed that the gut's transcriptional investment in sphingomyelinases and amino acid transporters peaked at 6 hrs pbm, and that carbohydrate digestive enzymes generally gained ground until $24 \mathrm{hrs}$ pbm but declined again at $48 \mathrm{hrs}$. Our granular cumulative expression analysis revealed that 
322 aminopeptidases, dipeptidases, and dipeptidyl peptidases reached peak investment at 6 hrs, 323 and carboxypeptidases at $24 \mathrm{hrs}$. Remarkably, the gut's investment in serine endopeptidases 324 (non-CLIP), which constitute the majority of peptidase transcripts in the gut by nearly an order of 325 magnitude, remained steady across sugar-fed, 6-hr, and 24-hr pbm guts, before plunging by approximately one third at $48 \mathrm{hrs} \mathrm{pbm}$.

We extended our cumulative investment approach to other functions in the gut by aggregating transcripts of other transcriptionally prominent families and comparing their relative proportions across all timepoints (Fig 3D). This revealed the dramatic temporary increase in the expression of a family of twelve genes containing the insect allergen domain (IPR010629) which are orthologous to the An. gambiae G12 gene and have been found to possess hemolytic, cytolytic, and antiviral properties [60]. We also observed that the family of MBF2 transcription factors - one member of which was previously noted among the highest expressed genes of the anterior midgut (Fig 2C) - surged from just over $1 \%$ of the transcriptome to more than $4 \%$ at 24 hrs pbm, partially subsiding to approximately $1.7 \%$ by $48 \mathrm{hrs}$ pbm. Our comparison of summed transcripts yielded an apparent paradox: while GOEA demonstrated the upregulation of multiple peptidases at 6 and $24 \mathrm{hrs}$ pbm, and no significant downregulation of the category, the gut's overall investment in peptidases (cumulative TPM) remained nearly constant in sugar-fed, 6-hr, and 24-hr pbm guts. This apparent stability is explained by the depletion of transcripts from the small "early" cohort of peptidases (ET, CHYMO, and JHA15) which compensated for the upregulation of other peptidases. It should be noted that, while peptidase investment remained flat, increased RNA yield (S3.1B Fig) caused peptidase transcript output to increase significantly at $24 \mathrm{hrs} \mathrm{pbm} \mathrm{(S3.1C} \mathrm{Fig).}$

To more closely examine the dynamics of peptidase transcription in the blood-fed gut, we performed a clustering analysis (S3.2A Fig) which revealed that the transcript levels of many peptidases in the gut change dramatically over the course of blood meal digestion, that these 
347 changes come in the form of both induction and repression/depletion, frequently followed by a 348 return to baseline at the subsequent timepoint, and that they manifest in multiple successive 349 waves. Our clustering analysis divided the dynamically expressed gut peptidases into three 350 waves of induced transcripts (rapid, intermediate, and delayed), and three corresponding waves 351 of repressed or depleted transcripts. Among induced peptidases, the rapid and delayed waves 352 comprise genes that peaked in our data set at $6 \mathrm{hrs}$ and $24 \mathrm{hrs}$ pbm, (23 and 40 genes 353 respectively). Our clustering analysis implied that another, "intermediate" cohort of induced 354 peptidases (16 genes) nests somewhere between these waves. These genes show sustained 355 induction from 6 to $24 \mathrm{hrs}$, and likely peak at some time between these two timepoints. The 356 waves of rapid, intermediate, and delayed repressed/depleted peptidases mirror the expression 357 patterns of their induced counterparts in inverse. Figure 3E shows the expression of 358 representative peptidases from each of the six cohorts across the blood feeding kinetic. We validated our findings by performing RT-qPCR on selected peptidases (two repressed/depleted and five induced genes) at $6,12,24,36,48$, and $72 \mathrm{hrs}$ pbm. We selected RpS30 (AAEL009653), a housekeeping gene with robust and steady expression over the course of blood meal digestion, as a reference gene for our assay (S3.2B Fig). Figure 3F shows the relative expression of each peptidase (for unscaled data normalized only to the reference gene, see S3.2C Fig). At each timepoint we assayed, we captured one or more genes peaking sharply, further illustrating the dynamic nature of peptidase expression in the blood-fed gut. Most peptidases are organized in genomic clusters which, we hypothesized, could underlie co-

367 regulation. We also examined the evolutionary relatedness of the peptidases from each 368 temporal cluster by comparing their positions on a phylogenetic tree (composed using Geneious 369 R11 software, Fig 3.3A). While sequence similarity corresponded closely with physical location 370 in most cases, neither parameter was correlated with temporal clustering. Altogether, our data 371 reveal that blood feeding initiates a well-orchestrated transcriptomic response in the gut, 
372 dominated by the dynamic up and down-regulation of peptidases throughout the entire process

373 of digestion.

375 Regional digestive specializations are preserved in the 376 blood-fed midgut

377 Considering the extensive functional regionalization of the Ae. aegypti gut and the profound 378 reshaping of the whole-gut transcriptome upon blood feeding, we asked whether regional 379 differences are preserved in the blood-fed gut. To evaluate the regionalized effects of blood 380 feeding, we generated transcriptomes for dissected anterior midguts (without proventriculus) 381 and posterior midguts at $24 \mathrm{hrs} \mathrm{pbm.} \mathrm{PCA} \mathrm{(Fig} \mathrm{4A)} \mathrm{revealed} \mathrm{that} \mathrm{all} \mathrm{profiles} \mathrm{clustered} \mathrm{both} \mathrm{by}$ 382 region and by blood feeding status. As we previously noted (Fig $2 \mathrm{~A}$ ), there was little difference 383 between sugar-fed whole gut and posterior midgut profiles. Upon blood feeding, both whole gut 384 and posterior midgut shifted in tandem, maintaining proximity, indicating that blood feeding does 385 not lessen the dominance of the posterior midgut's transcriptional yield over that of the anterior.

386 Both midgut regions shifted in response to blood feeding; moreover, they moved in the same 387 directions with respect to PC1 and PC2, suggesting that the overall transcriptional responses of 388 the two regions share some commonality. We noted that the relative investments of these two 389 regions in most of the prominent functional categories did not change dramatically upon blood 390 feeding (Fig 4B). However, two of the most remarkable changes in the transcriptome of blood391 fed mosquitoes, the upregulation of MBF2 transcription factors and G12 genes (Fig 3D), were 392 mainly localized to the posterior midgut.

A GOEA of categories upregulated and downregulated by blood feeding in the anterior 394 and posterior midgut (Fig 4C) mainly recapitulated changes already noted in blood-fed whole 
guts (Fig 3B). Most categories that were upregulated in one region were similarly upregulated in the other, albeit to differing extents. The fact that blood feeding promotes enrichment of many of the same digestive/absorptive categories in both anterior and posterior midgut could imply that the two regions are converging on a common role with respect to macronutrient exploitation. However, an analysis of cumulative expression (Fig 4D) demonstrated that the two regions' respective investments in digestive enzymes and transporters remained highly divergent. Consistent with the results of the GOEA, the posterior midgut substantially increased its investment in lipase transcripts, with a smaller increase in the anterior midgut. By contrast, the anterior midgut kept a substantial edge in its investment in lipid transporters and lipid carrier proteins. The posterior midgut increased its investment in amylases/maltases and glucosidases by approximately five and two-fold, respectively, and the anterior midgut increased both by less than two-fold. However, the difference in baseline expression was such that the blood-fed anterior midgut's investment was still ten times that of the blood-fed posterior midgut. Neither region substantially increased its investment in sugar transporters, peptidases, or amino acid

\section{Immune gene patterning reveals areas of immune activity}

\section{8 and immune tolerance in the mosquito body and gut}


As mosquitoes are prolific vectors of important human pathogens, their defensive functions are of paramount interest. We assembled a table recording the expression of immune genes in

421 each category by body part, gut region, and blood-fed timepoint (S5 Table). Many genes

422 associated with the siRNA and piRNA pathways display a strong tropism toward the ovaries (Fig $4235 \mathrm{~A}$ ), possibly indicating that, in mosquitoes, siRNAs as well as piRNAs [61] are required to 424 protect the germline from selfish elements. Accordingly, the gene loqs2, which has been 425 described as an essential component of Ae. aegypti's systemic siRNA response to Zika and 426 dengue viruses [62] was restricted to the ovaries to such an extent that it qualified as an ovary427 specific marker (Fig 1B). The ovaries were also the site of the highest expression of genes 428 coding for components of Toll, IMD, and JAK-STAT signaling. Remarkably, genes coding for 429 extracellular regulators (such as most CLIP-domain serine endopeptidases) and pattern 430 recognition proteins (PGRPs and Gram-negative bacteria-binding proteins, GNBPs) did not 431 show this pattern of expression. Instead, they were generally highly expressed in the head, 432 thorax and abdomen, the three compartments that contain fat body. Even more remarkably, 433 AMPs (Fig 5B) showed negligible expression in the ovaries. Our results suggest that, in the 434 female germline, portions of the IMD, Toll and JAK-STAT pathways are uncoupled from 435 upstream pattern recognition proteins and downstream AMP targets, possibly playing a 436 regulatory role in some alternative process (e.g., development).

An examination of the distribution of AMPs and lysozymes in the body (Fig 5B) revealed 438 that two AMPs, holotricin (GRRP) and gambicin, together accounted for most AMP transcripts in 439 the mosquito body. These two AMPs were expressed in different body parts in a near mutually 440 exclusive manner. The head, thorax, and abdomen of the mosquito predominantly expressed 441 holotricin transcripts, with very little gambicin, while the gut and Malpighian tubules were 442 dominated by gambicin expression and expressed very few holotricin transcripts. 
Immune activity in the gut is tightly regulated as this organ interfaces with both commensal and pathogenic microbes. In Drosophila, the IMD pathway is the main pathway controlling AMPs in the midgut, and its activity is strongly constrained by expression of amidase 446 PGRPs [59], while the Toll pathway is expressed mostly in the ectodermal portions of the gut. 447 We found a similar pattern in the gut of Ae. aegypti (Fig 5C) with orthologs of Toll pathway 448 recognition proteins most strongly expressed in the crop while IMD-activating PGRPs (PGRPLC 449 and $P G R P-L E)$ and IMD pathway components were enriched in the midgut. Investment in these 450 IMD-activating PGRPs was highest in the anterior midgut, while immune-modulating PGRPs 451 showed more divided expression. The amidase PGRPLB was most prominently expressed in 452 the anterior midgut, but the short amidase PGRPs (PGRP-SC1 and PGRPS4, orthologs of 453 Drosophila PGRP-SC1a and PGRP-SC1b) were most strongly expressed in the posterior 454 midgut. Likewise, an ortholog of caudal ( $c a d)$, a transcription factor that limits AMP expression 455 in the Drosophila midgut $[63,64]$, was profoundly enriched in the posterior midgut. Altogether, 456 we found that the expression patterns of these key genes suggested enhanced immune 457 vigilance in the anterior portion of the midgut, with hallmarks of immune tolerance prominent in 458 the posterior midgut. We also observed that blood feeding enhanced the expression of the short 459 amidase PGRPs in the posterior midgut, sharpening the regional divide.

A cumulative analysis of the expression of immune effectors (AMPs and lysozymes) in 461 the gut showed that the proventriculus and anterior midgut, respectively, invest $3.6 \%$ and $2.3 \%$ 462 of their transcriptomes in the expression of these effectors - especially gambicin (Fig 5D). The 463 posterior midgut, by contrast, expressed just 110 TPM of AMPs and lysozymes combined, 464 supporting our hypothesis that the posterior midgut is characterized by immune tolerance 465 toward microbes. When AMP and lysozyme expression is weighted by gut regional RNA yield 466 (Fig 5E) it is apparent that the anterior midgut and proventriculus contribute the majority of 467 transcripts in these categories despite their relatively small transcriptional yields. Overall, the 
expression patterns of immune activators, modulators, and effectors suggests that the anterior portions of the midgut may exert strong selection of microbes upon entry, while the posterior midgut is a region of greater immune tolerance.

\section{Gut digestive and defensive regionalization is well conserved}

\section{between the midguts of Aedes aegypti and Anopheles}

\section{gambiae}

Ae. aegypti and An. gambiae are both important hematophagous vectors, and their digestive tracts bear a clear anatomical similarity. To assess how similar these organs are at the transcriptomic level, we created RNAseq profiles for whole guts (comprising all regions from crop to hindgut) and midgut regions (proventriculus, anterior midgut and posterior midgut) from An. gambiae G3 mosquitoes and compared them to their Ae. aegypti counterparts. In a clustering analysis (Fig 6A) we found that the profiles of midgut regions and whole guts from each species were grouped similarly, with anterior midguts intermediate between proventriculi and posterior midguts. Also, in both species, whole guts clustered between anterior and posterior midgut regions but displayed more similarity to the latter, suggesting that for $A n$. gambiae, as for Ae. aegypti, the transcriptional yield of the posterior midgut greatly exceeds that of the anterior.

We repeated our analysis of regional transcriptomic investment in nutrient digestion and absorption by generating lists of genes encoding enzymes and transporters, in the same categories as in Figure 2C, summing their regional expression in TPM, and calculating their relative abundance. Since we lacked transcriptomes for whole body, crop, and hindgut for $A n$. gambiae, it was necessary to adjust the inclusion criteria we employed (S4 Table) for our 
491 previous investment analysis. Complete lists of genes in each category with adjusted inclusion

492 criteria can be found in S6 Table for Ae. aegypti and S7 Table for An. gambiae. Our comparison

493 across the two species (Fig 6B) revealed overall conservation of gut structure-function. This was

494 particularly evident for the anterior and posterior midguts which, respectively, remained the

495 strongest investors in sugar and protein digestion/absorption. However, in An. gambiae, the

496 posterior midgut appears to make a greater proportional investment in the digestion/absorption

497 of both lipids and sugars. We also noted that, while the posterior midgut in both species was the

498 dominant investor in peptidases, the amplitude of the Ae. aegypti investment far outstripped that

499 of An. gambiae (S6A Fig), particularly with respect to serine endopeptidases.

To compare the distribution of defensive functions in the two midguts, we examined the expression patterns of important orthologous immune activators, modulators, and effectors between the two mosquitoes (Fig 6C) and found clear similarities. In both species, the IMDactivating PGRPLC receptor as well as the immune-modulating PGRPLB amidase were most strongly expressed in the anterior midguts, the transcription factor cad was most strongly expressed in the posterior midguts, and the orthologs of GAM1 and $L Y S C 7 B$ (respectively the highest expressed AMP and lysozyme in the Ae. aegypti midgut) were most strongly expressed 507 in the proventriculi. This distribution of key genes leads us to hypothesize that the immune 508 regionalization of the An. gambiae midgut is likely similar to that of Ae. aegypti. It should be 509 noted, however, that the short amidase, PGRPS3, a putative negative regulator of the IMD 510 pathway, is robustly expressed in the An. gambiae proventriculus, in striking contrast to its $A e$.

511 aegypti counterparts. We further note that, while the amplitude of GAM1 and LYSC7B/LYSC7 512 investment is comparable in the two species, the An. gambaie proventriculus and anterior 513 midgut transcriptomes contained large quantities of transcripts for cecropins and defensins, 514 rendering their overall AMP investment more than five times higher than the same regions in 515 Ae. aegypti (S6B Fig). In both species, the posterior midgut's investment in AMPs was 
516

517

518

519

520

521

522

523

524

525

526

527

528

529

530

531

532

533

534

535

536

537

538

negligible. Altogether, the expression of digestive (Fig 6B) and defensive genes (Fig 6C) as well as a GOEA (S6C Fig) of the An. gambiae midgut regions confirm that the midgut structurefunction relationship is well conserved between the two mosquito species. Figure $6 \mathrm{D}$ provides a summary of enriched functions and prominently expressed gene families that are shared by the midgut regions of Ae. aegypti and An. gambiae.

\section{A small number of disparately expressed genes differentiate} Aedes aegypti and Anopheles gambiae midgut

\section{transcriptomes}

The conservation of gut functional regionalization may be due either to conserved expression patterns among orthologs across evolutionary distance, or to convergent patterning of nonhomologous genes of shared function. To evaluate how well the relative expression of individual orthologous genes has been maintained between Ae. aegypti and An. gambiae midgut regions, we performed a series of correlation analyses using only the 7430 genes classified by Orthogroups Analysis (S8 Table) as one-to-one orthologs. Scaled expression values for the orthologs were poorly correlated both in whole guts (Fig 7A), and in dissected regions (S7.1A Fig), with $\mathrm{R}^{2}$ values ranging from 0.08 (proventriculus) to 0.56 (posterior midgut). However, the distribution of data points in the correlation graphs suggested that a few highly/disparately expressed genes substantially depressed correlation. To test the effect of these genes on overall correlation, we sequentially censored genes that were strongly and significantly disparately expressed between both species (DESeq2, padj<0.05), rescaled the expression of the remaining one-to-one orthologs, and plotted the resulting changes in slope and correlation coefficient (Fig 7B, S7.1B). For the proventriculus, anterior midgut, posterior midgut, and whole 
539

540

541

542

543

544

545

546

547

548

549

550

551

552

553

554

555

556

557

558

559

560

561

562

563

gut the censorship of, respectively $4,10,20$, and 35 1-to-1 orthologous pairs was sufficient to reveal strong correlation between the remaining orthologs, with slopes ranging from 0.78 to 1.1 and $R^{2}$ values ranging from 0.77 to 0.89 . From this, we conclude that a 'species signature' masking the transcriptional similarity of Ae. aegypti and An. gambiae midguts is the product of a small number of highly expressed/disparately expressed genes.

Figure 7D displays the genes censored from our correlation analysis in the three midgut regions. The most disparately expressed gene in both the An. gambiae proventriculus and anterior midgut encodes an uncharacterized protein containing a domain (IPR007931) from the Tsetse EP protein which, in tsetse fly species has been shown to play a role in resisting the establishment of trypanosome infections [65]. MBF2 transcription factors were also censored in each region: twice they were expressed higher in Ae. aegypti (proventriculus and anterior midgut) and once in An. gambiae (posterior midgut). Among the disparately expressed orthologs, the most abundant category was ribosomal proteins. We observed that in both the anterior and posterior midgut, Ae. aegypti had significantly increased the expression of some ribosomal proteins relative to their one-to-one orthologs in An. gambiae, and vice versa. Phylogenetic analysis of ribosomal proteins (S7.2A Fig) confirmed that the putatively one-to-one orthologous ribosomal genes identified by Orthogroups Analysis were sister sequences and that the disparately expressed pairs of orthologous genes were widely distributed throughout the phylogenetic tree. We therefore conclude that evolutionary changes between the two species have reshuffled the expression of ribosomal proteins, significantly reducing the roles of some while increasing those of others.

Many of the genes censored in our correlation analysis were among the highest expressed genes in the three Ae. aegypti and An. gambiae midgut regions. A follow-up comparison of the twenty highest expressed genes in the midgut regions of the two species (Fig 2C, Fig 7E) revealed striking differences in both amplitude and function. In the proventriculus, 
564

565

566

567

568

569

570

571

572

573

574

575

576

577

578

579

580

581

582

583

\section{Discussion}

Aegypti-Atlas is a new resource which contextualizes and dissects the transcriptome of the sugar and blood-fed Aedes aegypti gut. Aegypti-Atlas will allow exploration of gene expression

An. gambiae devoted a higher proportion of its transcriptome to the expression of a small number of genes. The three highest expressed, including an uncharacterized gene (AGAP013543), the Tsetse EP gene (AGAP009313), and a cecropin (CEC2) together composed more than one third of the transcriptome. Both species' proventriculi shared expression of two MBF2 transcription factors (AAEL005428 and AAEL013885 in Ae. aegypti, AGAP011630 and AGAP000570 in An. gambiae), as well as the AMP gambicin (GAM1). However, the An. gambiae proventriculus also expressed three cecropins (CEC2, CEC1, CECB), one defensin (DEF1) and a lysozyme ( $L Y S C 7)$ among its top twenty genes, together totaling more than $25 \%$ of its transcriptome. Cecropins (CEC1, CEC2) and a defensin (DEF1) were likewise among the twenty highest expressed genes in the An. gambiae but not the $A e$. aegypti anterior midgut. In the posterior midgut, the highest expressed peptidases in $A n$. gambiae were much lower expressed than their counterparts in Ae. aegypti, and the top twenty genes in the An. gambiae posterior midgut included two MBF2 transcription factors (AGAP000570, AGAP003713) that were absent among the highest expressed genes in the corresponding region in Ae. aegypti. Altogether, we find that while gut regional specializations have been broadly conserved between Ae. aegypti and An. gambiae, and while most one-toone orthologous genes maintain closely correlated expression patterns, this correlation is lost among a few of the highest expressed genes in the midgut, creating a 'species signature' that differentiates the two midguts' transcriptomes. across the main parts/regions of the female mosquito body/gut in an easily accessible online 
database. In addition, we have performed a first analysis of this new dataset, examining how biological functions are distributed in the parts of the mosquito body and the regions of the gut, as well as how they change in the gut over the course of blood meal digestion. Our study demonstrates the importance of estimating investment, yield, and output in transcriptomic studies. In addition, this research has yielded new insights into such diverse areas as the regionalization of digestive function, the temporal patterning of peptidase transcription, the organization of immune defenses, and the similarities and differences between the guts of two hematophagous vectors.

\section{Assessments for Highest Expressed Genes and Categorical}

\section{Investment/Output are Valuable Complements to GO}

\section{Enrichment Analysis}

In bioinformatic analysis of large-scale transcriptomic data sets, GOEA is often the preferred method for determining the functional role of a tissue or body part, or for detecting functional differences across conditions. We have employed GOEA to derive valuable information about the enrichment of functions in mosquito body parts, gut regions, and blood-fed conditions. However, enrichment analysis alone cannot capture all the complexities of comparative transcriptomics, as it is primarily sensitive not to quantities of transcripts from a given category, but to quantities of genes belonging to that category. Furthermore, GOEA is substantially less robust in non-model species, owing to incomplete annotations which impact many key genes. We propose that complementary approaches, such as identifying highest expressed genes and examining transcriptomic profiles through the lenses of investment and output, can help to strengthen conclusions and capture dynamics which might otherwise be overlooked. By 
611 examining the twenty highest expressed genes in each body part and gut region, we were able

612 to identify genes that account for large proportions of the transcriptome, but which were missed

613 by enrichment analysis (e.g., GAM1 in the proventriculus, MBF2 factors in the anterior midgut).

614 Comparing the top-expressed genes across transcriptomes allowed us to see that some body

615 parts are dominated by a small number of highly expressed genes (e.g., the gut) while others

616 spread their transcriptome more equally over the genome (e.g., the ovaries). Comparing the

617 relative expression of one-to-one orthologs between species allowed us to identify genes that

618 are disproportionately expressed in one species (e.g., the Tsetse EP protein, a putative

619 antimicrobial effector in the An. gambiae proventriculus) and to detect a reshuffling of

620 expression among ribosomal proteins across the two species.

Another approach we adopted - summing transcripts belonging to a functional category

622 and comparing the sums across body parts, regions, or timepoints - allowed us to assess

623 relative investment in the given category. We confined the use of this method to categories of

624 genes encoding proteins that are all presumed to have similar molecular function, narrowly

625 defined (e.g., peptidases cleaving proteins, or antimicrobial peptides killing pathogens). The

626 utility of evaluating regional or temporal specialization by summing transcripts (investment) as

627 opposed to counting genes (enrichment), is evident when we consider that using GOEA, the

628 highest expressed peptidase in the gut carries no more weight than the fifth highest - despite a

629 difference of over 165,000 TPM, or $16.5 \%$ of the total gut transcriptome. Using this investment

630 approach, we were also able to break large categories (e.g., peptidases) into smaller categories

631 (e.g., carboxypeptidases, dipeptidases, etc.) for a fine-grained picture of where and when each

632 was most expressed. There is, however, an important caveat to the interpretation of cumulative

633 analysis as it fails to account for differential transcriptional yields between profiled body parts,

634 regions, or conditions. We overcame this caveat by weighting transcriptional investment by RNA

635 yield to calculate estimated regional/temporal output of digestive transcripts, from which we 
636

637

638

639

640

641

642

643

644

645

646

647

648

649

650

651

652

653

654

655

656

657

658

659

were able to infer how certain tasks (e.g., sugar digestion) are divided between the regions of the gut, as well as how peptidase transcript output changes over the course of blood meal digestion.

Spatial organization of gut function is conserved across

\section{mosquito species; few highly/disparately expressed genes}

\section{drive transcriptomic differences}

The Ae. aegypti gut is linearly divided into five anatomically distinct regions. With the caveat that the crop only admits sugar meals, ingested materials encounter each of these regions sequentially. The regions of the gut therefore possess an ordinal quality, corresponding to stages (either transient or prolonged) of the ingestion/digestion process. Through GOEA and quantitative evaluation of transcripts belonging to digestive categories, we discerned a clear pattern of strong investment in sugar digestion/absorption in the anterior midgut, as hypothesized by Hecker [66]. Peptidases, by contrast, were predominantly expressed in the posterior midgut. These specializations were maintained under blood-fed conditions, and largely conserved in An. gambiae midguts. Other notable instances of conserved regional function are apparent in the proventriculus, where both species share enrichment of wingless signaling components [31] and AMPS [67] with other dipteran species.

While the midgut regions of $A$ e. aegypti and An. gambiae shared many important functions, and their one-to-one orthologs maintained strikingly close transcriptional correlation, we noted that differences in the expression of a small number of highly expressed genes created large disparities in their overall categorical apportionment of transcripts. Most notably, the An. gambiae proventriculus and anterior midgut expressed far greater quantities of AMPs possibly in response to some microbial presence - as well as a handful of highly expressed but 
660

661

662

663

664

665

666

667

668

669

670

671

672

673

674

675

676

677

678

679

680

681

682

683 poorly characterized genes, including an apparent ortholog of a tsetse midgut protein with a defensive function [65]. Meanwhile, the An. gambiae posterior midgut expressed far fewer peptidase transcripts than its Ae. aegypti counterpart, and far more of an MBF2 family of transcription cofactors which, in the Ae. aegypti gut, was only prominent in the anterior regions of the sugar-fed midgut and, intriguingly, the blood-fed posterior midgut. In Drosophila and Bombyx mori, MBF2 factors have been shown to complex with the transcription factor FTZ-F1 and cofactor MBF1 to activate transcription of target genes $[68,69]$. We cannot say whether this role is conserved in Ae. aegypti and An. gambiae. However, the expression of MBF2 factors in both species outstripped the expression of their orthologs of FTZ-F1 (AAEL019863, AAEL026810, AGAP005661) and MBF1 (AAEL008768, AGAP004990) by several orders of magnitude in multiple conditions and/or gut regions (see Aegypti-Atlas website), suggesting MBF2 may not be confined to cofactoring FTZ-F1 in these species. Altogether, this analysis yielded multiple 'species signature' genes worthy of closer scrutiny and functional study.

\section{The anterior midgut participates in the transcriptional}

\section{response to blood feeding}

The anterior midgut has been held to play little or no role in the process of blood meal digestion, as the blood bolus is sealed into the posterior midgut by the formation of the peritrophic matrix shortly after ingestion [70]. However, late in the blood meal response (24 hrs) we found that the anterior midgut had increased its investment in some categories of digestive enzymes and transporters (e.g., sphingomyelinases, sterol transporters, amylases/maltases, glucosidases, Fig 4D) as well as its overall transcriptional yield (Fig 4E). While the proportional output of the anterior midgut drops relative to the posterior midgut (Fig 4F), it still contributes approximately one third of the transcripts for sugar-digesting enzymes in the whole midgut (exclusive of 
684

685

686

687

688

689

690

691

693

694

695

696

697

698

699

700

701

702

703

704

705

706

707

proventriculus). This finding is congruent with Billingsley and Hecker's observation that alphaglucosidase activity was elevated in homogenates of Anopheles stephensi anterior midguts at $24 \mathrm{hrs}$ pbm [71]. As the majority of amylases/maltases and glucosidases in the Ae. aegypti genome possess signal peptides but lack transmembrane domains, it is possible that enzymes secreted in the anterior midgut are capable of diffusing into the extra-peritrophic area in the posterior midgut where they may participate in blood meal digestion.

\section{Gut peptidases are dynamically up and downregulated in} sequential transcriptional waves upon blood feeding

Peptidase expression in the Ae. aegypti gut unfolds in a series of phases, coordinated by rising and falling titers of $\mathrm{JH}$ and ecdysone. In the post-emergence/pre-vitellogenic phase, $\mathrm{JH}$ drives the transcription of a cohort of "early" peptidases, priming the gut for its first blood meal $[39,40,42,72]$. Within hours of blood feeding, translation of this pool of transcripts is initiated and peptidase activity begins to increase [37]. Next, rising ecdysone titers drive the transcription of a "late" cohort of peptidases, which complete the digestive process [48]. Finally, early peptidases are transcribed anew $[38,40]$ amid a postprandial surge of $\mathrm{JH}[73-76]$, restoring the gut to a state of readiness for its next blood meal.

Peptidase activity peaks somewhere between 18 and 36 hours pbm [43,44,47], as do transcripts for some of the highest expressed "late" phase peptidases [49,50,52]. However, a few publications have documented peptidases peaking at earlier timepoints [51-53], and that at least one of these $(S P I)$ is directly responsive to/dependent on ecdysone signaling [48]. Here, our genome-wide multi-timepoint series has demonstrated that these early-peaking genes are not isolated and exceptional but are, rather, members of large transcriptional cohorts. We show that peptidases in the blood-fed Ae. aegypti gut are expressed not only in two phases: "early" 
708

709

710

711

712

713

714

715

716

717

718

719

720

721

722

723

724

725

726

727

728

729

730

731

732

(translational) and "late" (transcriptional), but that the "late" transcriptional response manifests in multiple successive waves or shifts. We have divided these into three ("rapid", "intermediate", and "delayed"), but because we only obtained RNAseq profiles for guts at baseline and three blood-fed timepoints, we can only speculate how many of these shifts are actually triggered over the course of blood meal digestion, and how synchronously any of the peptidases that our clustering analysis grouped together are actually regulated. Our timepoints were too broadly spaced to say at what time each gene reached its true peak, or whether peptidases that were apparently quiescent throughout blood meal digestion in fact participated in a shift that was too transient to be detected by our experimental design. Future work will likely uncover even more complexity than we have described.

The sharp temporal patterning of peptidase transcription in the blood-fed mosquito gut raises intriguing questions. How is this transcriptional choreography achieved? Is the transcription of all "late" phase peptidases ecdysone-dependent, and are rising ecdysone levels sufficient to drive them? To what extent is the transcriptional induction of succeeding waves dependent on the activity of prior ones? Why are some "delayed" peptidases so slow to show any transcriptional response when ecdysone titers are ascendent (e.g., AAEL008782, Fig 3E)?. And what mechanism effects the precipitous drop in the "rapid" cohort of induced peptidases (ascendent at $6 \mathrm{hrs} \mathrm{pbm}$ ) at a timepoint (24 hrs pbm) when ecdysone titers are still high (e.g., AAEL013715) [77]? What is the adaptive significance of the rapid up and down-regulation of so many genes of shared function? We observed that the gut's investment in aminopeptidases, dipeptidases, and carboxypeptidases has distinct temporal peaks, suggesting that polypeptides may be attacked more from one terminus or the other at different times over the course of digestion. However, most of the peptidases that participate in shift-changes are endopeptidases, and it is not clear how the sequential substitution of one set of endopeptidases for another - as opposed to simultaneous expression - helps to move the process of digestion 
forward. We speculate that rapidly changing conditions in the blood-fed gut may alter the stability and kinetics of specific peptidases, and that different peptidases predominate at different times because they are adapted to function in specific, transient conditions obtaining at corresponding stages of the digestive process.

\section{characterized by signs of immune activity and immune}

\section{tolerance}

In the midguts of both Ae. aegypti and An. gambiae, the majority of AMP transcripts are contributed by the proventriculus and anterior midgut (Fig 5D, S6B Fig) with minimal expression in the posterior midgut. Also, in both species, the transcription factor caudal which, in Drosophila [64] and An. gambiae [63] has been shown to repress AMP expression, is dominantly expressed in the posterior midgut. The expression of immune activating recognition proteins (PGRPLC and, in Ae. aegypti, PGRP-LE) is less profoundly patterned, but still displays some tropism toward the anterior midgut in both mosquitoes. Altogether, these patterns suggest that ingested microbes are subjected to heightened immune surveillance and antimicrobial activity in the first regions of the midgut but are thereafter well tolerated by the posterior midgut, where they may serve some mutualistic functions. We speculate that selection by gambicin in the proventriculus and anterior midgut of Ae. aegypti and An. gambiae may play an important role in determining the composition of the microbiota that seed the posterior midgut (S7.3A Fig).

\section{Holotricin and gambicin are highly expressed under baseline}

\section{conditions in mutually exclusive regions of the body}


756 Our examination of the expression of immune effectors yielded the observation that at baseline,

757 AMP expression in Ae. aegypti is dominated by two genes: holotricin and gambicin. We

758 observed that holotricin predominated in the carcass, while gambicin was highly expressed in

759 the gut and Malpighian tubules. While it is not uncommon for antimicrobial effectors to display

760 strong tropisms to specific tissues, we are not aware of comparable instances where a single

761 AMP exhibits such overwhelming transcriptional dominance. In future work, it might be

762 interesting to compare the activity of holotricin and gambicin against different types of microbes

763 (Gram-positive, Gram-negative, fungi, etc.), and to examine the effects that silencing these

764 genes has on midgut communities, and on mosquitoes' survival in the contexts of oral and

765 systemic infection.

766

767 Conclusion

768 In this manuscript we introduce Aegypti-Atlas, a repository of RNAseq data, and demonstrate

769 how these data can yield insights into tissue function, the organization of digestive 770 specializations, regulatory networks, and immune effectors, as well as the changes wrought by

771 diet and evolution in mosquitoes. This resource may also be useful for the creation of functional

772 genomic tools (e.g., tissue-specific expression systems) which will afford researchers a greater

773 degree of control in experiments and allow for more confidence in the interpretation of results. It

774 is our hope that Aegypti-Atlas will be valuable to other investigators in many areas of mosquito

775 biology.

776

777 Methods

778 Mosquito provenance and rearing 
779 For all experiments, we used 5 to 12 day-old mated female mosquitoes of the Thai strain (Ae. aegypti) or the G3 strain (An. gambiae) kindly provided by Laura Harrington. Mosquitoes were reared at a density of 200 larvae per 1 -liter tray. Ae. aegypti received $720 \mathrm{mg}$ of fish food (Hikari \#04428). An. gambiae received $50 \mathrm{mg}$ of ground fish food per day from day 1-4 of development, and $150 \mathrm{mg}$ per day thereafter until pupation. Adults were maintained in humidified chambers at $29^{\circ} \mathrm{C}$ on a diet of $10 \%$ sucrose ad libitum.

\section{Blood feeding and mock blood feeding}

For all RNA-seq experiments involving blood-fed guts, mosquitoes were starved for twenty-four hours, then blood-fed on live chickens without anesthetic in accordance with Cornell University IACUC approved protocol \#01-56. For our extended blood feeding time series by RT-qPCR, mosquitoes were fed through a membrane on rooster blood treated with the anticoagulant sodium citrate (Lampire Biological Laboratories, Pipersville, PA, catalogue \#7208806). For experiments where RNA yield was estimated in guts and midgut regions under blood-fed conditions, we employed an artificial formulation (SkitoSnack) [78] fed through a membrane. This formulation was used in order to avoid any skewing of yield which might result from RNA content in a natural blood meal. For RNA yield experiments, boluses were removed during dissection.

\section{Dissections \& RNA extraction}

Mosquitoes were sacrificed by submersion in $70 \%$ ethanol and dissected in sterile PBS. For body part samples, the last 2-3 abdominal segments were removed to eliminate the spermcontaining spermatheca. Whole guts, Malpighian tubules, and ovaries were then dissected out. The residual carcass was divided into head, thorax, and abdomen. A small anterior section of the thoracic carcass containing the salivary glands was excised to exclude salivary gland 
802 transcripts from thoracic profiles. For RNAseq experiments, a minimum of 20 individuals per

803 replicate was used for large body parts (e.g., whole body, abdominal carcass, whole guts) and

804 up to 500 individuals per replicate for small parts (e.g., crop, proventriculus). For RT-qPCR time-

805 series experiments, a minimum of 10 individuals was dissected per replicate. For all

806 experiments, a minimum of 3 replicates was prepared per part and/or condition. All samples

807 were homogenized in TRIzol and stored at $-80^{\circ} \mathrm{C}$. For RNAseq experiments, RNA was

808 extracted via a modified phenol-chloroform method [79]. For RT-qPCR time series and RNA

809 yield experiments, a standard phenol-chloroform extraction was performed, and RNA

810 concentration was evaluated by Qubit fluorometer.

\section{Library preparation \& sequencing}

812 Libraries were prepared using the Quantseq 3' mRNA-seq prep kit from Lexogen according to

813 the manufacturer's instructions. Sample quality was evaluated before and after library

814 preparation using a fragment analyzer (Advanced Analytical). Libraries were pooled and

815 sequenced on the Illumina Nextseq 500 platform using standard protocols for $75 b p$ single-end

816 read sequencing at the Cornell Life Sciences Sequencing Core. Sequences have been

817 deposited on NCBI (BioProject ID: PRJNA789580).

818 Analysis pipelines

819 Quality control of raw reads was performed with fastqc (https://github.com/s-andrews/FastQC)

820 and reads were trimmed by BBMap (https://jgi.doe.gov/data-and-tools/bbtools/) and then

821 mapped to the Ae. aegypti transcriptome (version 152) or the An. gambiae transcriptome

822 (version P4.12) using Salmon version 0.9.1 with default parameters. Salmon's transcript-level

823 quantifications were then aggregated to the gene level for gene-level differential expression 
824

825

826

827

828

829

830

831

832

833

834

835

836

837

838

839

840

841

842

843

844

845

analysis with the "tximport" package on the R version 3.5. DEseq2 was used for differential expression analysis and PCA analysis. GOEA was performed using the TopGO package.

All phylogenetic trees were constructed using Geneious software version R11, with the following settings. Alignment type: Global alignment, Cost Matrix: Blosum62, Genetic Distance Model: Jukes-Cantor, Tree Build Method: Neighbor-Joining. Clustering was performed using the Pheatmap package in $\mathrm{R}$ with gene expression scaled by row. Z-scores were calculated by first censoring all genes expressed at less than 2 TPM in the relevant body parts or gut regions, then employing the following expression for each gene in each body part or gut region: $z=(x-\mu) / s$, where $\mathrm{x}$ is the expression in the body part or gut region, $\mu$ represents the mean expression of all body parts or gut regions, and $s$ is the standard deviation. The peptide sequences of AaegL5.2 and AgamP4.12 were used to find orthogroups and orthologs in the two species using OrthoFinder v2.3 [80]. The longest transcript variant of each gene was extracted to run the OrthoFinder with the following options: "-M msa -S blast -A muscle -T iqtree".

\section{Calculating the "mosquito equation"}

If $\mathrm{X}$ is defined as the expression of a specific gene in a given body part (in TPM), and the part's initial stands for the relevant scaling factor, the relationship between the expression of that gene in each body part versus in the whole body can be expressed as:

$\left(\mathrm{X}_{\text {Head }}{ }^{*} \mathrm{H}\right)+\left(\mathrm{X}_{\text {Thorax }}{ }^{*} \mathrm{~T}\right)+\left(\mathrm{X}_{\text {Abdomen }}{ }^{*} \mathrm{~A}\right)+\left(\mathrm{X}_{\mathrm{Gut}}{ }^{*} \mathrm{G}\right)+\left(\mathrm{X}_{\mathrm{MT}}{ }^{*} \mathrm{MT}\right)+\left(\mathrm{X}_{\text {Ovaries }}{ }^{*} \mathrm{O}\right)=\mathrm{X}_{\text {Whole Body }}$

Where $\mathrm{H}+\mathrm{T}+\mathrm{A}+\mathrm{G}+\mathrm{MT}+\mathrm{O}=100 \%$ Whole Body expression

For marker genes the expression in other body parts may be considered to be negligible, (i.e., for a head marker, $\mathrm{X}_{\text {Thorax }}, \mathrm{X}_{\mathrm{Abdomen}}, \mathrm{X}_{\mathrm{Gut}}, \mathrm{X}_{\mathrm{MT}}$, and $\mathrm{X}_{\text {Ovaries }}$ are all $\approx 0$ ). Therefore:

$\mathrm{X}_{\text {Head }}{ }^{*} \mathrm{H} \approx \mathrm{X}_{\text {Whole Body }}$ 
846 We solved for the estimated scaling factor for each of our qualifying markers, then averaged the

847 values we obtained for each body part to create a rough estimate of the percent of transcripts in

848 the whole body that are contributed by each part.

849

\section{RT-qPCR}

850 For all RT-qPCR amplifications, RNA was pretreated with DNase (Quantabio 95150-01K) and

851 cDNA was prepared using the qScript cDNA synthesis kit (Quantabio 95047-100) and amplified

852 using Perfecta SYBR Green Fastmix (Quantabio 95072-012) in a Bio-Rad CFX-Connect

853 Instrument. The primer sequences used in this study are available in S9 Table.

855 Acknowledgements

856 Special thanks to Jonathan Revah for creating the Aegypti-Atlas website, and to Laura

857 Harrington, Sylvie Pitcher, and Garrett League for their kind provision of Thai and G3 strain

858 mosquitoes. We also acknowledge members of the Buchon lab, Kristin Michel, Courtney

859 Murdock, Laura Harrington, and Jeffrey Scott for helpful comments on the manuscript.

\section{References}

861 1. Vector-borne diseases. In: WHO [Internet]. 2020 [cited 20 Nov 2020]. Available:

862 https://www.who.int/en/news-room/fact-sheets/detail/vector-borne-diseases

863 2. WHO | Insecticide resistance. WHO. 2020 [cited 20 Nov 2020]. Available:

http://www.who.int/malaria/areas/vector_control/insecticide_resistance/en/

3. Ranson H, N'Guessan R, Lines J, Moiroux N, Nkuni Z, Corbel V. Pyrethroid resistance in African anopheline mosquitoes: What are the implications for malaria control? Trends in 
868

869

870

871

872

873

874

875

876

877

878

879

880

881

882

883

884

885

886

887

888

889

890

891

4. Moyes CL, Vontas J, Martins AJ, Ng LC, Koou SY, Dusfour I, et al. Contemporary status of insecticide resistance in the major Aedes vectors of arboviruses infecting humans. PLoS Neglected Tropical Diseases. Public Library of Science; 2017. doi:10.1371/journal.pntd.0005625

5. Liu Y, Lillepold K, Semenza JC, Tozan Y, Quam MBM, Rocklöv J. Reviewing estimates of the basic reproduction number for dengue, Zika and chikungunya across global climate zones. Environmental Research. Academic Press Inc.; 2020. p. 109114.

doi:10.1016/j.envres.2020.109114

6. Cui Y, Franz AWE. Heterogeneity of midgut cells and their differential responses to blood meal ingestion by the mosquito, Aedes aegypti. bioRxiv. 2020; 2020.08.31.275941. doi:10.1101/2020.08.31.275941

7. Hyde J, Correa MA, Hughes GL, Steven B, Brackney DE. Limited influence of the microbiome on the transcriptional profile of female Aedes aegypti mosquitoes. Sci Rep. 2020;10: 10880. doi:10.1038/s41598-020-67811-y

8. Dong S, Behura SK, Franz AWE. The midgut transcriptome of Aedes aegypti fed with saline or protein meals containing chikungunya virus reveals genes potentially involved in viral midgut escape. BMC Genomics. 2017;18: 1-17. doi:10.1186/s12864-017-3775-6

9. Raquin V, Merkling SH, Gausson V, Moltini-Conclois I, Frangeul L, Varet H, et al. Individual co-variation between viral RNA load and gene expression reveals novel host factors during early dengue virus infection of the Aedes aegypti midgut. PLoS Negl Trop Dis. 2017;11: 1-21. doi:10.1371/journal.pntd.0006152

10. Vedururu RK, Neave MJ, Tachedjian M, Klein MJ, Gorry PR, Duchemin JB, et al. RNAseq analysis of aedes albopictus mosquito midguts after chikungunya virus infection. Viruses. 2019;11: 1-12. doi:10.3390/v11060513 
11. Baker DA, Nolan T, Fischer B, Pinder A, Crisanti A, Russell S. A comprehensive gene expression atlas of sex- and tissue-specificity in the malaria vector, Anopheles gambiae. BMC Genomics. 2011;12: 296. doi:10.1186/1471-2164-12-296

12. Vlachou D, Schlegelmilch T, Christophides GK, Kafatos FC. Functional Genomic Analysis of Midgut Epithelial Responses in Anopheles during Plasmodium Invasion. Curr Biol. 2005;15: 1185-1195. doi:10.1016/j.cub.2005.06.044

13. Warr E, Aguilar R, Dong Y, Mahairaki V, Dimopoulos G. Spatial and sex-specific dissection of the Anopheles gambiae midgut transcriptome. BMC Genomics. 2007;8: 37. doi:10.1186/1471-2164-8-37

14. Powell JR. Perspective piece mosquito-borne human viral diseases: Why aedes aegypti? American Journal of Tropical Medicine and Hygiene. American Society of Tropical Medicine and Hygiene; 2018. pp. 1563-1565. doi:10.4269/ajtmh.17-0866

15. Iwamura T, Guzman-Holst A, Murray KA. Accelerating invasion potential of disease vector Aedes aegypti under climate change. Nat Commun. 2020;11. doi:10.1038/s41467020-16010-4

16. Matthews BJ, Dudchenko O, Kingan SB, Koren S, Antoshechkin I, Crawford JE, et al. Improved reference genome of Aedes aegypti informs arbovirus vector control. Nature. 2018;563: 501-507. doi:10.1038/s41586-018-0692-z

17. Chintapalli VR, Wang J, Dow JAT. Using FlyAtlas to identify better Drosophila melanogaster models of human disease. Nature Genetics. Nature Publishing Group; 2007. pp. 715-720. doi:10.1038/ng2049

18. Leader DP, Krause SA, Pandit A, Davies SA, Dow JAT. FlyAtlas 2: A new version of the Drosophila melanogaster expression atlas with RNA-Seq, miRNA-Seq and sex-specific 
data. Nucleic Acids Res. 2018;46: D809-D815. doi:10.1093/nar/gkx976

916

917

918

919

920

921

922

923

924

925

926

927

928

929

930

931

932

933

934

935

936

937

19. Sreenivasamurthy SK, Madugundu AK, Patil AH, Dey G, Mohanty AK, Kumar M, et al. Mosquito-Borne Diseases and Omics: Tissue-Restricted Expression and Alternative Splicing Revealed by Transcriptome Profiling of Anopheles stephensi. Omi A J Integr Biol. 2017;21: 488-497. doi:10.1089/omi.2017.0073

20. Martínez-Barnetche J, Gómez-Barreto RE, Ovilla-Muñoz M, Téllez-Sosa J, López DEG, Dinglasan RR, et al. Transcriptome of the adult female malaria mosquito vector Anopheles albimanus. BMC Genomics. 2012;13: 1-17. doi:10.1186/1471-2164-13-207

21. Ptitsyn AA, Reyes-Solis G, Saavedra-Rodriguez K, Betz J, Suchman EL, Carlson JO, et al. Rhythms and synchronization patterns in gene expression in the Aedes aegypti mosquito. BMC Genomics. 2011;12. doi:10.1186/1471-2164-12-153

22. Li Y, Piermarini PM, Esquivel CJ, Drumm HE, Schilkey FD, Hansen IA. RNA-Seq Comparison of Larval and Adult Malpighian Tubules of the Yellow Fever Mosquito Aedes aegypti Reveals Life Stage-Specific Changes in Renal Function. Front Physiol. 2017;8. doi:10.3389/FPHYS.2017.00283

23. Cui Y, Franz AWE. Heterogeneity of midgut cells and their differential responses to blood meal ingestion by the mosquito, Aedes aegypti. Insect Biochem Mol Biol. 2020; 103496. doi:10.1016/j.ibmb.2020.103496

24. Xiao X, Yang L, Pang X, Zhang R, Zhu Y, Wang P, et al. A Mesh-Duox pathway regulates homeostasis in the insect gut. Nat Microbiol. 2017;2. doi:10.1038/NMICROBIOL.2017.20

25. Liu J, Liu Y, Nie K, Du S, Qiu J, Pang X, et al. Flavivirus NS1 protein in infected host sera enhances viral acquisition by mosquitoes. Nat Microbiol 2016 19. 2016;1: 1-11. 
26. Dong S, Behura SK, Franz AWE. The midgut transcriptome of Aedes aegypti fed with saline or protein meals containing chikungunya virus reveals genes potentially involved in viral midgut escape. BMC Genomics. 2017;18. doi:10.1186/S12864-017-3775-6

942

943

944

945

946

947

948

949

950

951

952

953

954

955

956

957

958

959

960

27. Angleró-Rodríguez YI, MacLeod HJ, Kang S, Carlson JS, Jupatanakul N, Dimopoulos G. Aedes aegypti molecular responses to Zika Virus: Modulation of infection by the toll and Jak/Stat immune pathways and virus host factors. Front Microbiol. 2017;8: 2050. doi:10.3389/fmicb.2017.02050

28. Akbari OS, Antoshechkin I, Amrhein H, Williams B, Diloreto R, Sandler J, et al. The developmental transcriptome of the mosquito Aedes aegypti, an invasive species and major arbovirus vector. G3 (Bethesda). 2013;3: 1493-1509. doi:10.1534/G3.113.006742

29. Nag DK, Dieme C, Lapierre P, Lasek-Nesselquist E, Kramer LD. RNA-Seq analysis of blood meal induced gene-expression changes in Aedes aegypti ovaries. BMC Genomics. $2021 ; 22$. doi:10.1186/S12864-021-07551-Z

30. Choi Y-J, Fuchs JF, Mayhew GF, Yu HE, Christensen BM. Tissue-enriched expression profiles in Aedes aegypti identify hemocyte-specific transcriptome responses to infection. Insect Biochem Mol Biol. 2012;42: 729-738. doi:10.1016/j.ibmb.2012.06.005

31. Buchon N, Osman D, David FPA, Yu Fang H, Boquete JP, Deplancke B, et al. Morphological and Molecular Characterization of Adult Midgut Compartmentalization in Drosophila. Cell Rep. 2013;3: 1725-1738. doi:10.1016/j.celrep.2013.04.001

32. Dutta D, Buchon N, Xiang J, Edgar BA. Regional Cell Specific RNA Expression Profiling of FACS Isolated Drosophila Intestinal Cell Populations. Curr Protoc Stem Cell Biol. 2015;34: 2F.2.1-2F.2.14. doi:10.1002/9780470151808.sc02f02s34 
961

962

963

964

965

966

967

968

969

970

971

972

973

974

975

976

977

978

979

980

981

982

983

33. Benguettat O, Jneid R, Soltys J, Loudhaief R, Brun-Barale A, Osman D, et al. The DH31/CGRP enteroendocrine peptide triggers intestinal contractions favoring the elimination of opportunistic bacteria. 2018. doi:10.1371/journal.ppat.1007279

34. Buchon N, Osman D. All for one and one for all: Regionalization of the Drosophila intestine. Insect Biochem Mol Biol. 2015;67: 2-8. doi:10.1016/j.ibmb.2015.05.015

35. Clements AN. The Biology of Mosquitoes Volume 1: Development, Nutrition and Reproduction. London: Chapman \& Hall; 1992.

36. Hecker $\mathrm{H}$. Structure and function of midgut epithelial cells in culicidae mosquitoes (insecta, diptera). Cell Tissue Res. 1977;184: 321-341. doi:10.1007/BF00219894

37. Felix CR, Betschart B, B1llingsleyt PF, Freyvogel TA. Post-feeding Induction Of Trypsin In The Midgut Of Aedes Aegypti L. (Diptera: Culicidae) Is Separable Into Two Cellular Phases. Insect Biochem. 1991.

38. Noriega FG, Pennington JE, Barillas-Mury C, Wang XY, Wells MA. Aedes aegypti midgut early trypsin is post-transcriptionally regulated by blood feeding. Insect Mol Biol. 1996;5: 25-29. doi:10.1111/j.1365-2583.1996.tb00037.x

39. Jiang Q, Halls M, Noriega FG, Wellst M. cDNA Cloning and Pattern of Expression of an Adult, Female-Specific Chymotrypsin from Aedes aegypti Midgut. Insect Biochem Molec Biol. 1997.

40. Bian G, Raikhel AS, Zhu J. Characterization of a juvenile hormone-regulated chymotrypsin-like serine protease gene in Aedes aegypti mosquito. 2008 [cited 18 May 2020]. doi:10.1016/j.ibmb.2007.10.008

41. Noriega FG, Shah DK, Wells MA. Juvenile hormone controls early trypsin gene transcription in the midgut of Aedes aegypti. Insect Mol Biol. 1997. 
42. Noriega FG, Edgar KA, Goodman WG, Shah DK, Wells MA. Neuroendocrine factors affecting the steady-state levels of early trypsin mRNA in Aedes aegypti. J Insect Physiol. 2001;47: 515-522. doi:10.1016/S0022-1910(00)00145-1

43. Gooding RH. Physiological aspects of digestion of the blood meal by Aedes aegypti (Linnaeus) and Culex fatigans Wiedemann. J Med Entomol. 1966;3: 53-60. doi:10.1093/jmedent/3.1.53

44. Graf R, Briegel H. Comparison between aminopeptidase and trypsin activity in blood-fed females of Aedes aegypti. Rev suisse Zool. 1982;89: 845-850. doi:10.5962/bhl.part.82479

45. Barillas-Mury $\mathrm{C}$, Graf R, Hagedorn $\mathrm{HH}$, Wells MA. cDNA and deduced amino acid sequence of a blood meal-induced trypsin from the mosquito, Aedes aegypti. Insect Biochem. 1991;21: 825-831. doi:10.1016/0020-1790(91)90089-W

46. Graf R, Lea AO, Briegel H. A temporal profile of the endocrine control of trypsin synthesis in the yellow fever mosquito, Aedes aegypti. J Insect Physiol. 1998;44: 451-454. doi:10.1016/S0022-1910(98)00042-0

47. Noriega FG, Edgar KA, Bechet R, Wells MA. Midgut exopeptidase activities in Aedes aegypti are induced by blood feeding. J Insect Physiol. 2002. Available: www.elsevier.com/locate/jinsphys

48. He Y-Z, Ding Y, Wang X, Zou Z, Raikhel AS. E93 confers steroid hormone responsiveness of digestive enzymes to promote blood meal digestion in the midgut of the mosquito Aedes aegypti. Insect Biochem Mol Biol. 2021; 103580. doi:10.1016/j.ibmb.2021.103580

49. Brackney DE, Isoe J, Iv BW, Zamora J, Foy BD, Miesfeld RL, et al. Expression profiling 
and comparative analyses of seven midgut serine proteases from the yellow fever mosquito, Aedes aegypti. J Insect Physiol. 56: 736-744.

doi:10.1016/j.jinsphys.2010.01.003

50. Isoe J, Rascón AA, Kunz S, Miesfeld RL. Molecular Genetic Analysis of Midgut Serine Proteases in Aedes aegypti Mosquitoes. Insect Biochem Mol Biol. 2009; 1-24. doi:10.1016/j.ibmb.2009.10.008

51. Sanders HR, Evans AM, Ross LS, Gill SS. Blood meal induces global changes in midgut gene expression in the disease vector, Aedes aegypti. Insect Biochem Mol Biol. 2003;33: 1105-1122. doi:10.1016/S0965-1748(03)00124-3

52. Isoe J, Zamora J, Miesfeld RL. Molecular analysis of the Aedes aegypti carboxypeptidase gene family. Insect Biochem Mol Biol. 2009;39: 68-73. doi:10.1016/j.ibmb.2008.09.006

53. Brackney DE, Isoe J, W.C. B, Zamora J, Foy BD, Miesfeld RL, et al. Expression profiling and comparative analyses of seven midgut serine proteases from the yellow fever mosquito, Aedes aegypti. J Insect Physiol. 2010;56: 736-744.

doi:10.1016/j.jinsphys.2010.01.003

54. League GP, Baxter LL, Wolfner MF, Harrington LC. Male accessory gland molecules inhibit harmonic convergence in the mosquito Aedes aegypti. Current Biology. Cell Press; 2019. pp. R196-R197. doi:10.1016/j.cub.2019.02.005

55. Dzaki N, Ramli KN, Azlan A, Ishak IH, Azzam G. Evaluation of reference genes at different developmental stages for quantitative real-time PCR in Aedes aegypti. Sci Rep. 2017;7. doi:10.1038/srep43618

56. Weng XH, Huss M, Wieczorek H, Beyenbach KW. The V-type H+-ATPase in Malpighian tubules of Aedes aegypti: Localization and activity. J Exp Biol. 2003;206: 2211-2219. 
doi:10.1242/jeb.00385

1031

1032

1033

1034

1035

1036

1037

1038

1039

1040

1041

1042

1043

1044

1045

1046

1047

1048

1049

1050

1051

1052

57. Hagedorn HH, O'Connor JD, Fuchs MS, Sage B, Schlaeger DA, Bohm MK. The ovary as a source of a ecdysone in an adult mosquito. Proc Natl Acad Sci U S A. 1975;72: 32553259. doi:10.1073/pnas.72.8.3255

58. Gusmão DS, Santos A V., Marini DC, Bacci M, Berbert-Molina MA, Lemos FJA. Culturedependent and culture-independent characterization of microorganisms associated with Aedes aegypti (Diptera: Culicidae) (L.) and dynamics of bacterial colonization in the midgut. Acta Trop. 2010;115: 275-281. doi:10.1016/j.actatropica.2010.04.011

59. Buchon N, Broderick NA, Poidevin M, Pradervand S, Lemaitre B. Drosophila intestinal response to bacterial infection: activation of host defense and stem cell proliferation. Cell Host Microbe. 2009;5: 200-211. doi:10.1016/j.chom.2009.01.003

60. Foo ACY, Thompson PM, Chen S-H, Jadi R, Lupo B, DeRose EF, et al. The mosquito protein AEG12 displays both cytolytic and antiviral properties via a common lipid transfer mechanism. Proc Natl Acad Sci. 2021;118: e2019251118. doi:10.1073/pnas.2019251118

61. Siomi MC, Sato K, Pezic D, Aravin AA. PIWI-interacting small RNAs: the vanguard of genome defence. Nat Rev Mol Cell Biol 2011 124. 2011;12: 246-258. doi:10.1038/nrm3089

62. Olmo RP, Ferreira AGA, Izidoro-Toledo TC, Aguiar ERGR, de Faria IJS, de Souza KPR, et al. Control of dengue virus in the midgut of Aedes aegypti by ectopic expression of the dsRNA-binding protein Loqs2. Nat Microbiol. 2018;3: 1385-1393. doi:10.1038/s41564018-0268-6

63. Clayton AM, Cirimotich CM, Dong Y, Dimopoulos G. Caudal is a negative regulator of the Anopheles IMD pathway that controls resistance to Plasmodium falciparum infection. Dev 
1054

1055

1056

1057

1058

1059

1060

1061

1062

1063

1064

1065

1066

1067

1068

1069

1070

1071

1072

1073

1074

1075

64. Ryu J-H, Kim S-H, Lee H-Y, Bai JY, Nam Y-D, Bae J-W, et al. Innate immune homeostasis by the homeobox gene caudal and commensal-gut mutualism in Drosophila. Science. 2008;319: 777-782. doi:10.1126/science.1149357

65. Haines LR, Lehane SM, Pearson TW, Lehane MJ. Tsetse EP Protein Protects the Fly Midgut from Trypanosome Establishment. Vernick KD, editor. PLoS Pathog. 2010;6: e1000793. doi:10.1371/journal.ppat.1000793

66. Hecker $\mathrm{H}$. Structure and function of midgut epithelial cells in culicidae mosquitoes (insecta, diptera). Cell Tissue Res. 1977;184: 321-341. doi:10.1007/BF00219894

67. Hao Z, Kasumba I, Aksoy S. Proventriculus (cardia) plays a crucial role in immunity in tsetse fly (Diptera: Glossinidiae). Insect Biochem Mol Biol. 2003;33: 1155-1164. doi:10.1016/j.ibmb.2003.07.001

68. Li FQ, Takemaru KI, Goto M, Ueda H, Handa H, Hirose S. Transcriptional activation through interaction of MBF2 with TFIIA. Genes to Cells. 1997;2: 143-153. doi:10.1046/j.1365-2443.1997.1090306.x

69. Liu QX, Ueda $\mathrm{H}$, Hirose S. MBF2 is a tissue- and stage-specific coactivator that is regulated at the step of nuclear transport in the silkworm Bombyx mori. Dev Biol. 2000;225: 437-446. doi:10.1006/dbio.2000.9836

70. Billingsley PF. The Midgut Ultrastructure of Hematophagous Insects. Annu Rev Entomol. 1990;35: 219-248. doi:10.1146/annurev.en.35.010190.001251

71. Billingsley PF, Hecker H. Blood digestion in the mosquito, Anopheles stephensi Liston (Diptera: Culicidae): activity and distribution of trypsin, aminopeptidase, and alphaglucosidase in the midgut. J Med Entomol. 1991;28: 865-871. 
1077 72. Noriega FG, Shah DK, Wells MA. Juvenile hormone controls early trypsin gene transcription in the midgut of Aedes aegypti. Insect Mol Biol. 1997;6: 63-66. doi:10.1046/j.1365-2583.1997.00154.x

73. Shapiro AB, Wheelock GD, Hagedorn HH, Baker FC, Tsai LW, Schooley DA. Juvenile hormone and juvenile hormone esterase in adult females of the mosquito Aedes aegypti. J Insect Physiol. 1986;32: 867-877. doi:10.1016/0022-1910(86)90102-2

74. Hernández-Martínez S, Rivera-Perez C, Nouzova M, Noriega FG. Coordinated changes in $\mathrm{JH}$ biosynthesis and $\mathrm{JH}$ hemolymph titers in Aedes aegypti mosquitoes. $\mathrm{J}$ Insect Physiol. 2015;72: 22-27. doi:10.1016/j.jinsphys.2014.11.003

75. Lucas KJ, Roy S, Ha J, Gervaise AL, Kokoza VA, Raikhel AS. MicroRNA-8 targets the wingless signaling pathway in the female mosquito fat body to regulate reproductive processes. Proc Natl Acad Sci U S A. 2015;112: 1440-1445.

76. Zhao B, Hou Y, Wang J, Kokoza VA, Saha TT, Wang XL, et al. Determination of juvenile system in Aedes aegypti mosquitoes. Insect Biochem Mol Biol. 2016;77: 69-77. doi:10.1016/j.ibmb.2016.08.003

1094 77. Hagedorn HH, O’Connor JD, Fuchs MS, Sage B, Schlaeger DA, Bohm MK. The ovary as a source of a ecdysone in an adult mosquito. Proc Natl Acad Sci U S A. 1975;72: 32553259. doi:10.1073/pnas.72.8.3255

1097 78. Gonzales KK, Rodriguez SD, Chung HN, Kowalski M, Vulcan J, Moore EL, et al. The 
1100 79. Troha K, Im JH, Revah J, Lazzaro BP, Buchon N. Comparative transcriptomics reveals CrebA as a novel regulator of infection tolerance in D. melanogaster. Schneider DS, editor. PLOS Pathog. 2018;14: e1006847. doi:10.1371/journal.ppat.1006847

1103 80. Emms DM, Kelly S. OrthoFinder: Phylogenetic orthology inference for comparative genomics. Genome Biol. 2019;20: 238. doi:10.1186/s13059-019-1832-y 


\section{Figure Legends}

1120

1121

1122

1123

1124

1125

1126

1127

1128

1129

1130

1131

1132

1133

1134

1135

1136

1137

1138

1139

1140

1141

1142

Fig 1. The transcriptomes of Aedes aegypti body parts reflect their embryonic origins and functional specializations

(A) PCA of the transcriptomes of whole body and body parts; 3 to 6 replicates per body part. Circled clusters contain body parts of dominantly endodermal (left) and mesodermal/ectodermal (right) derivation. (B) Body part-specific putative tissue markers; expression values are scaled as a percentage of the maximum expression observed for each gene. (C) Calculated estimates of body parts' contributions to whole body transcriptome; Bubble plots: TopGO GOEA of genes enriched 5x (head, gut thorax, Malpighian tubules, abdomen) or 2x (ovaries) relative to whole body (DESeq2, padj <0.05); Pie charts: 20 highest expressed genes per body part, grouped by category/function.

Fig 2: Mosquito gut regions' transcriptomic investments and outputs reveal digestive specializations

(A) Principal component analysis of the transcriptomes of whole gut and gut regions; 3 to 6 replicates. Circled clusters contain body parts of partial endodermal (left) and ectodermal (right) derivation. (B) Bubble plots: TopGO GOEA of regionally enriched genes (5x over whole gut for crop, proventriculus, and anterior midgut, 5x over other regions for posterior midgut) in Aedes aegypti (DESeq2, padj <0.05) (C) Pie charts: 20 highest expressed genes per region, grouped by category/function. (D) Regional investments in categories of digestive enzymes and transporters, scaled as a percentage of the most invested region (as measured by cumulative TPM). (E) Estimates of regions' transcriptional output by empirical quantification of RNA yield; statistics: One-way ANOVA, Tukey HSD. (F) Estimated output of digestive enzymes/transporters by region (categorical investments weighted by regional RNA yield). 


\section{Fig 3: The gut's transcriptome shifts continuously throughout blood meal digestion}

1145 (A) PCA of the transcriptomes of sugar-fed and blood-fed guts; 3 to 6 replicates per condition.

1146 (B) TopGO GOEA of up to 400 most upregulated and 400 most downregulated genes in each 1147 comparison (DESeq2, padj $<0.05$, minimum of $2 x$ fold-change). (C) Investments in categories of 1148 digestive enzymes and transporters by timepoint/condition, scaled as a percentage of highest 1149 investment (as measured by cumulative TPM). (D) Proportional investment (out of whole 1150 transcriptome) in selected gene categories/families by timepoint/condition. (E) Expression of 1151 selected peptidases, scaled as a percentage of maximum expression. (F) Relative expression of 1152 selected peptidases at $0,6,12,24,36$, 48, and 72 hrs post-blood meal measured by RT-qPCR; 1153 reference gene: AAEL009653; 3 replicates.

Fig 4: Regional specializations in sugar and protein digestion are preserved in the blood-

1157 (A) PCA of the transcriptomes of sugar-fed and 24-hr blood-fed whole guts and anterior and 1158 posterior midguts; 3 to 6 replicates per condition. (B) TopGO GOEA of up to 400 most 1159 upregulated and 400 most downregulated genes in blood-fed versus sugar-fed regions 1160 (DESeq2, padj <0.05, minimum of $2 x$ fold-change inclusion criterion. (C) Proportional 1161 expression (out of whole transcriptome) of selected gene categories/families by 1162 region/condition. (D) Regional investments in categories of digestive enzymes and transporters, 1163 scaled as a percentage of the most invested region/condition (as measured by cumulative 1164 TPM). (E) Estimates of midgut regions' transcriptional yield by empirical quantification of RNA in 1165 sugar-fed guts versus 24 hrs after feeding with an artificial blood replacement diet; statistics: 
unpaired t-test. (F) Estimated output of digestive enzymes/transporters by midgut region in sugar-fed and blood-fed mosquitoes (categorical investments weighted by regional RNA yield).

Fig 5. Immune gene patterning reveals zones of immune activity and tolerance in the mosquito body and gut

1171 (A) Body parts' investments in immune pathway-related genes, scaled as a percentage, scaled

1172 as a percentage of the most invested body part. (B) Cumulative antimicrobial peptide

1173 expression by body part (TPM); statistics: One-way ANOVA, Tukey HSD. (C) Expression of

1174 immune activating/modulating genes, scaled as a percentage of the highest expressing gut

1175 region. (D) Cumulative antimicrobial peptide expression by gut region (TPM); statistics: One-

1176 way ANOVA, Tukey HSD. (E) Output of immune-related genes and gene categories by gut

1177 region, weighted by regional RNA yield.

Fig 6. Digestive and defensive regional specializations are well conserved between the

\section{Aedes aegypti and Anopheles gambiae midguts}

1181 (A) Clustering analyses of the transcriptomes of Aedes aegypti and Anopheles gambiae whole 1182 gut and midgut regions; 3 to 6 replicates (B) Regional investments in categories of digestive 1183 enzymes and transporters, scaled as a percentage of expression in the most invested midgut 1184 region (as measured by cumulative TPM) (C) Expression of immune activating/modulating 1185 genes and effectors, scaled as a percentage of the expression in the most invested region. (D)

1186 Conserved regional enrichment of gene families and functions in Ae. aegypti and An. gambiae 1187 midgut regions, as evaluated by TopGO GOEA, investment analysis, and a comparison of the 1188 twenty highest expressed transcripts. 
1190 Fig 7. A small number of disparately expressed genes constitute a 'species signature' 1191 differentiating midgut transcriptomes in Aedes aegypti and Anopheles gambiae

1192 (A-C) Correlation of one-to-one orthologous genes before and after censorship of 35 most 1193 disparately expressed orthologous pairs. (D) One-to-one orthologs censored in a regional 1194 correlation analysis; $\left({ }^{\wedge}\right)$ signifies orthologous pairs censored in both proventriculus and anterior 1195 midgut, $(\dagger)$ signifies orthologous pairs censored in both anterior midgut and posterior midgut $\left({ }^{\star}\right)$ 1196 signifies orthologous pairs censored in both proventriculus and posterior midgut. (E) 20 highest 1197 expressed transcripts per region, grouped by category/function. 


\section{Supplemental Figure Legends}

1211 S1.1 Fig. Ovaries possess many highly enriched genes relative to other body parts, but

1212 few relative to whole body

1213 (A) Diagram of included/excluded structures/tissues in dissected body parts (B) Transcriptome-

1214 wide z-scores for gene expression by body part. Data are z-scores for genes expressed $\geq 2$

1215 TPM in one or more body parts; black diamonds mark mean z-scores; statistics: One-way

1216 ANOVA, Tukey HSD. (B) Transcriptomic variation from whole body expression by body part

1217 (fold change adjusted by DESeq2, no significance criterion applied).

1220 (A) Comparison of candidate reference genes for RT-qPCR analysis of putative marker genes; 1221 expression values are scaled as a percentage of the maximum expression observed (in TPM).

1222 (B) RT-qPCR validation of putative marker gene expression; reference gene: AAEL013144; 3 1223 replicates; statistics: One-way ANOVA, Tukey HSD.

S1.3 Fig. Calculated scaling factors accurately predict whole body gene expression

1226 (A) Validation of estimated scaling factors for body part transcript contribution to whole body expression, with (left) and without (right) outlying gene. 
1231 (A) Transcriptomic variation from whole gut expression by gut region (fold change adjusted by

1232 DESeq2, no significance criterion applied). (B) Transcriptome-wide z-scores for gene 1233 expression by gut region. Data are z-scores for genes expressed $\geq 2$ TPM in one or more 1234 regions; black diamonds mark mean z-scores; statistics: One-way ANOVA, Tukey HSD. meal

(A) Dissected guts from sugar-fed mosquitoes and mosquitoes at 6, 24, and $48 \mathrm{hrs}$ pbm. (B) Estimates of gut's transcriptional output in sugar-fed mosquitoes and at 6,24 , and $48 \mathrm{hrs} \mathrm{pbm}$ by empirical quantification of RNA yield; statistics: One-way ANOVA, Tukey HSD. (C) Estimated output of peptidases by category (categorical investments weighted by RNA yield, scaled to SF output); statistics: One-way ANOVA, Tukey HSD.

S3.2 Fig. Gut peptidase transcripts are induced and depleted asynchronously during

1246 (A) Clustering analysis of the expression of peptidases across all timepoints of blood feeding 1247 time series. (B) Comparison of candidate reference genes for RT-qPCR analysis of peptidases 1248 in blood-fed guts; expression values are scaled as a percentage of the maximum expression 1249 observed (in TPM). (C) Unscaled results of RT-qPCR for selected peptidases relative to 1250 reference gene (AAEL009653); 3 replicates; statistics: One-way ANOVA, Tukey HSD. 
1254 (A) Phylogenetic tree for serine endopeptidases in Aedes aegypti with regulated genes labeled

1255 by temporal cluster; Note: superimposed chromosomal cluster labels indicate where a plurality

1256 of genes from that locus are located on the diagram, but not all genes proximal to a label belong

1257 to that chromosomal locus

S6 Fig. Midgut regions in Aedes aegypti and Anopheles gambiae display similar regional specializations, but disparate amplitudes of investment in key functions

1261 Midgut regional investments in (A) digestive peptidases and (B) AMPs and lysozymes in Ae.

1262 aegypti and An. gambiae; statistics: unpaired t-test. (C) TopGO GOEA of regionally enriched 1263 genes (5x over whole gut for proventriculus, and anterior MG, 5x over other midgut regions for 1264 posterior MG) in Anopheles gambiae (DESeq2, padj <0.05).

1269 (A) Correlation of expression of one-to-one orthologous genes in the Aedes aegypti and 1270 Anopheles gambiae midgut regions. (B) Plotted slopes and correlation coefficients for 1271 correlations of one-to-one orthologous genes during a process of sequential censoring of 1272 disparately expressed orthologs and re-scaling of TPMs; Black arrows indicate the number of 1273 genes censored in: (C) Adjusted correlation plots reflecting the relationships of one-to-one 1274 orthologs post-censorship/rescaling. 
1277 ribosomal proteins are sister sequences

1278 (A) Geneious phylogenetic tree depicting the evolutionary relatedness of ribosomal proteins in 1279 Aedes aegypti and Anopheles gambiae. Pairs of censored one-to-one orthologs from the 1280 correlational analysis are shown in colored boxes. A red box indicates that the Aedes gene was 1281 higher expressed compared to the Anopheles gene. A blue box indicates that the Anopheles 1282 gene was higher expressed.

1284 S7.3 Fig. A model for regionalized microbe selection and immune tolerance in the 1285 mosquito gut

1286 (A) A model of the proposed effects of regional specializations in immune recognition/AMP 1287 expression (proventriculus/anterior midgut) and tolerance (posterior midgut). 
bioRxiv preprint doi: https://doi.org/10.1101/2021.12.19.473372; this version posted December 21,2021 . The copyright holder for this preprint (which was not certified by peer review) is the author/funder, who has granted bioRxiv a license to display the preprint in perpetuity. It is made available under aCC-BY 4.0 International license.

A

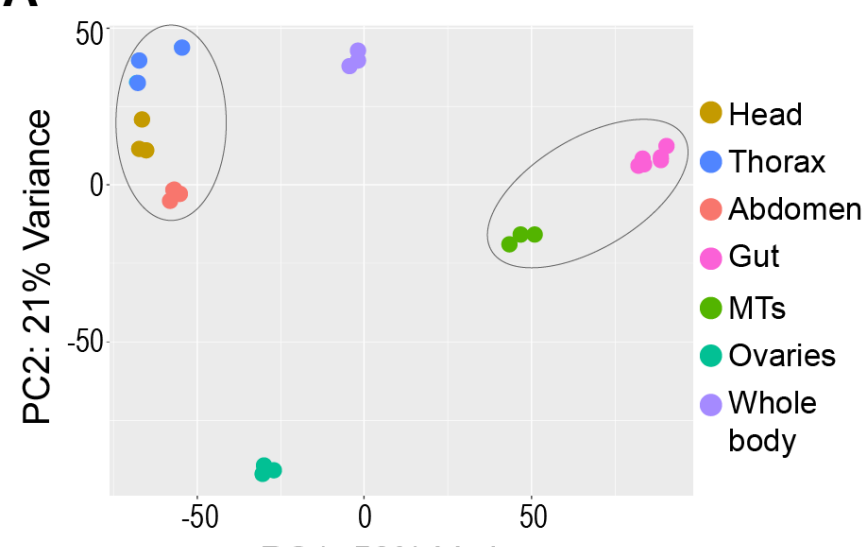

PC1: $53 \%$ Variance
B

\begin{tabular}{|c|c|c|c|c|c|c|c|c|}
\hline & & \multicolumn{6}{|c|}{$\%$ of $\max$ TPM } & \\
\hline Gene ID & Description & Head & Thrx & Abd & Gut & MTs & Ov & \\
\hline AAEL006451 & Neuropeptide & 100 & 0 & 0 & 0 & 0 & 0 & 155 \\
\hline AAEL000937 & Insulin-lik & 100 & 0 & & & & 0 & 68 \\
\hline AAEL003894 & GNBP & 0 & 100 & c & & & 0 & 40 \\
\hline AAEL005964 & Actin & 1 & 100 & 2 & & 0 & 0 & 27 \\
\hline AAEL022506 & Fatty acid synthase & 1 & 0 & 100 & & 1 & 0 & 86 \\
\hline AAEL001737 & Fatty acyl-CoA reductase & 0 & 0 & 100 & 0 & 1 & 0 & 38 \\
\hline AAEL022387 & Acyltransferas & 0 & 2 & 0 & 100 & 1 & 1 & 100 \\
\hline AAEL008599 & Carboxypeptidase & 0 & 0 & 0 & 100 & 0 & 0 & 116 \\
\hline AAEL001650 & Niemann Pick & 0 & 0 & 0 & 0 & 100 & 0 & 124 \\
\hline AAEL007016 & $\mathrm{Na}+/$ gluc cotransporter & 0 & 0 & 0 & 0 & 100 & 0 & 153 \\
\hline AAEL 000584 & SoxN transcription factor & 0 & 1 & 0 & 0 & 0 & 100 & 45 \\
\hline AAEL 013721 & logs2; siRNA pathway & 0 & 0 & 0 & 0 & 0 & 100 & 44 \\
\hline
\end{tabular}

\begin{tabular}{l|l|l|l|l|l|l|}
\hline Color scale & 100 & 80 & 60 & 40 & 20 & 0 \\
\hline
\end{tabular}

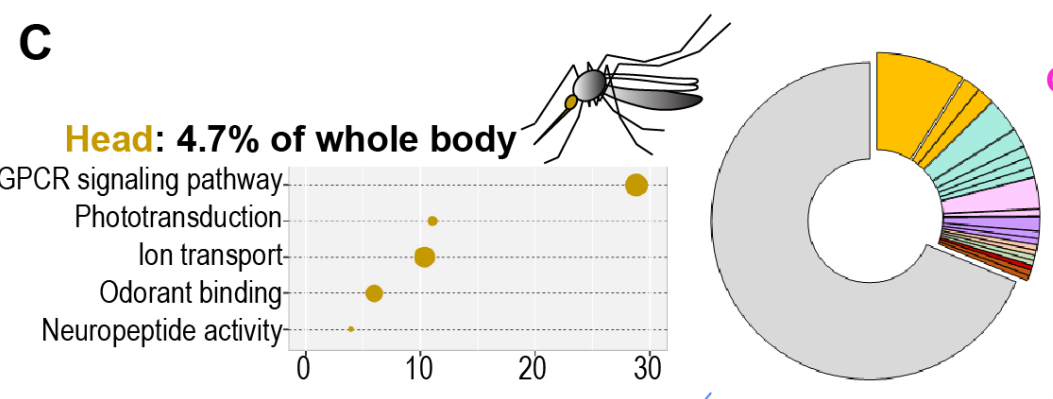

Gut: $14.0 \%$ of WB

Peptidase activity -

Heme binding -

PGN catabolism -

Carbohydrate metabolism -

Defense response

Apoptotic process

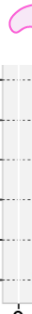

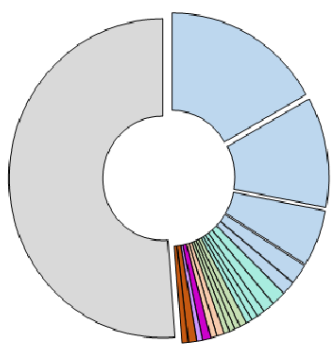

Thorax: $19.4 \%$ of WB

Cellular respirationIon transportCarbohydrate catabolism SOD activity

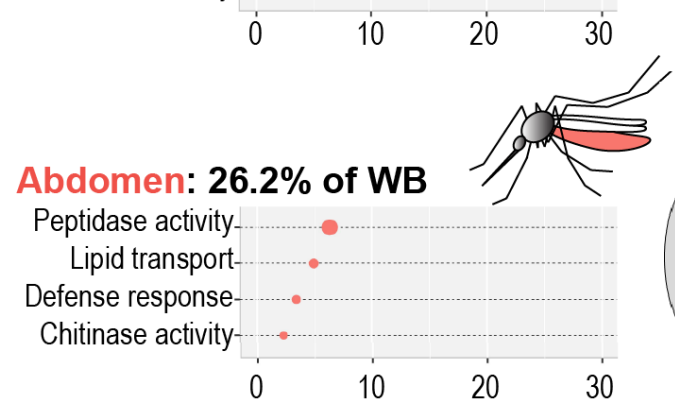

Bubble plots' $x$ axes $=-\log 10(p)$

\# of genes

25

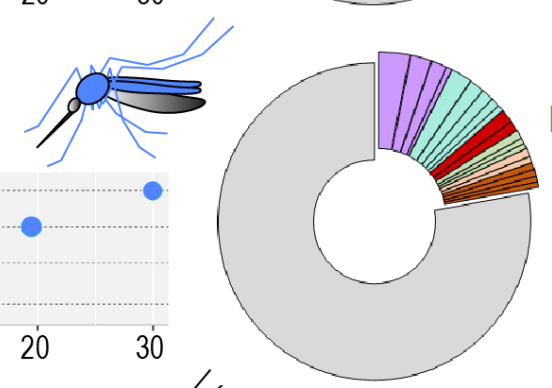

Malpighian tubules: $1.7 \%$ of WB Heme binding Active $\mathrm{H}+$ transport - . Ion transport PGN catabolism Defense response

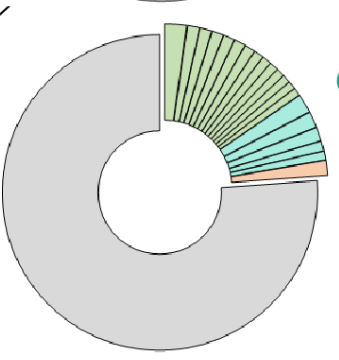

Ovaries: $\mathbf{2 8 . 8 \%}$ of WB

DNA replication DNA repair -.......

Protein methylation

Cell cycle mRNA splicing-

0

10
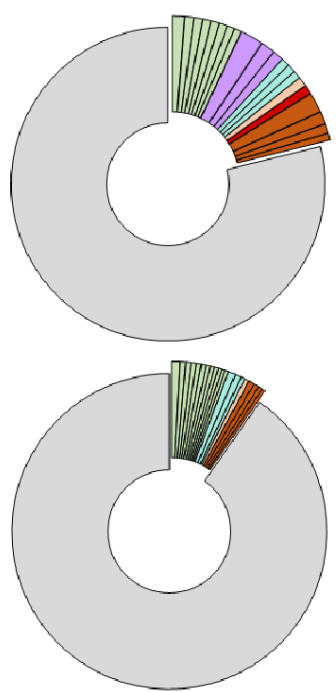

$\square$ Arrestin $\square$ GPCR $\square$ rRNA $\square$ ATP synthase $\square$ IncRNA $\square$ Peptidase

Cytochrome c oxidase

MBF2 $\square$ Ribosomal protein

Miscellaneous 
bioRxiv preprint doi: https://doi.org/10.1101/2021.12.19.473372; this version posted December 21, 2021. The copyright holder for this preprint (which was not certified by peer review) is the author/funder, who has granted bioRxiv a license to display the preprint in perpetuity. It is made available under aCC-BY 4.0 International license.

A

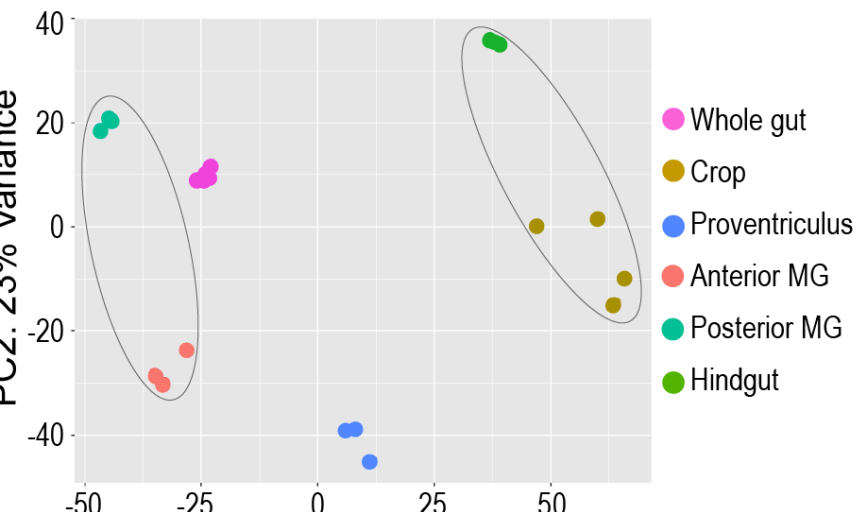

PC1: $53 \%$ Variance

D

\begin{tabular}{|c|c|c|c|c|c|c|}
\hline \multirow[t]{2}{*}{ D } & \multicolumn{5}{|c|}{$\%$ of max TPM } & \multirow{2}{*}{$\begin{array}{l}\text { Max } \\
\text { TPM }\end{array}$} \\
\hline & Crop & Prov & Ant & Post & Hind & \\
\hline & \multicolumn{6}{|c|}{ Lipid digestion } \\
\hline Phospholipases & 100 & 97 & 77 & 28 & 57 & 145 \\
\hline Sphingomyelinases & 3 & 89 & 100 & 44 & 3 & 290 \\
\hline Other lipases & 68 & 38 & 51 & 100 & 86 & 365 \\
\hline \multicolumn{7}{|c|}{ Lipid absorption/transport } \\
\hline Lipid carrier proteins & 100 & 39 & 25 & 4 & 62 & 2732 \\
\hline Fatty acid transporters & 100 & 50 & 39 & 26 & 39 & 210 \\
\hline Phospholipid transporters & 22 & 70 & 100 & 35 & 31 & 372 \\
\hline Sterol transporters & 15 & 71 & 100 & 41 & 8 & 3215 \\
\hline \multicolumn{7}{|c|}{ Sugar digestion } \\
\hline Amylases/maltases & 3 & 71 & 100 & 3 & 9 & 18833 \\
\hline Glucosidases & 2 & 70 & 100 & 4 & 3 & 10845 \\
\hline \multicolumn{7}{|c|}{ Sugar absorption/transport } \\
\hline Sugar transporters & 11 & 48 & 100 & 11 & 10 & 10528 \\
\hline \multicolumn{7}{|c|}{ Protein digestion } \\
\hline Cysteine peptidases & 100 & 35 & 29 & 14 & 67 & 376 \\
\hline Dipeptidases & 37 & 69 & 100 & 89 & 46 & 135 \\
\hline Dipeptidyl peptidases & 10 & 18 & 34 & 100 & 75 & 781 \\
\hline Aminopeptidases & 11 & 32 & 58 & 100 & 24 & 3075 \\
\hline Carboxypeptidases & 4 & 3 & 34 & 100 & 4 & 23232 \\
\hline Serine endopeptidases & 3 & 7 & 27 & 100 & 4 & 395993 \\
\hline Other peptidases & 5 & 3 & 10 & 100 & 4 & 25553 \\
\hline \multicolumn{7}{|c|}{ Amino acid absorption/transport } \\
\hline Amino acid transporters & 20 & 33 & 40 & 48 & 100 & 2124 \\
\hline Color scale & 100 & 80 & 60 & 40 & 20 & 0 \\
\hline
\end{tabular}

E

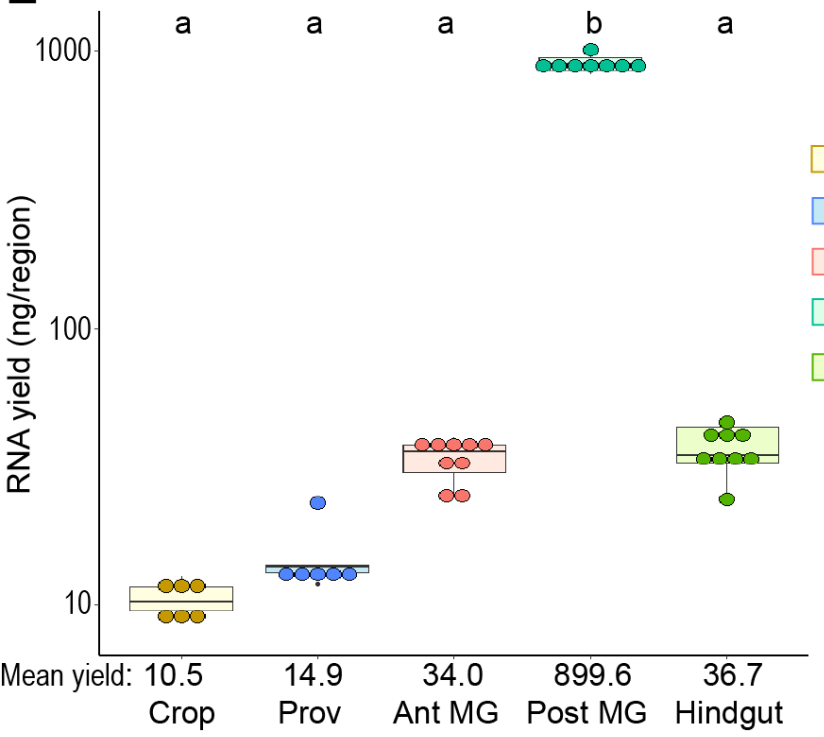

B

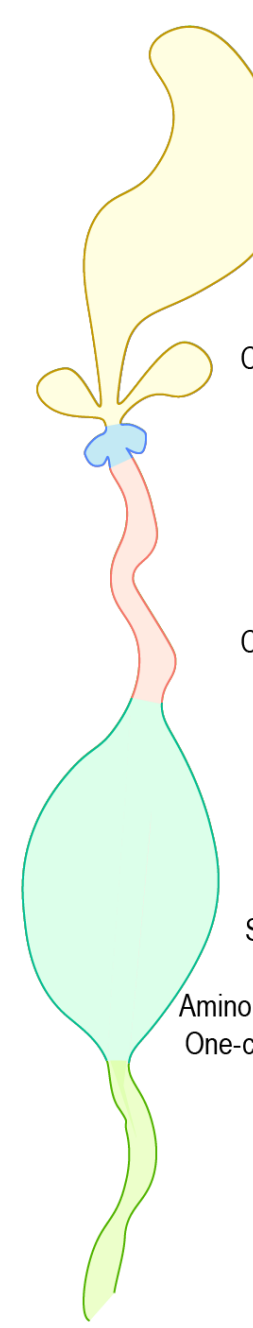

$x$ axis $=-\log 10(p)$

$\square$ Amylase/maltase/glucosidase

$\square$ Chitin-binding

$\square$ Peptidase
Crop

Peptidase activity

lon transport-

Cholinergic synapse

Scavenger receptors

Chitinase activity-

Lipid metabolism-

Proventriculus

Wnt signaling pathway

Carbohydrate metabolism

Lysozyme activity

Chitinase activity-

Peptidase activity-

Diuretic hormone-

Anterior midgut $\begin{array}{llll}\dot{0} & 3 & \dot{6} & 9\end{array}$ Heme binding

Carbohydrate metabolism -

PGN catabolism

Diuretic hormone

Bicarbonate transport.

Posterior midgut $\begin{array}{llll}0 & 3 & 6 & 9\end{array}$

Translation

Peptidase activity

SRP-dependent targeting

Amino acid metabolism

Amino acid transmemb. transp.

One-carbon metabolic process

\section{Hindgut \\ Peptidase activity \\ lon transport \\ Cholinergic synapse \\ Lipid metabolism \\ Chitinase activity -}

$$
\begin{aligned}
& \begin{array}{llll}
0 & 3 & 6 & 9
\end{array} \\
& \text { \# of genes } 25 \bullet 50 \bullet 75
\end{aligned}
$$

C
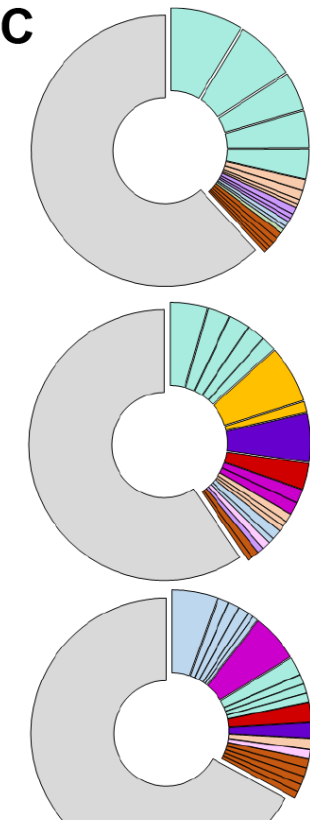

.

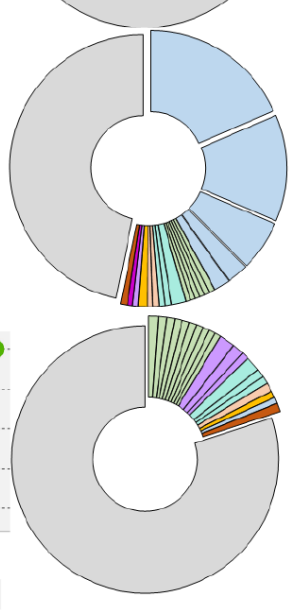

Antimicrobial peptide $\square$ Cytochrome c oxidase Fibrinogen $\square$ IncRNA

$\square \mathrm{MBF} 2$

Miscellaneous

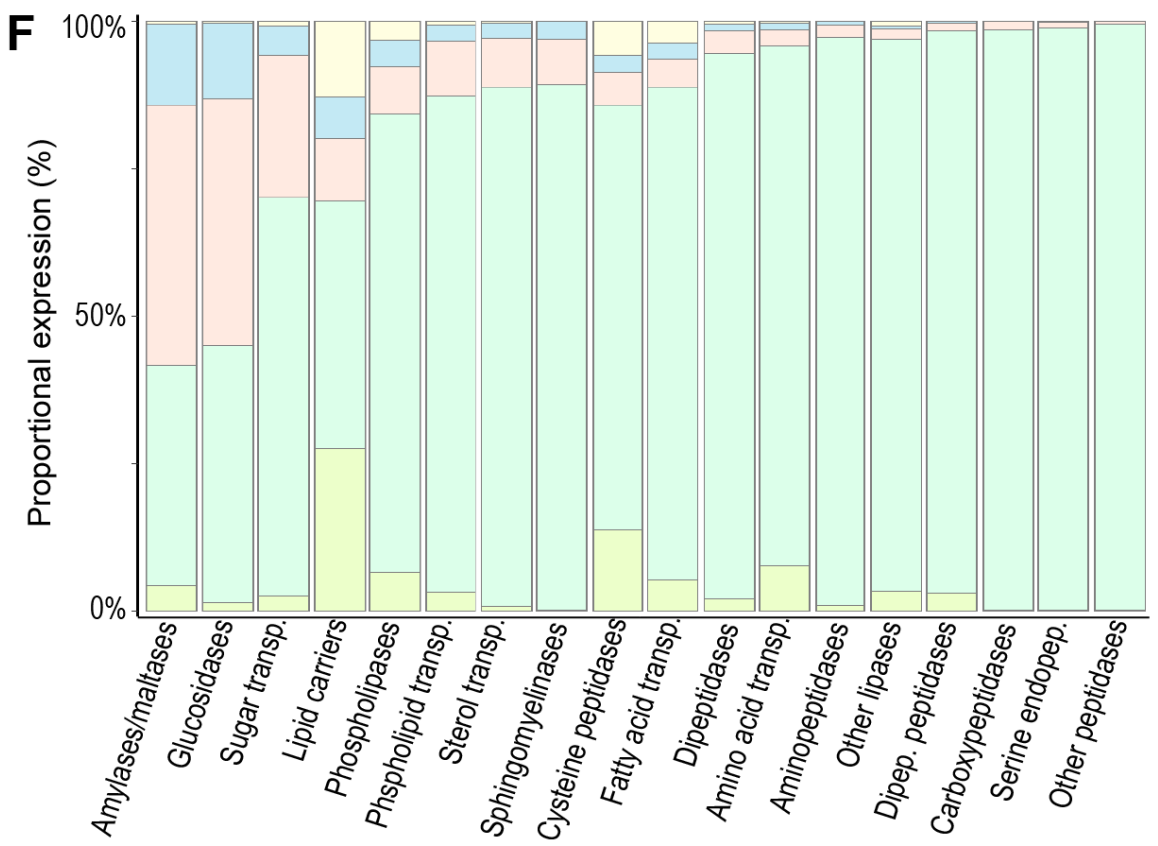


bioRxiv preprint doi: https://doi.org/10.1101/2021.12.19.473372; this version posted December 21, 2021. The copyright holder for this preprint (which was not certified by peer review) is the author/funder, who has granted bioRxiv a license to display the preprint in perpetuity. It is made available under aCC-BY 4.0 International license.

A

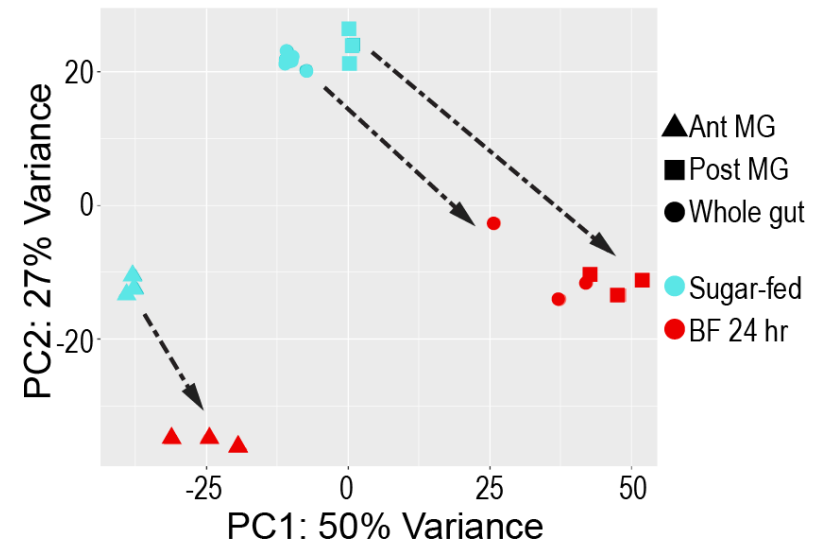

B

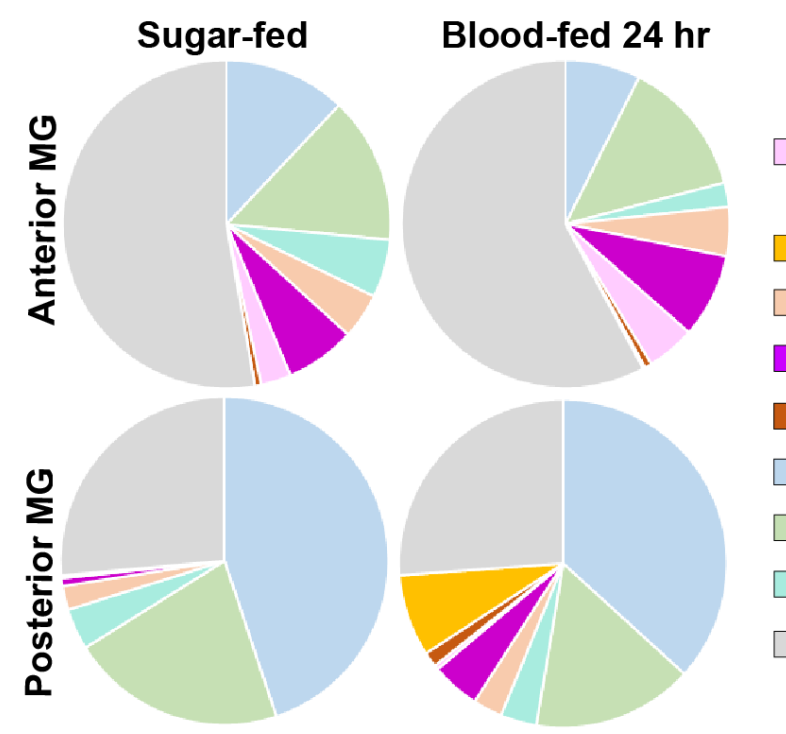

$\square$ Amylases/maltases/ glucosidases

$\square$ G12 proteins

$\square$ IncRNAs

MBF2s

Iron-binding

$\square$ Peptidases

$\square$ Ribosomal proteins

$\square$ rRNAs

$\square$ All remaining transcripts
E

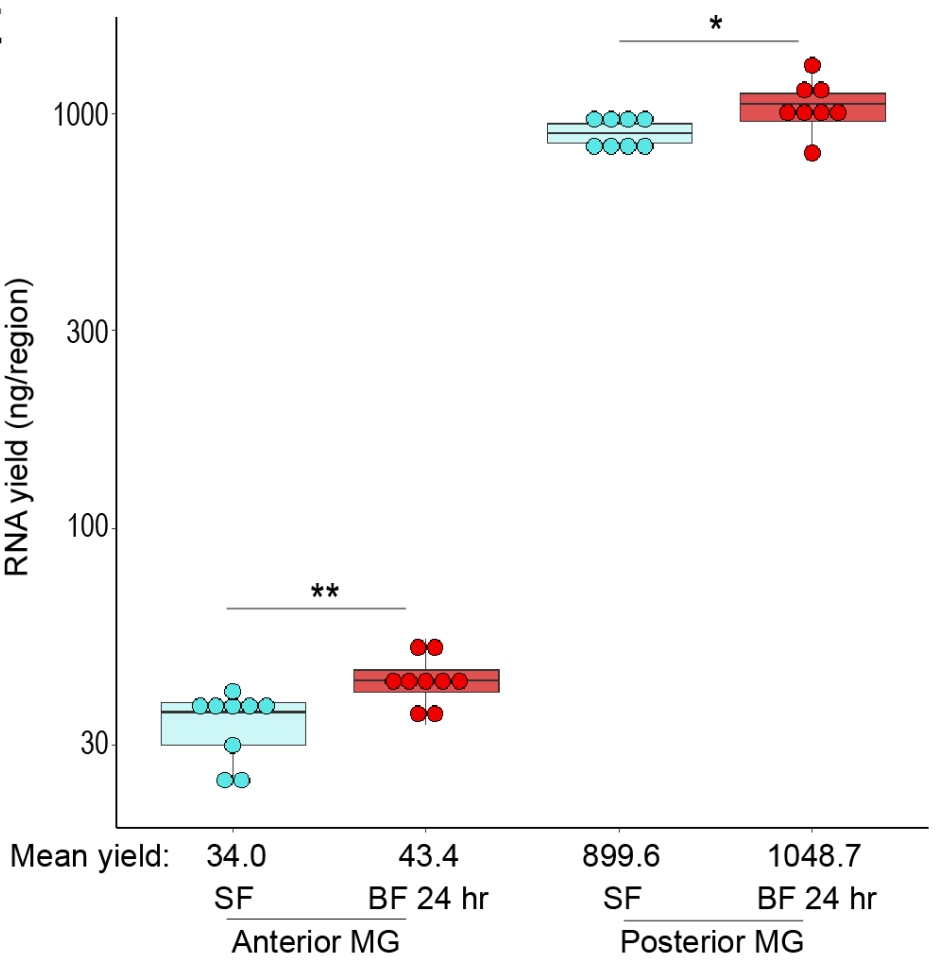

C Anterior midgut $24 \mathrm{hr}$

Defense response-

Peptidase activity-

Carbohydrate metabolism-

Lysozyme activity-

Lipid transport-

miRNA inhibition of transl. -

Steroid receptor activity-

One-carbon met. process-

Amino acid metabolism-

Bicarbonate transport-

\section{Posterior midgut $24 \mathrm{hr}$}

- Peptidase activity

Carb. metabolism

Defense response

Ferric iron-binding

Lipid metabolism

Lipid transport-

Lysozyme activity

Cholesterol transp.

Trehalase activity

$$
\mathrm{x} \text { axis }=-\log 10(\mathrm{p}) \quad \text { \# of genes } \quad 10 \bullet 20 \bullet 40 \bullet \quad \text { Up } \bigcirc \text { Down }
$$

D 
bioRxiv preprint doi: https://doi.org/10.1101/2021.12.19.473372; this version posted December 21, 2021. The copyright holder for this preprint (which was not certified by peer review) is the author/funder, who has granted bioRxiv a license to display the preprint in perpetuity. It is made available under aCC-BY 4.0 International license.

A

\begin{tabular}{|c|c|c|c|c|c|c|c|c|c|c|}
\hline \multirow{2}{*}{\multicolumn{4}{|c|}{ M }} & \multicolumn{7}{|c|}{ Expression of immune pathway-related genes } \\
\hline & & & & \multicolumn{6}{|c|}{$\%$ of $\max$ TPM } & \multirow[b]{2}{*}{ Max TPM } \\
\hline Gene ID & Family & $\begin{array}{c}\text { VB } \\
\text { symbol }\end{array}$ & $\begin{array}{c}\text { Dmel } \\
\text { ortholog }\end{array}$ & Head & Thorax & Abd & Gut & MTs & Ovaries & \\
\hline \multicolumn{11}{|c|}{ pIRNA \& siRNA pathways } \\
\hline AAEL006794 & RNAi & - & Dcr-2 & 76 & 35 & 57 & 100 & 79 & 76 & 73 \\
\hline AAEL017251 & RNAi & $\mathrm{AGO2}$ & AGO2 & 44 & 25 & 18 & 26 & 24 & 100 & 50 \\
\hline AAEL007823 & RNAi & - & AGO3 & 4 & 3 & 5 & 2 & 3 & 100 & 110 \\
\hline AAEL011753 & RNAi & - & $12 \mathrm{~d} 2$ & 44 & 20 & 30 & 23 & 22 & 100 & 31 \\
\hline AAEL008687 & RNAi & logs & logs & 32 & 19 & 36 & 10 & 10 & 100 & 86 \\
\hline AAEL013721 & RNAi & logs2 & & 0 & 0 & 0 & 0 & 0 & 100 & 44 \\
\hline AAEL000293 & RNAi & - & Tudor-SN & 21 & 18 & 53 & 39 & 17 & 100 & 167 \\
\hline AAEL010029 & RNAi & & Hen1 & 27 & 12 & 10 & 10 & 15 & 100 & 82 \\
\hline \begin{tabular}{|l|} 
AAEL 013692 \\
\end{tabular} & RNAi & PIWI3 & aub & 0 & 0 & 0 & 0 & 0 & 100 & 118 \\
\hline \begin{tabular}{|l|} 
AAEL 013227 \\
\end{tabular} & RNAi & PIWI6 & aub & 19 & 11 & 8 & 5 & 4 & 100 & 154 \\
\hline AAEL008098 & RNAi & PIWI2 & aub & 0 & 0 & 0 & 0 & 0 & 100 & 82 \\
\hline AAEL 007698 & RNAi & PIWI4 & aub & 12 & 9 & 18 & 8 & 6 & 100 & 149 \\
\hline AAEL 013233 & RNAi & PIWI5 & aub & 75 & 37 & 100 & 52 & 35 & 92 & 35 \\
\hline AAEL000289 & RNAi & - & Gasz & 24 & 11 & 11 & 9 & 21 & 100 & 41 \\
\hline AAEL019460 & RNAi & - & armi & 25 & 21 & 23 & 23 & 46 & 100 & 173 \\
\hline AAEL013072 & RNAi & - & papi & 54 & 97 & 40 & 15 & 62 & 100 & 23 \\
\hline \begin{tabular}{|l|} 
AAEL 004978 \\
\end{tabular} & RNAi & - & vas & 0 & 0 & 0 & 0 & 0 & 100 & 1769 \\
\hline AAEL027589 & RNAi & - & qin & 7 & 5 & 4 & 2 & 6 & 100 & 93 \\
\hline AAEL001939 & RNAi & - & SoYb & 5 & 3 & 4 & 2 & 3 & 100 & 192 \\
\hline AAEL023716 & RNAi & - & spn-E & 15 & 10 & 11 & 6 & 10 & 100 & 166 \\
\hline \begin{tabular}{|l|} 
AAEL 020359 \\
\end{tabular} & RNAi & & vret & 7 & 8 & 13 & 4 & 5 & 100 & 71 \\
\hline \multicolumn{11}{|c|}{ immune recognition } \\
\hline AAEL 000652 & Toll & GNBPA2 & GNBP1/3 & 7 & 100 & 42 & 0 & 0 & 17 & 3 \\
\hline AAEL007626 & Toll & GNBPA1 & GNBP1 & 56 & 77 & 100 & 2 & 2 & 16 & 23 \\
\hline AAEL 009474 & Toll & PGRPS1 & PGRP-SA & 29 & 37 & 100 & 35 & 85 & 6 & 77 \\
\hline \begin{tabular}{|l|} 
AAEL 027982 \\
\end{tabular} & IMD & PGRP-LE & PGRP-LE & 6 & 3 & 2 & 100 & 5 & 2 & 37 \\
\hline AAEL014640 & IMD & PGRPLC & PGRP-LC & 14 & 19 & 25 & 29 & 100 & 4 & 404 \\
\hline
\end{tabular}

$$
\text { Immune signaling: extracellular }
$$

\begin{tabular}{|c|c|c|c|c|c|c|c|c|c|c|}
\hline AAEL 012713 & Toll & CIPC16 & Havan/psh & 100 & 78 & 97 & 7 & 18 & 43 & 198 \\
\hline AAEL 004524 & Toll & CLIPC5B & Hayan/psh & 69 & 90 & 100 & 2 & 1 & 18 & 60 \\
\hline AAEL012711 & Toll & CLIPC12 & Hayan/psh & 33 & 45 & 100 & 1 & 11 & 41 & 12 \\
\hline AAEL019853 & Toll & - & Hayan/psh & 44 & 52 & 77 & 1 & 2 & 100 & 78 \\
\hline AAEL017003 & Toll & - & grass & 70 & 100 & 58 & 16 & 40 & 82 & 4 \\
\hline AAEL003253 & Toll & CLIPB13B & grass & 25 & 48 & 100 & 0 & 1 & 4 & 15 \\
\hline \begin{tabular}{|l|} 
AAELL25028 \\
\end{tabular} & Toll & & grass & 25 & 32 & 45 & 7 & 15 & 100 & 5 \\
\hline AAEL 003243 & Toll & CLIPB13A & grass & 22 & 53 & 46 & 1 & 1 & 100 & 181 \\
\hline AAEL 007593 & Toll & GLIPG2 & spirit/snk & 42 & 100 & 17 & 13 & 54 & 51 & 128 \\
\hline AAEL 007597 & Toll & CLIPC3 & spirit/snk & 47 & 100 & 57 & 6 & 4 & 52 & 120 \\
\hline AAEL 011991 & Toll & CLIPC1 & spirit/snk & 15 & 58 & 100 & 12 & 3 & 4 & 27 \\
\hline AAEL005064 & Toll & CLIPB 5 & SPE/ea & 55 & 63 & 38 & 8 & 3 & 100 & 220 \\
\hline AAEL 023229 & Toll & 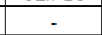 & modSP & 38 & 60 & 67 & 4 & 2 & 100 & 22 \\
\hline AAEL 013434 & Toll & - & $\mathrm{spz}$ & 81 & 100 & 39 & 12 & 3 & 20 & 27 \\
\hline AAEL013433 & Toll & SPZ1C & $\mathrm{spz}$ & 29 & 42 & 100 & 0 & 1 & 3 & 11 \\
\hline AAEL001929 & Toll & SPZ5 & spz5 & 0 & 0 & 0 & 0 & 100 & 1 & 196 \\
\hline AAEL007897 & Toll & SPZ4 & spz4 & 21 & 8 & 8 & 7 & 100 & 43 & 13 \\
\hline \begin{tabular}{|l|} 
AAEL 008596 \\
\end{tabular} & Toll & SPZ3A & spz3 & 19 & 40 & 39 & 3 & 100 & 14 & 45 \\
\hline \multicolumn{11}{|c|}{ Immune signaling: intracellular } \\
\hline AAEL000057 & Toll & TOLL5B & 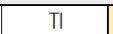 & 16 & 22 & 11 & 6 & 6 & 100 & 2 \\
\hline AAEL007619 & Toll & TOLL5A & $\mathrm{TI}$ & 81 & 64 & 100 & 8 & 53 & 29 & 11 \\
\hline AAEL026297 & Toll & - & $\mathrm{Tl}$ & 33 & 19 & 13 & 4 & 45 & 100 & 38 \\
\hline AAEL007768 & Toll & MYD & Myd88 & 78 & 28 & 51 & 52 & 43 & 100 & 9 \\
\hline AAEL 006571 & Toll & PELLE & pll & 94 & 43 & 23 & 23 & 26 & 100 & 20 \\
\hline AAEL007642 & Toll & TUBE & - & 21 & 7 & 6 & 6 & 14 & 100 & 94 \\
\hline AAEL000709 & Toll & cact & cact & 23 & 54 & 32 & 23 & 5 & 100 & 190 \\
\hline AAEL007696 & Toll & REL1A & dl & 19 & 45 & 22 & 10 & 14 & 100 & 170 \\
\hline AAEL 010083 & IMD & $\mathrm{IMD}$ & ind & 59 & 22 & 73 & 43 & 51 & 100 & 2 \\
\hline AAEL018130 & IMD & TAK1 & Tak1 & 55 & 100 & 24 & 16 & 22 & 97 & 22 \\
\hline \begin{tabular}{|l|} 
AAEL 021557 \\
\end{tabular} & IMD & pirk & pirk & 2 & 3 & 3 & 100 & 4 & 3 & 67 \\
\hline AAEL 012510 & IMD & $1 \mid K K 2$ & key & 44 & 8 & 5 & 25 & 28 & 100 & 31 \\
\hline AAEL 022729 & IMD & - & akiin & 39 & 23 & 22 & 18 & 22 & 100 & 294 \\
\hline AAEL 000590 & IMD & DNR1 & dnr1 & 38 & 25 & 20 & 13 & 16 & 100 & 145 \\
\hline AAEL027860 & IMD & casp & casp & 16 & 15 & 14 & 10 & 11 & 100 & 396 \\
\hline AAEL 026170 & IMD & tab2 & Tab2 & 8 & 22 & 12 & 7 & 9 & 100 & 56 \\
\hline AAEL001932 & IMD & FADD & Fadd & 33 & 22 & 20 & 13 & 8 & 100 & 17 \\
\hline AAEL 003245 & IMD & IKK1 & IKKbeta & 13 & 0 & 2 & 6 & 0 & 100 & 27 \\
\hline AAEL011873 & IMD & Uev1A & Uev1A & 71 & 21 & 26 & 18 & 29 & 100 & 237 \\
\hline AAEL014642 & IMD & ben & ben & 51 & 19 & 24 & 15 & 16 & 100 & 236 \\
\hline AAEL003103 & IMD & eff & eff & 40 & 33 & 29 & 16 & 15 & 100 & 492 \\
\hline AAEL007624 & IMD & REL2 & Rel & 30 & 44 & 88 & 45 & 100 & 19 & 22 \\
\hline AAEL012471 & JAK-STAT & DOME & dome & 32 & 12 & 6 & 8 & 35 & 100 & 88 \\
\hline \begin{tabular}{|l|} 
AAEL 019728 \\
\end{tabular} & $\begin{array}{l}\text { JAK-STAT } \\
\end{array}$ & SOCS & Socs $36 \mathrm{E}$ & 47 & 41 & 16 & 15 & 86 & 100 & 157 \\
\hline AAEL026694 & JAK-STAT & PIAS2 & Su(var)2-10 & 15 & 6 & 10 & 5 & 7 & 100 & 168 \\
\hline AAEL000255 & JAK-STAT & & Socs44A & 8 & 3 & 2 & 3 & 5 & 100 & 12 \\
\hline AAEL015099 & JAKSTAT & PIAS1 & Su(var)2-10 & 6 & 9 & 10 & 8 & 0 & 100 & 9 \\
\hline AAEL012553 & JAK-STAT & HOP & hop & 18 & 8 & 12 & 7 & 77 & 100 & 49 \\
\hline AAEL020559 & JAK-STAT & STAT & Stat92E & 56 & 40 & 32 & 23 & 40 & 100 & 329 \\
\hline
\end{tabular}

B

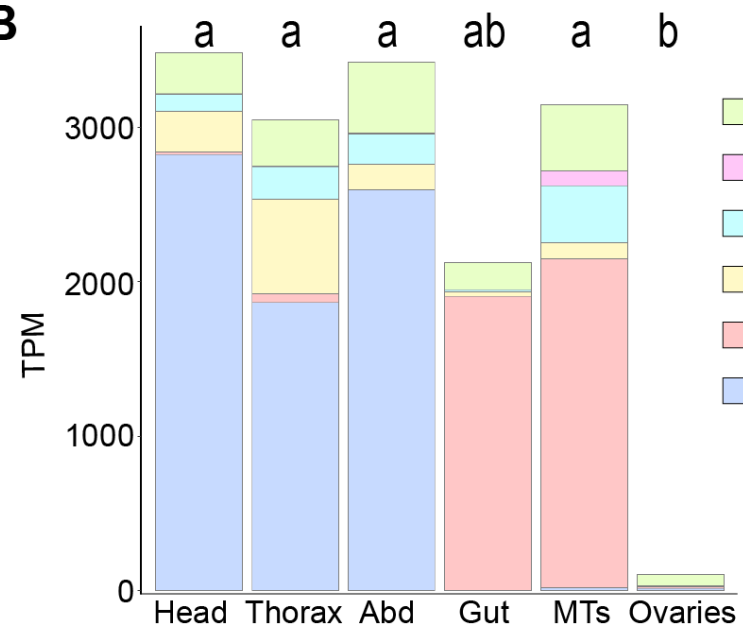

C

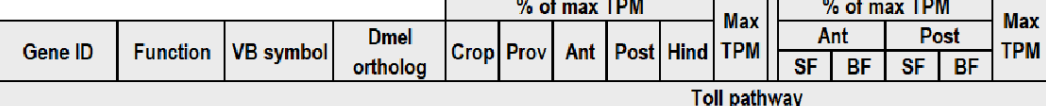

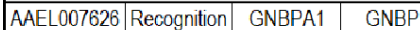

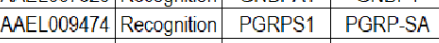

\begin{tabular}{|l|c|c|c|}
\hline AAEL 007696 & TF & REL1A & dorsal \\
\hline
\end{tabular}

\begin{tabular}{|l|l|l|l}
\hline AAEL000709 & Modulation & CACT & cact \\
\hline
\end{tabular}

\begin{tabular}{|l|c|c|c|c|c|c|c|c|c||c|}
\hline AAEL007624 & TF & REL2 & Relish & 51 & 100 & 47 & 36 & 55 & 24 & 41 \\
\hline
\end{tabular}

\begin{tabular}{|l|l|l|l|l|c|c|c|c|}
\hline AAELL014640 Recognition & PGRPLC & PGRP-LC & 46 & 64 & 100 & 57 & 52 & 225 \\
\hline AEL02082 & RGe & \\
\hline
\end{tabular}

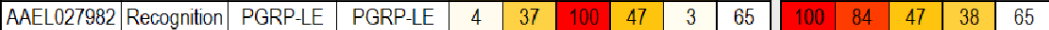

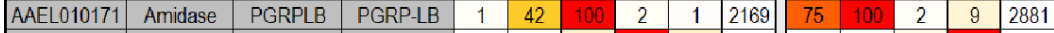

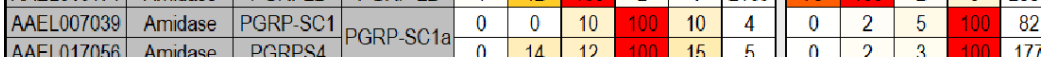

\begin{tabular}{l|l|l|l|l|l|}
\hline AAEL017056 & Amidase & PGRPS4 & 0 & 14 & 12 \\
\hline AAE & & & 0
\end{tabular}

\begin{tabular}{|l|c|c|c|}
\hline AAEL014557 & TF & cad \\
\hline
\end{tabular}

D

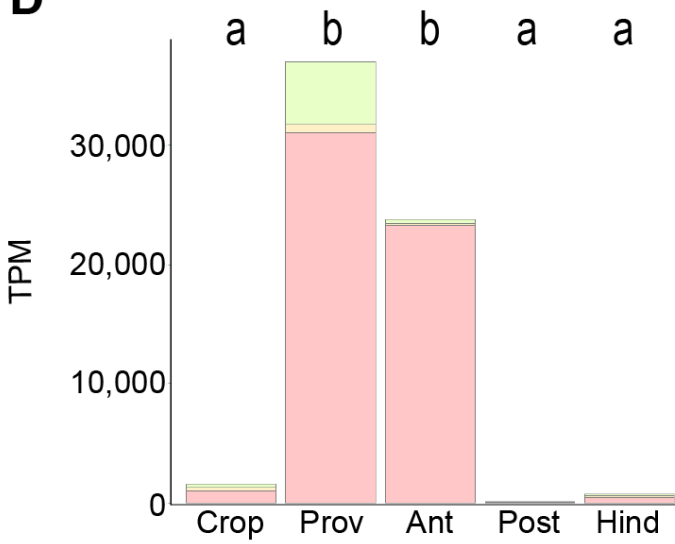

$\square$ Lysozymes

$\square$ All other AMPs

$\square$ Gambicin

E

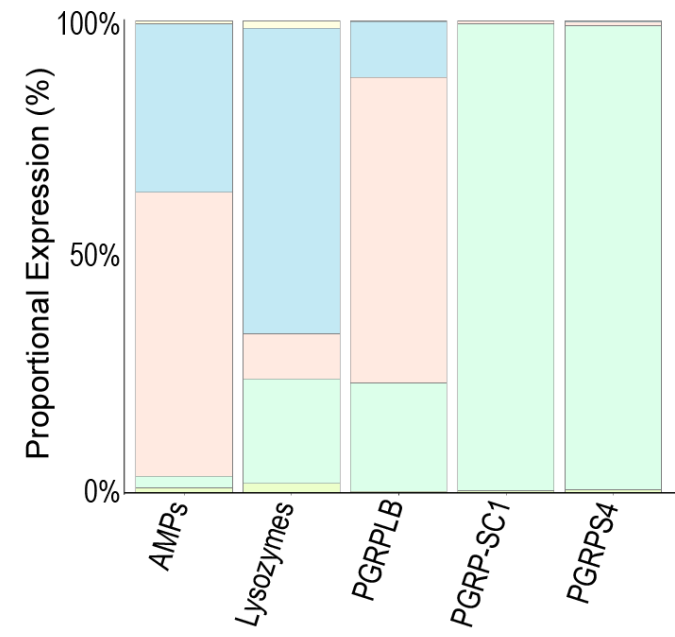

Crop

Prov

Ant MG

Post MG

Hindgut 
bioRxiv preprint doi: https://doi.org/10.1101/2021.12.19.473372; this version posted December 21, 2021. The copyright holder for this preprint (which was not certified by peer review) is the author/funder, who has granted bioRxiv a license to display the preprint in perpetuity. It is made available under aCC-BY 4.0 International license.

A

Aedes aegypti

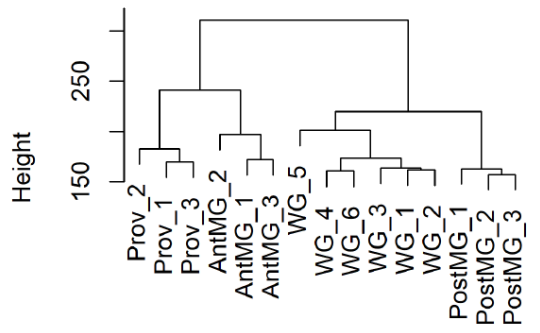

Anopheles gambiae

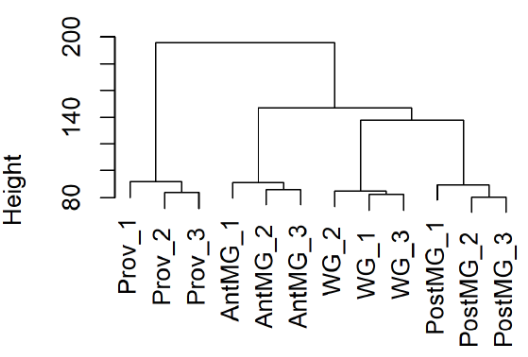

C

\begin{tabular}{|c|c|c|c|c|c|c|c|c|c|c|}
\hline & \multicolumn{8}{|c|}{ modulators, and effectors } \\
\hline & & & \multicolumn{4}{|c|}{ Aedes aegypti } & \multicolumn{4}{|c|}{ Anopheles gambiae } \\
\hline & & & \multicolumn{3}{|c|}{$\%$ of $\max$ TPM } & \multirow{2}{*}{$\begin{array}{l}\text { Max } \\
\text { TPM }\end{array}$} & \multicolumn{3}{|c|}{$\%$ of $\max$ TPM } & \multirow{2}{*}{$\begin{array}{ll}\text { Max } \\
\text { TPM }\end{array}$} \\
\hline Gene ID & Function & VB symbol & Prov & Ant & Post & & Prov & Ant & Post & \\
\hline & & & \multicolumn{8}{|c|}{ IMD pathway } \\
\hline AAEL007624/AGAP006747 & $\mathrm{TF}$ & REL2 & 100 & 47 & 36 & 24 & 97 & 100 & 83 & 26 \\
\hline AAEL014640/AGAP005203 & Recognition & PGRPLC & 64 & 100 & 57 & 225 & 45 & 100 & 73 & 98 \\
\hline AAEL027982/NA & Recognition & PGRP-LE/NA & 37 & 100 & 47 & 65 & & & & \\
\hline AAEL010171/AGAP001212 & Amidase & PGRPLB & 42 & 100 & 2 & 2169 & 65 & 100 & 30 & 1193 \\
\hline AAEL007039/AGAP006342 & Amidase & PGRP-SC1/PGRPS3 & 0 & 10 & 100 & 4 & & 22 & 17 & 0 \\
\hline AAEL017056/AGAP006342 & Amidase & PGRPS4/PGRPS3 & 14 & 12 & 100 & 5 & & 22 & 13 & 3,52 \\
\hline AAEL 014557/AGAP009646 & TF & $\mathrm{cad} / \mathrm{Cad}$ & 3 & 6 & 100 & 16 & 2 & 1 & 100 & 27 \\
\hline \multicolumn{11}{|c|}{ Immune effectors } \\
\hline AAEL015404/AGAP007386 & Lysozyme & LYSC7B/LYSC7 & & 4 & 1 & 5040 & 100 & 70 & 3 & 4824 \\
\hline AAEL004522/AGAP008645 & AMP & GAM1 & 100 & 75 & 0 & 31062 & 100 & 98 & 20 & 26120 \\
\hline
\end{tabular}

of orthologous immune activators, modulators, and effectors
B

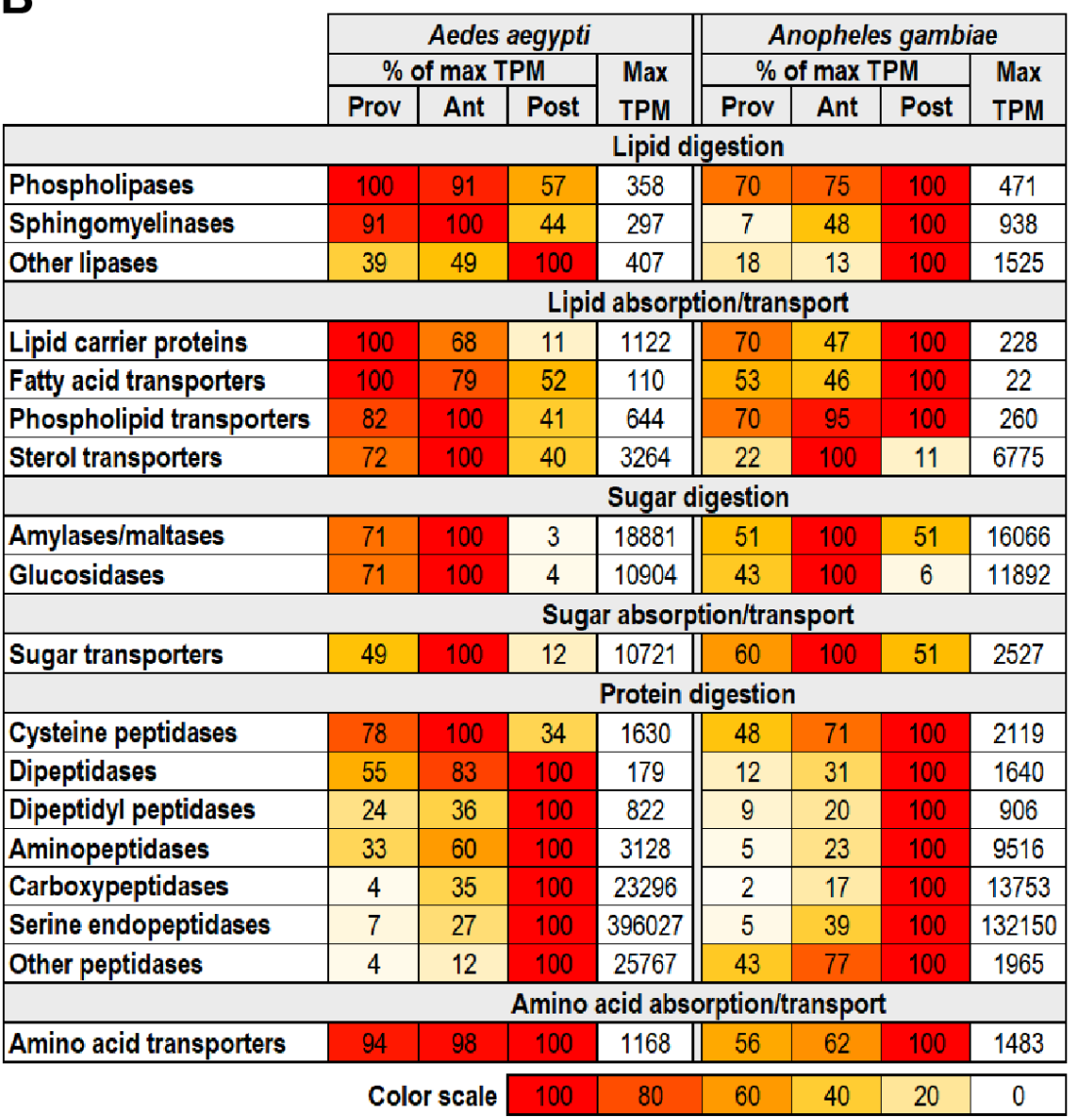

D

\section{Shared gene families \& functions:}

Proventriculus

Wnt signaling

Lysozymes

Antimicrobial peptides

Carbohydrate metabolism

Chitinases

Diuretic hormone

MBF2s

Anterior midgut

Carbohydrate metabolism

Sugar transporters

Heme binding (cytochrome p450s)

Antimicrobial peptides

Bicarbonate transport

Diuretic hormone

MBF2s

Posterior midgut

Peptidases

Translation

Amino acid transporters 
bioRxiv preprint doi: https://doi.org/10.1101/2021.12.19.473372; this version posted December 21, 2021. The copyright holder for this preprint (which was not certified by peer review) is the author/funder, who has granted bioRxiv a license to display the preprint in perpetuity. It is made available under aCC-BY 4.0 International license.

\section{A Major tissues/structures included in dissected body parts:}

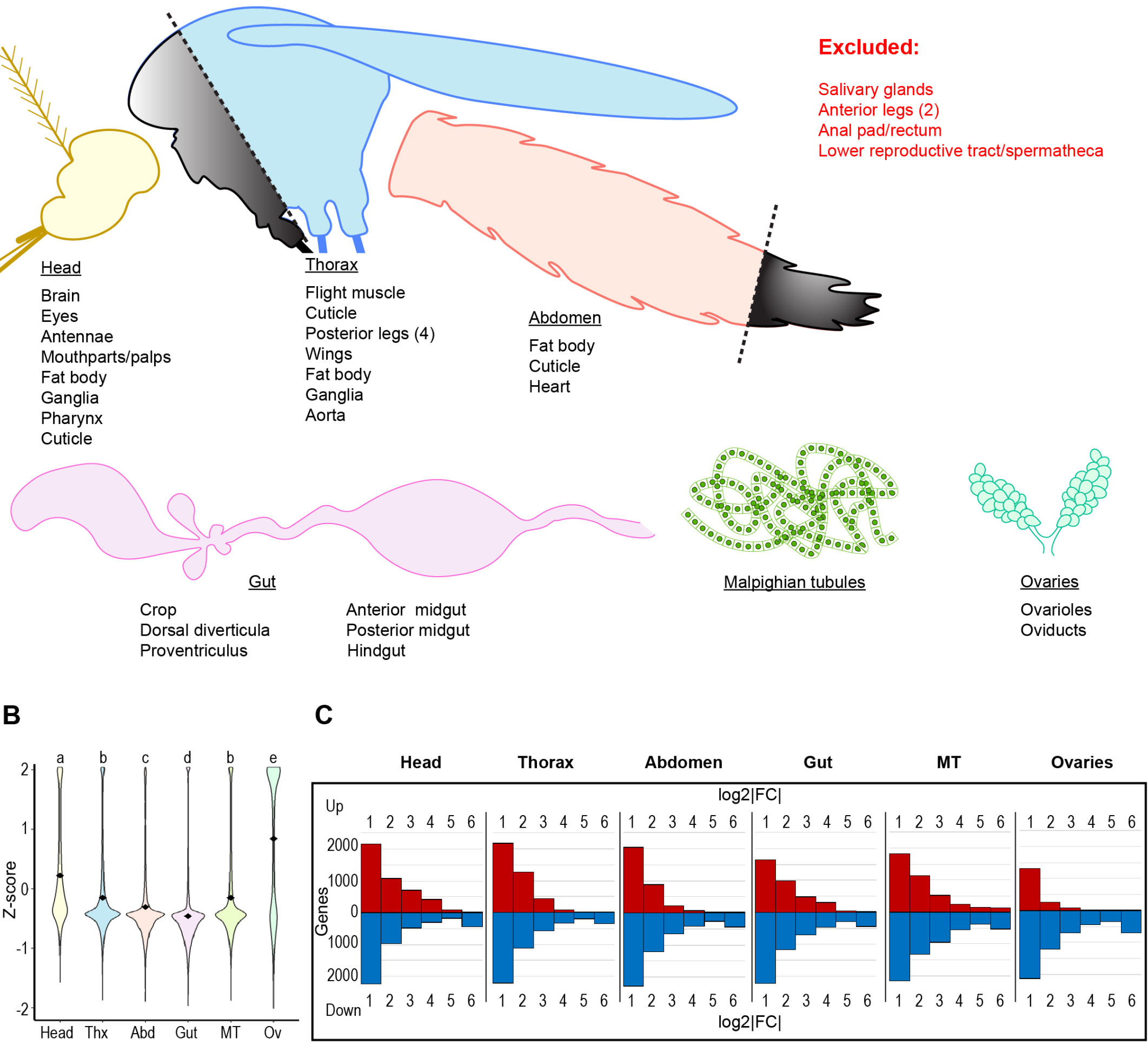


bioRxiv preprint doi: https://doi.org/10.1101/2021.12.19.473372; this version posted December 21, 2021. The copyright holder for this preprint (which was not certified by peer review) is the author/funder, who has granted bioRxiv a license to display the preprint in perpetuity. It is made available under aCC-BY 4.0 International license.

A

\begin{tabular}{|c|c|c|c|c|c|c|c|c|c|c|}
\hline & & & \multicolumn{6}{|c|}{$\%$ of $\max$ TPM } & \multirow[b]{2}{*}{$\begin{array}{l}\text { Max } \\
\text { TPM }\end{array}$} & \multirow[b]{2}{*}{$\begin{array}{c}\text { Max } \\
\text { FC }\end{array}$} \\
\hline Gene ID & VB symbol & $\begin{array}{c}\text { Dmel } \\
\text { ortholog }\end{array}$ & Head & Thro & Abd & Gut & MTs & Ov & & \\
\hline AAEL010977 & - & CG9281 & 60 & 100 & 96 & 50 & 84 & 56 & 1476 & 2.0 \\
\hline AAEL 013144 & - & elF3i & 66 & 62 & 94 & 89 & 100 & 47 & 528 & 2.1 \\
\hline AAEL004175 & RpS17 & RpS17 & 44 & 55 & 100 & 43 & 73 & 42 & 6550 & 2.4 \\
\hline AAEL003396 & rp49 & RpL32 & 37 & 46 & 100 & 45 & 72 & 48 & 6239 & 27 \\
\hline AAEL009496 & - & RpS7 & 34 & 45 & 100 & 45 & 68 & 48 & 6275 & 2.9 \\
\hline AAEL000987 & RpL8 & RpL8 & 32 & 46 & 100 & 41 & 71 & 42 & 11965 & 3.1 \\
\hline AAEL011197 & - & Act5C & 54 & 16 & 21 & 100 & 84 & 63 & 2037 & 6.2 \\
\hline AAEL013229 & PIWI5 & alphaTub84B & 100 & 44 & 7 & 38 & 10 & 20 & 334 & 14.3 \\
\hline AAEL016984 & - & Gapdh1 & 25 & 100 & 4 & 10 & 10 & 7 & 5299 & 26.2 \\
\hline AAEL017301 & GPROR81 & eEF1alpha2 & 87 & 100 & 2 & 2 & 1 & 2 & 1062 & 143.7 \\
\hline & & & & & 100 & 80 & 60 & 40 & 20 & 0 \\
\hline
\end{tabular}
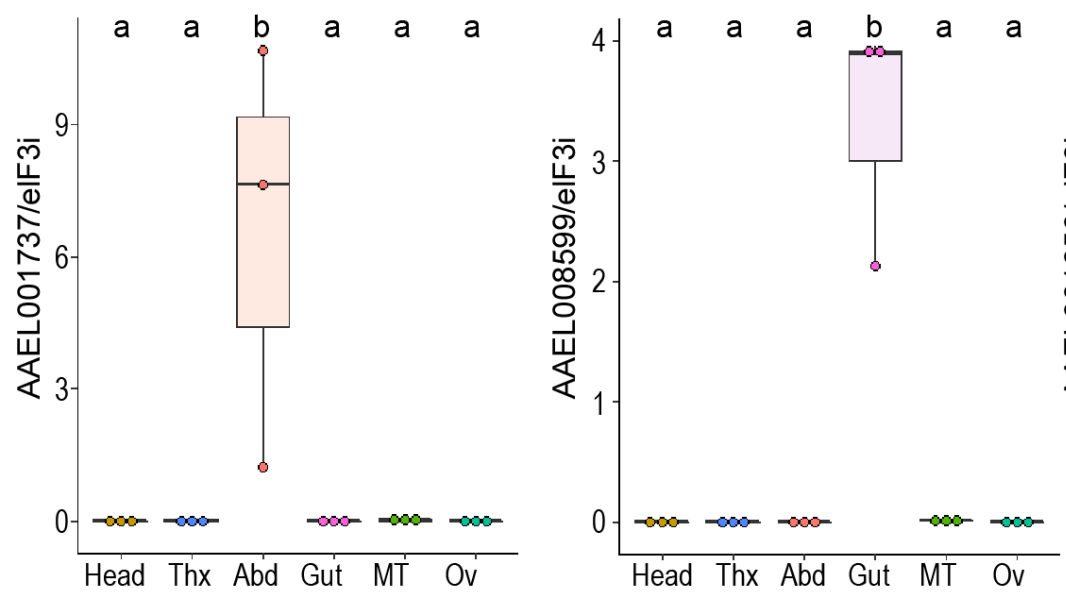
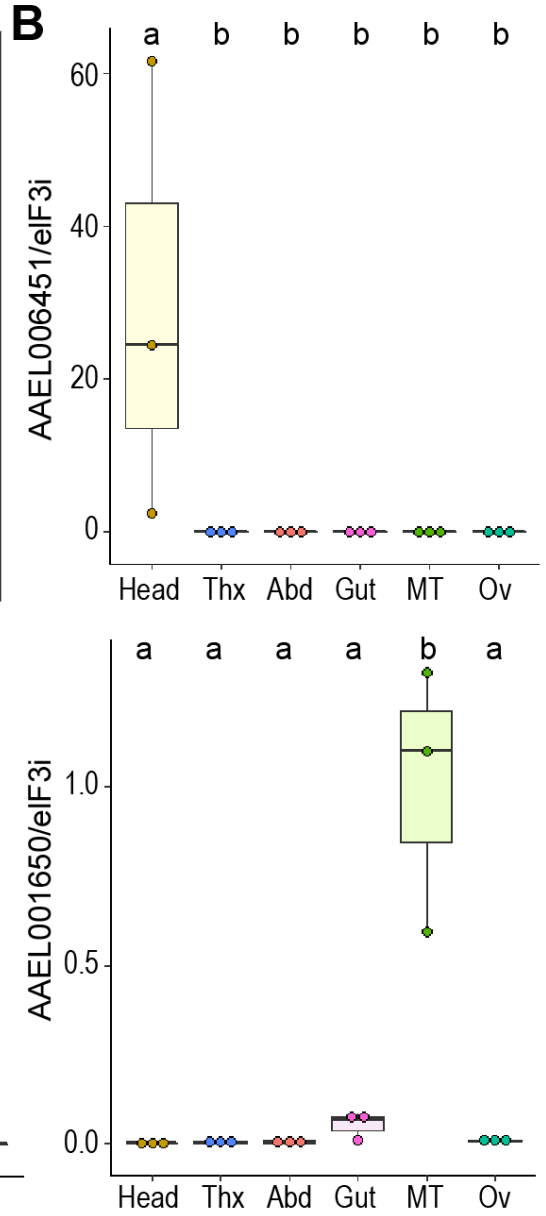
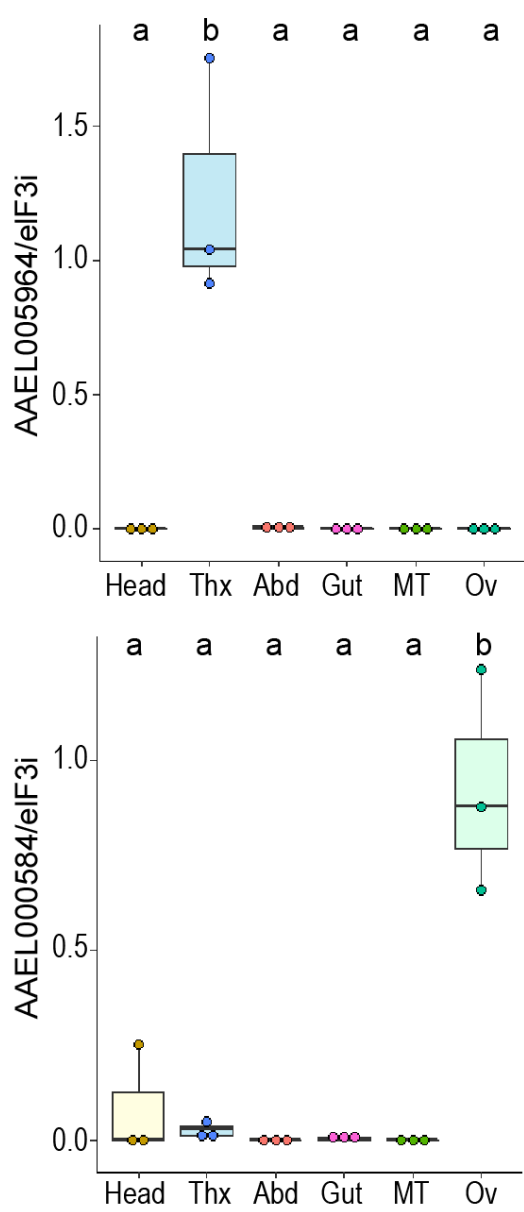
bioRxiv preprint doi: https://doi.org/10.1101/2021.12.19.473372; this version posted December 21, 2021. The copyright holder for this preprint (which was not certified by peer review) is the author/funder, who has granted bioRxiv a license to display the preprint in perpetuity. It is made available under aCC-BY 4.0 International license.

A
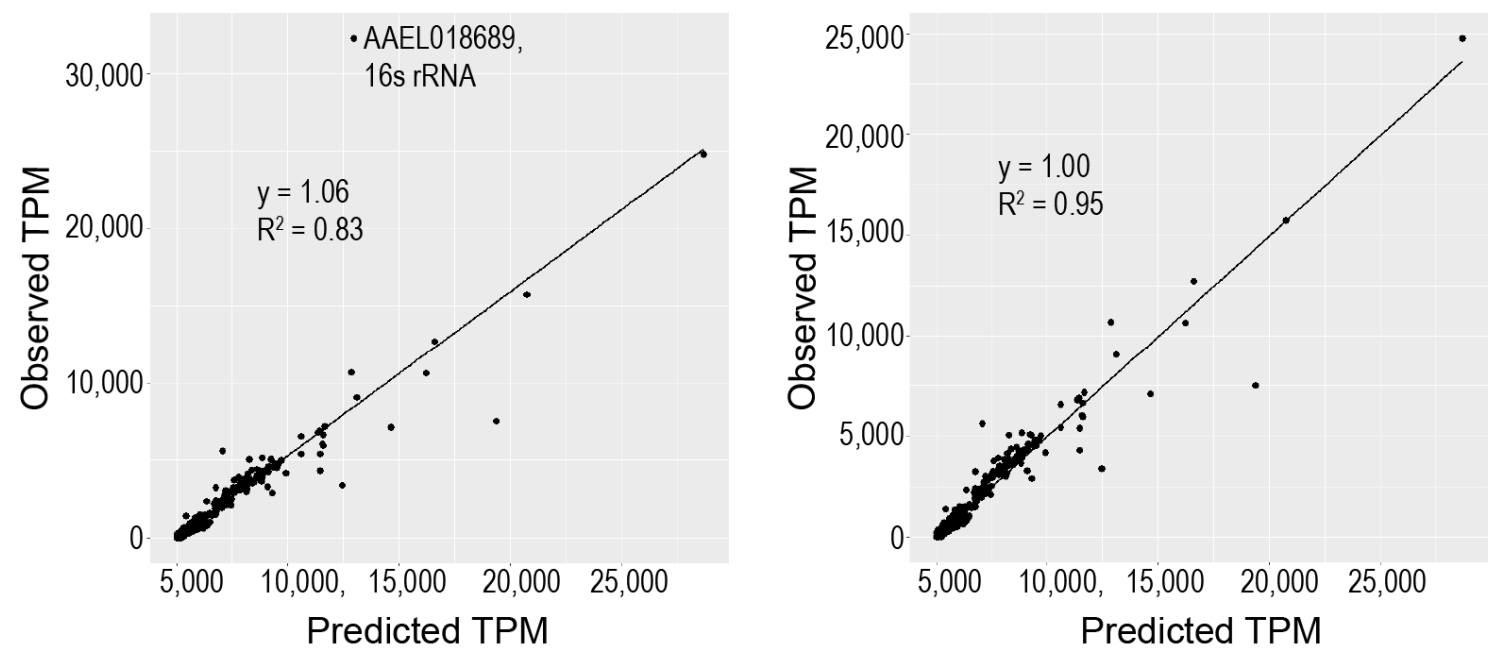
bioRxiv preprint doi: https://doi.org/10.1101/2021.12.19.473372; this version posted December 21, 2021. The copyright holder for this preprint (which was not certified by peer review) is the author/funder, who has granted bioRxiv a license to display the preprint in perpetuity. It is made available under aCC-BY 4.0 International license.

A

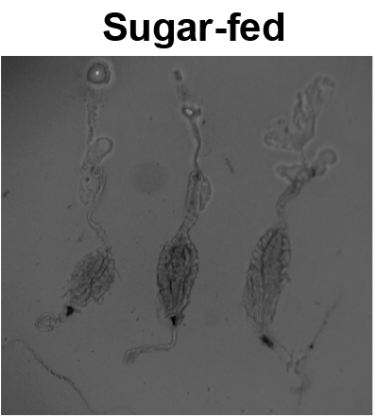

B
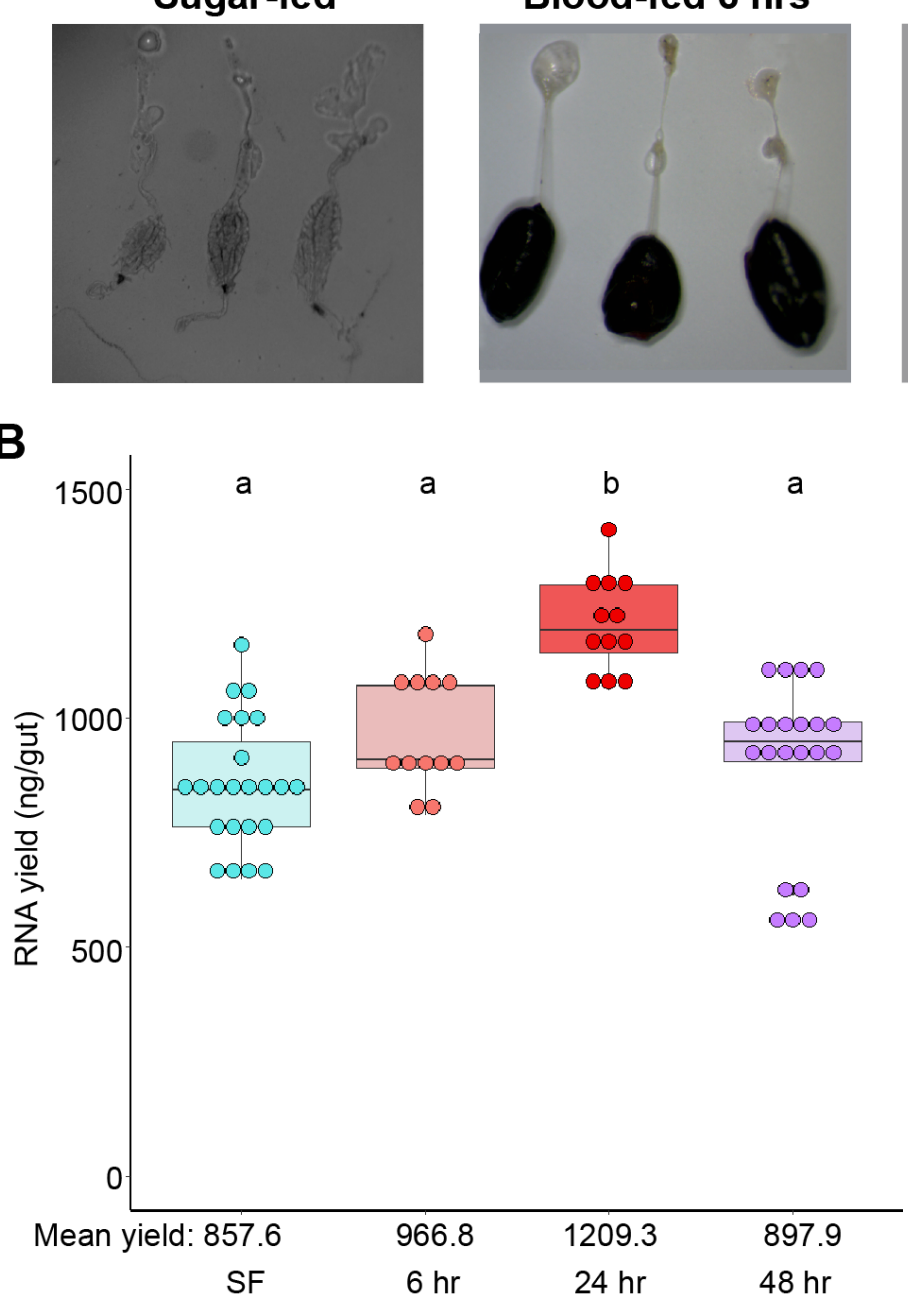

Blood-fed 24 hrs

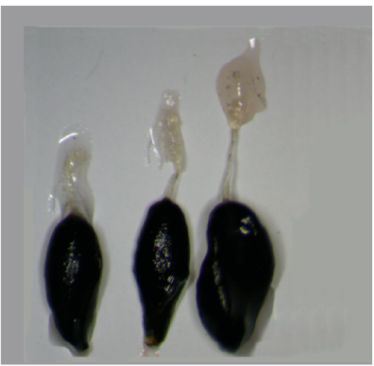

C

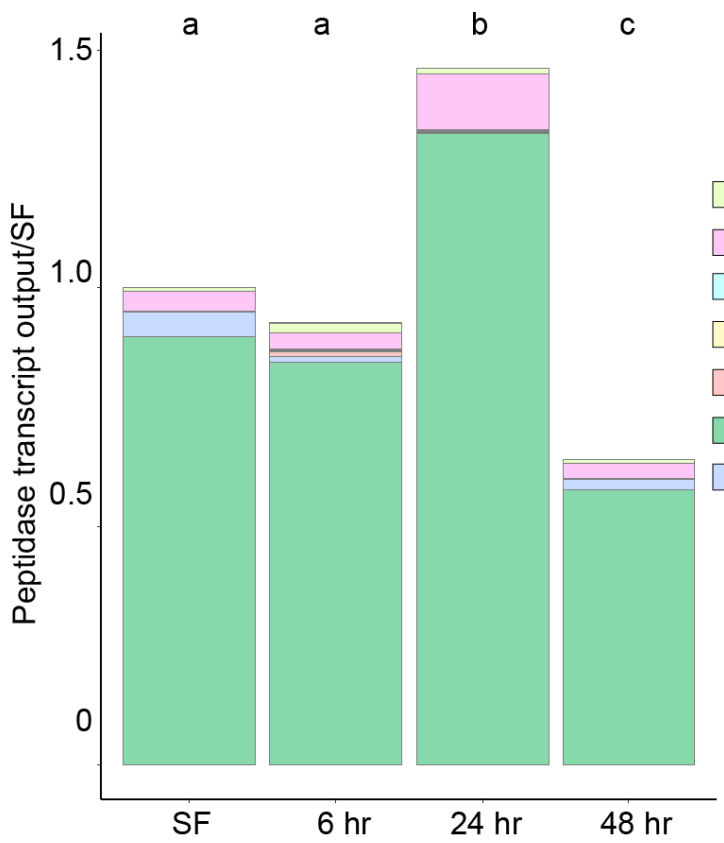

Blood-fed 48 hrs

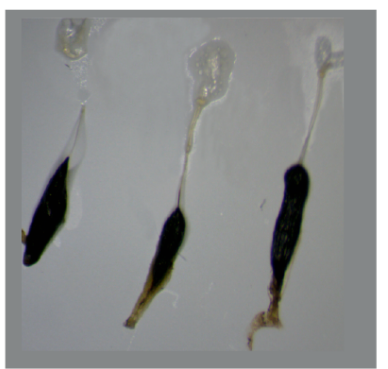

Aminopeptidases

$\square$ Carboxypeptidases

$\square$ Cysteine peptidases

$\square$ Dipeptidases

$\square$ Dipeptidyl peptidases

$\square$ Serine endopeptidases

$\square$ Other peptidases 
bioRxiv preprint doi: https://doi.org/10.1101/2021.12.19.473372; this version posted December 21,2021 . The copyright holder for this preprint (which was not certified by peer review) is the author/funder, who has granted bioRxiv a license to display the preprint in perpetuity. It is made available under aCC-BY 4.0 International license.

A

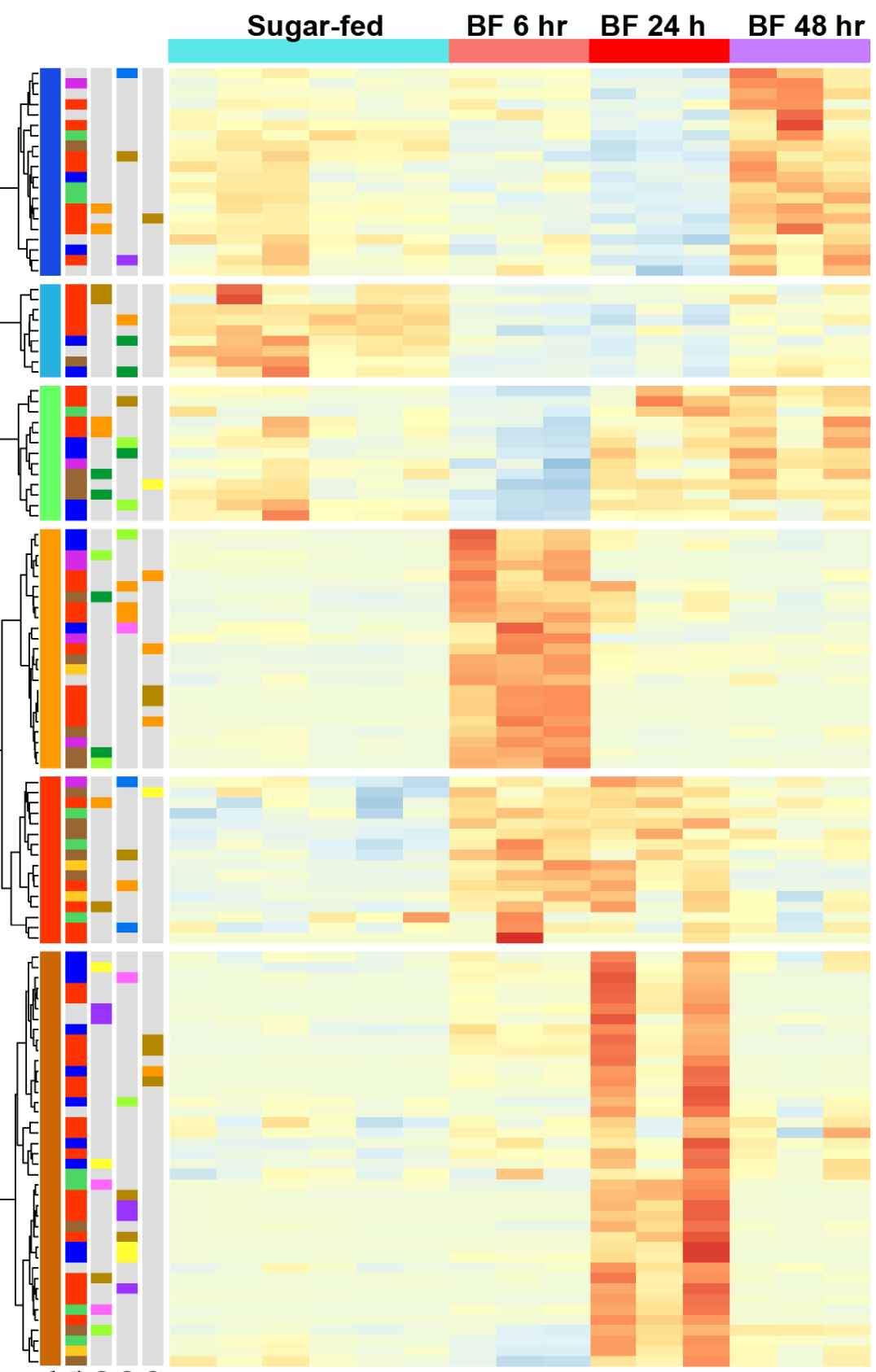

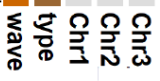

B

\begin{tabular}{|c|c|c|c|c|c|c|c|c|}
\hline \multirow[b]{2}{*}{ Gene ID } & \multirow[b]{2}{*}{\begin{tabular}{|c|} 
VB \\
symbol
\end{tabular}} & \multirow[b]{2}{*}{$\begin{array}{c}\text { Dmel } \\
\text { ortholog }\end{array}$} & \multicolumn{4}{|c|}{$\%$ of $\max$ TPM } & \multirow[b]{2}{*}{$\begin{array}{l}\text { Max } \\
\text { TPM }\end{array}$} & \multirow[b]{2}{*}{$\begin{array}{c}\text { Max } \\
\text { FC } \\
\end{array}$} \\
\hline & & & SF & $6 \mathrm{hr}$ & $24 \mathrm{hr}$ & $48 \mathrm{hr}$ & & \\
\hline AAEL010819 & - & VhaM9.7-a & 89 & 100 & 78 & 98 & 363 & 1.3 \\
\hline AAEL 009653 & RpS30 & RpS30 & 81 & 100 & 58 & 95 & 5832 & 1.7 \\
\hline AAEL004175 & RpS17 & RpS17 & 81 & 78 & 51 & 100 & 3367 & 1.9 \\
\hline AAEL003396 & $\mathrm{rp} 49$ & RpL32 & 91 & 100 & 58 & 100 & 3259 & 1.7 \\
\hline AAEL009496 & RpS7 & Rps7 & 95 & 100 & 45 & 97 & 3177 & 2.2 \\
\hline AAEL000987 & RpL8 & RpL8 & 100 & 90 & 46 & 100 & 4981 & 2.2 \\
\hline AAEL011197 & - & Act5C & 41 & 44 & 13 & 100 & 3092 & 7.5 \\
\hline AAEL013229 & - & alphaTub84B & 30 & 100 & 14 & 53 & 225 & 7.1 \\
\hline AAEL016984 & - & Gapdh1 & 39 & 50 & 21 & 100 & 945 & 4.7 \\
\hline AAEL017301 & - & eEF1alpha2 & 96 & 81 & 73 & 100 & 23 & 1.4 \\
\hline & & Color scale & 100 & 80 & 60 & 40 & 20 & 0 \\
\hline
\end{tabular}

C
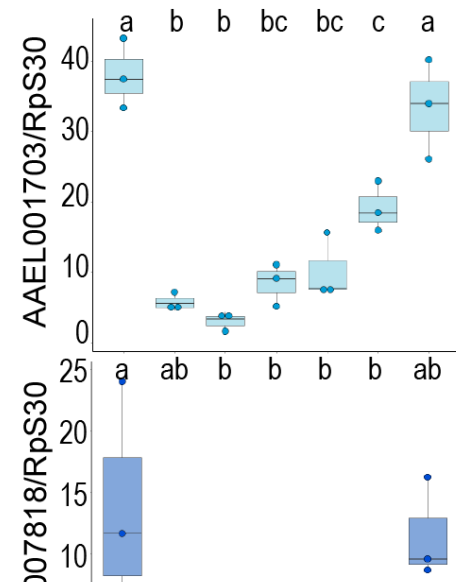

Cys_P

Di_P

Dip_tidyl_P

N_P

Ser_eP

Other

Chr1_cluster

Chr1_cl1

Chr1_cl2

Chr1_Cl3

Chr1_cl4

Chr1_cl5

Chr1_cl6

Chr1_cl7

no

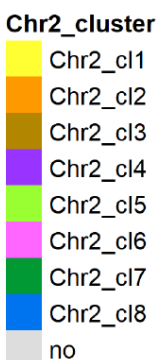

Chr3_cluster

Chr3_cl1

Chr3_cl2

Chr3_cl3

no

岸
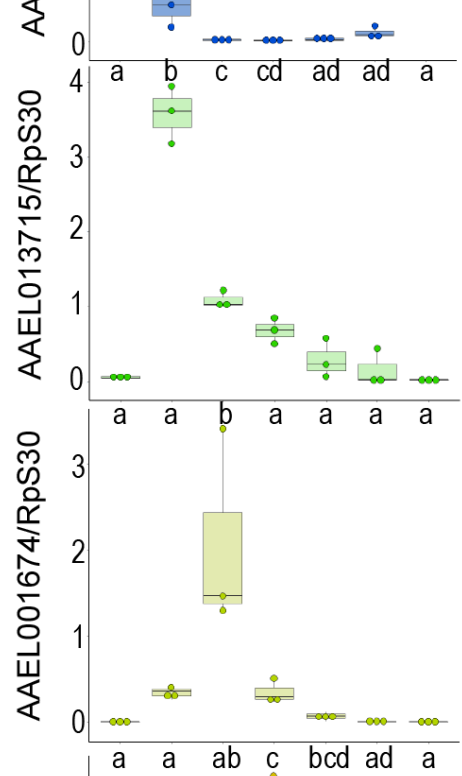

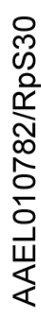

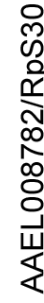

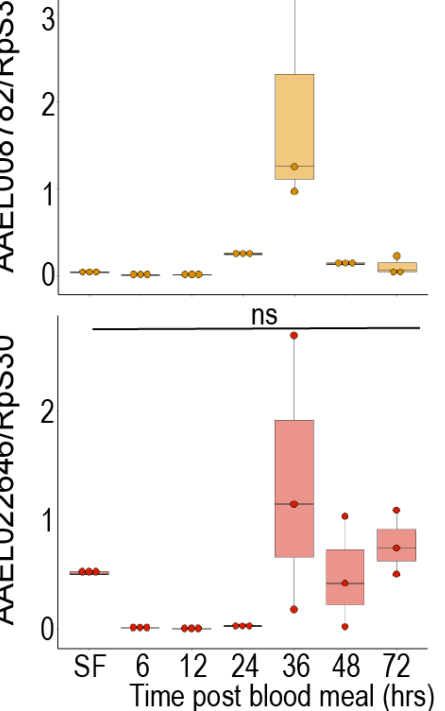


bioRxiv preprint doi: https://doi.org/10.1101/2021.12.19.473372; this version posted December 21, 2021. The copyright holder for this preprint (which was not certified by peer review) is the author/funder, who has granted bioRxiv a license to display the preprint in perpetuity. It is made available under aCC-BY 4.0 International license.

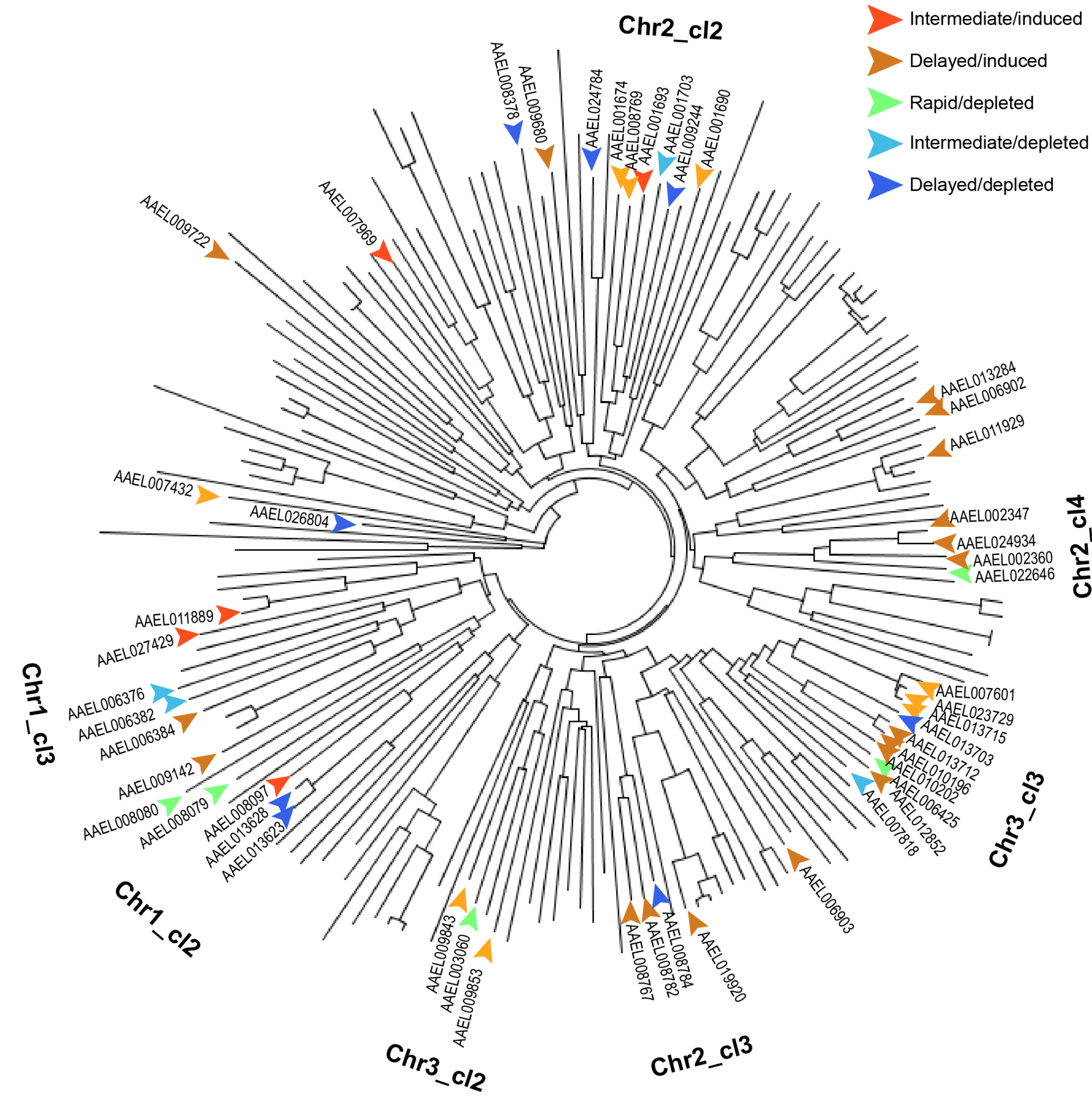


bioRxiv preprint doi: https://doi.org/10.1101/2021.12.19.473372; this version posted December 21, 2021. The copyright holder for this preprint (which was not certified by peer review) is the author/funder, who has granted bioRxiv a license to display the preprint in perpetuity. It is made available under aCC-BY 4.0 International license.

A

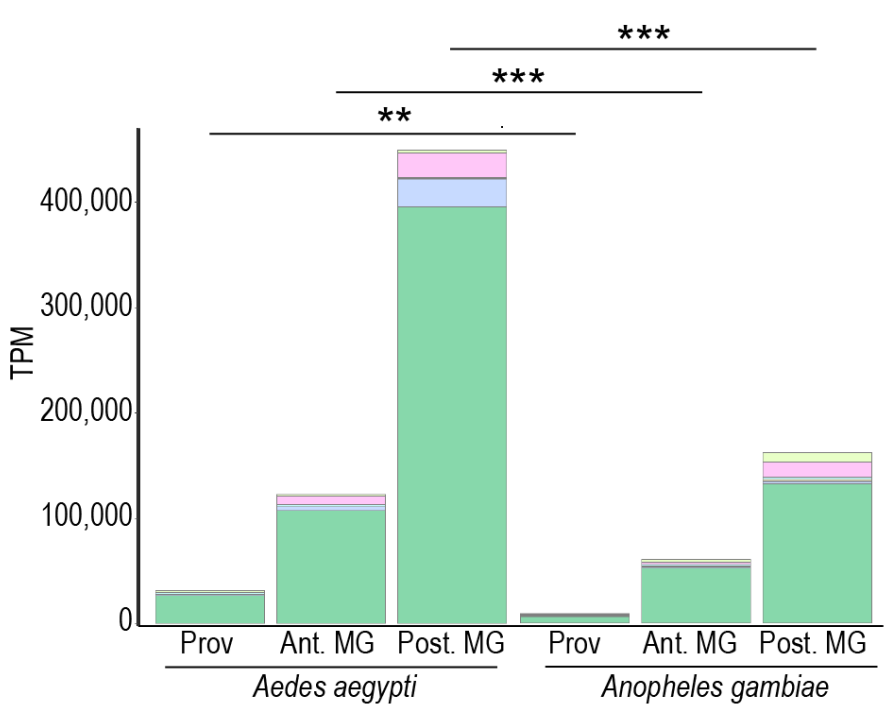

B

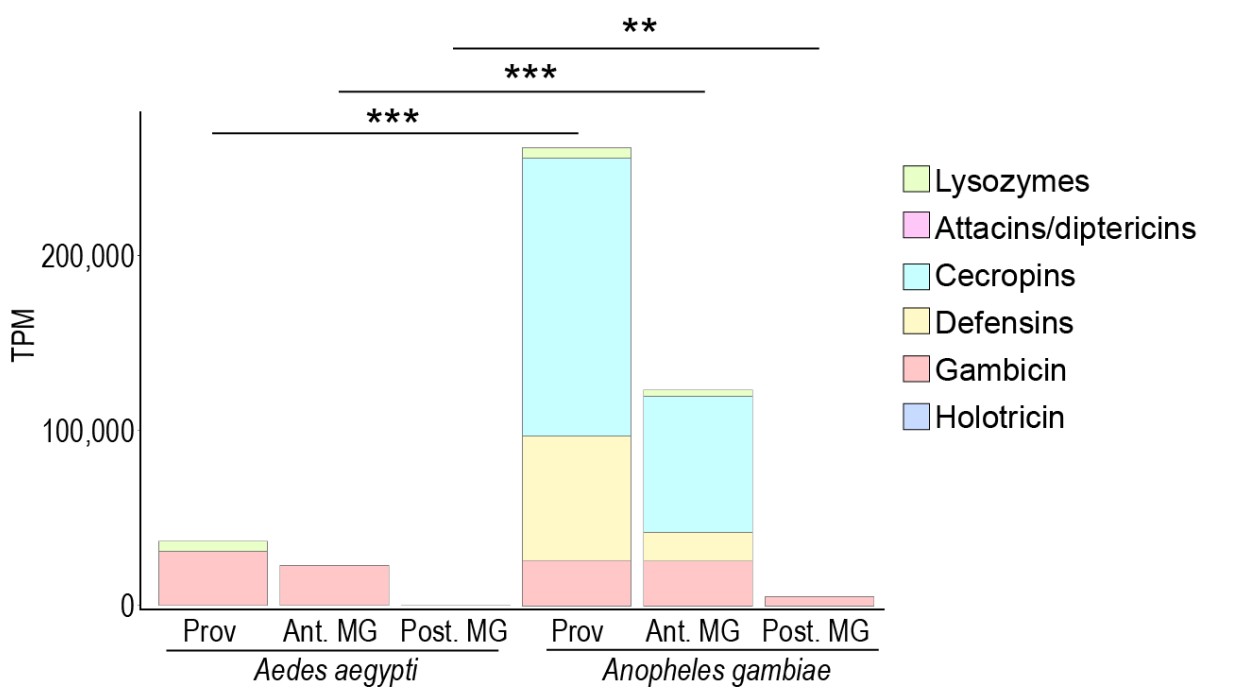

$\square$ Aminopeptidases

$\square$ Carboxypeptidases

$\square$ Cysteine peptidases

Dipeptidases

$\square$ Dipeptidyl peptidases

$\square$ Serine endopeptidases

$\square$ Other peptidases

ysozymes

(a)

Cecropins

Defensins

Anterior midgut

Heme binding

Organic anion transport

Diuretic hormone

Bicarbonate transport -

Lysosomal transport .

Phospholipase A2 activity

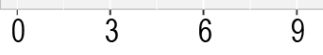

Posterior midgut

Translation

Active $\mathrm{H}+$ transport

Cellular respiration Ion transport

Peptidase activity+

Regulation of $\mathrm{pH}$

Cholesterol transp.

$\begin{array}{lllll}0 & 3 & 6 & 9 & 30\end{array}$

$x$ axis $=-\log 10(p) \quad$ \# of genes

$25 \bullet 50 \bullet 75$ 
bioRxiv preprint doi: https://doi.org/10.1101/2021.12.19.473372; this version posted December 21, 2021. The copyright holder for this preprint (which was not certified by peer review) is the author/funder, who has granted bioRxiv a license to display the preprint in perpetuity. It is made available under aCC-BY 4.0 International license.

A

250,000

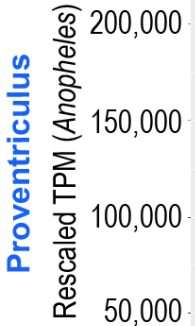

0

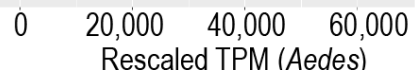

Rescaled TPM (Aedes)
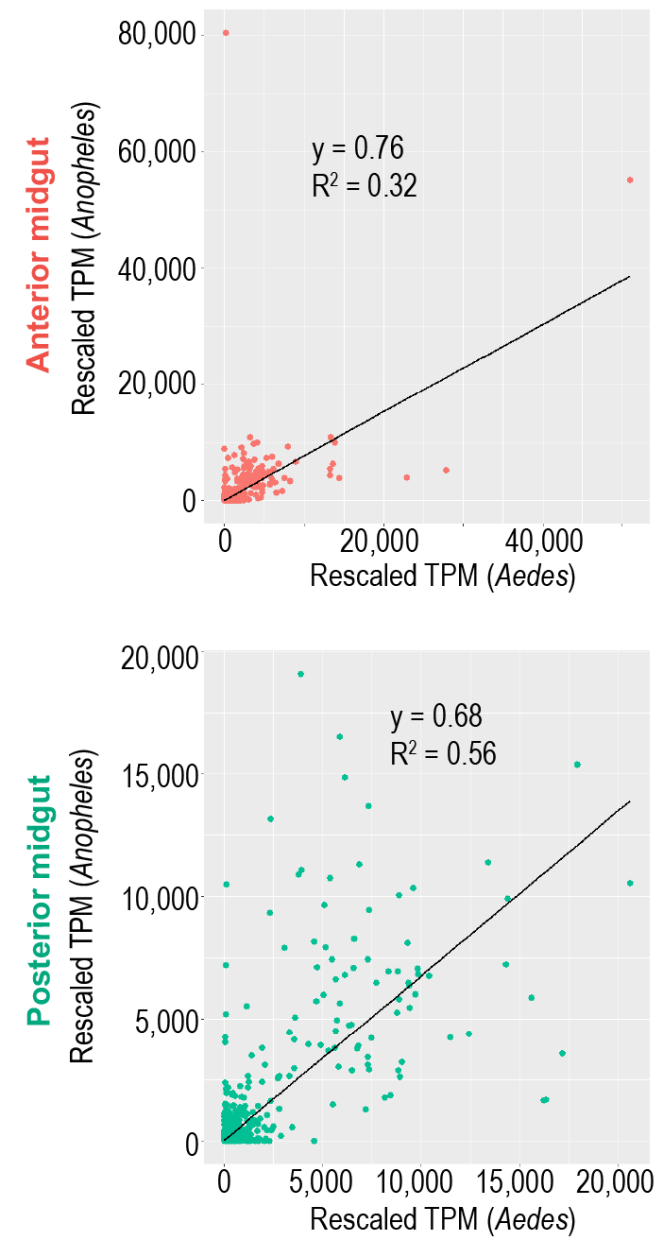

B
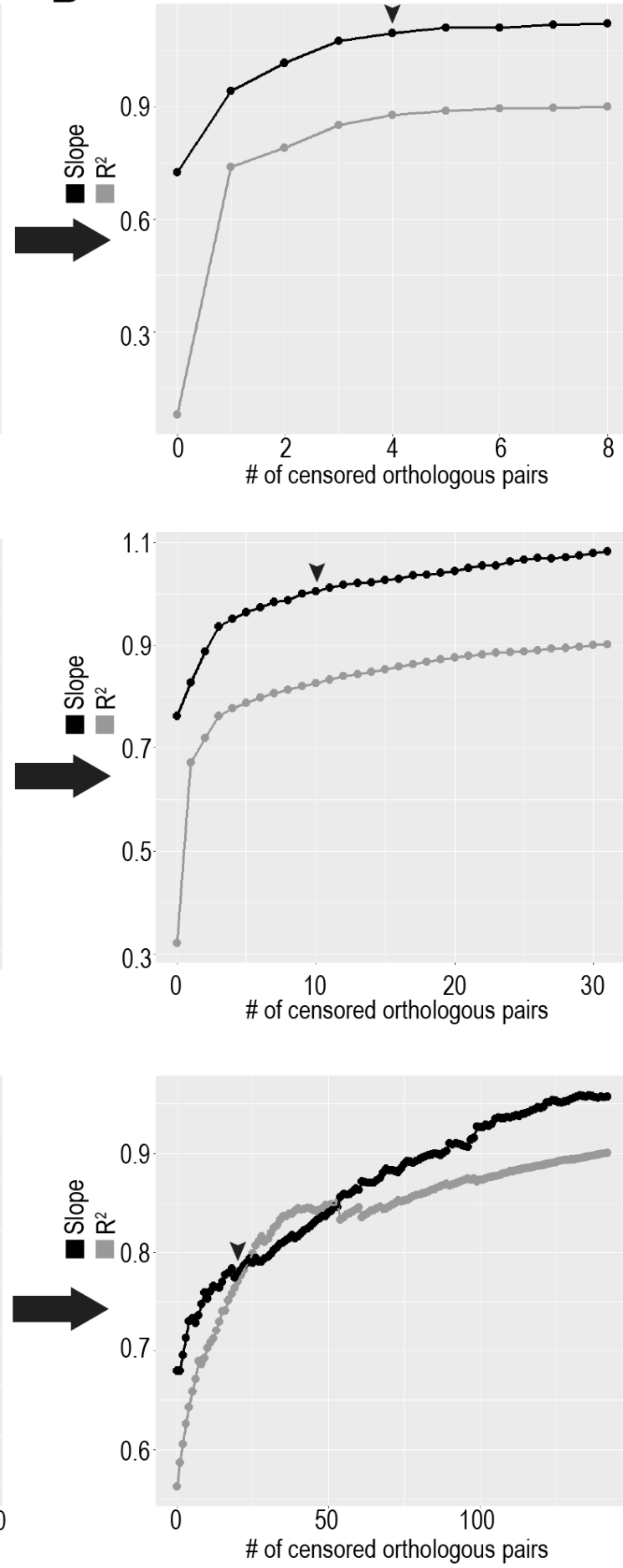

C

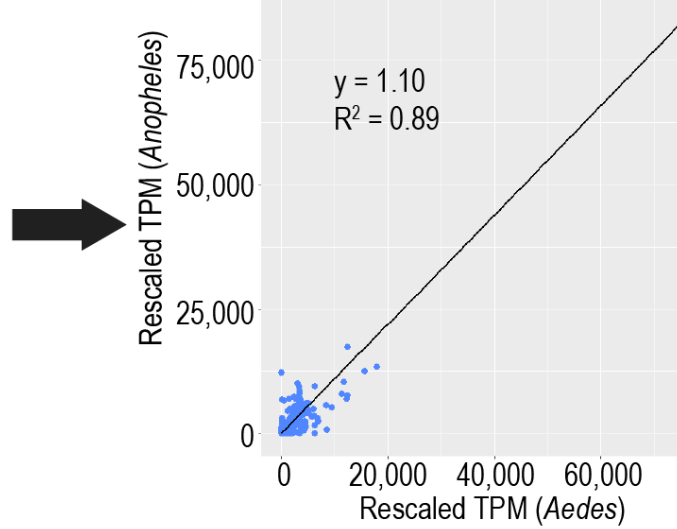

60,000

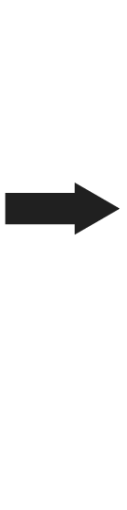

20,000

0

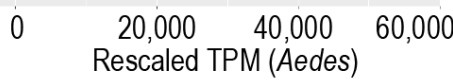

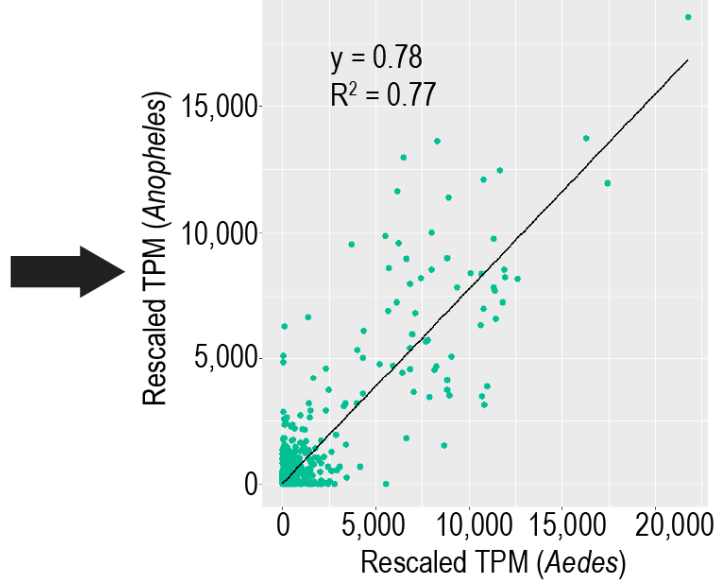


bioRxiv preprint doi: https://doi.org/10.1101/2021.12 19.473372; this version posted December 21, 2021. The copyright holder for this preprint (which was not certified by peer review) is the author/funder, who has granted bioRxiv a license to display the preprint in perpetuity. It is made available under aCC-BY 4.0 International license.

A

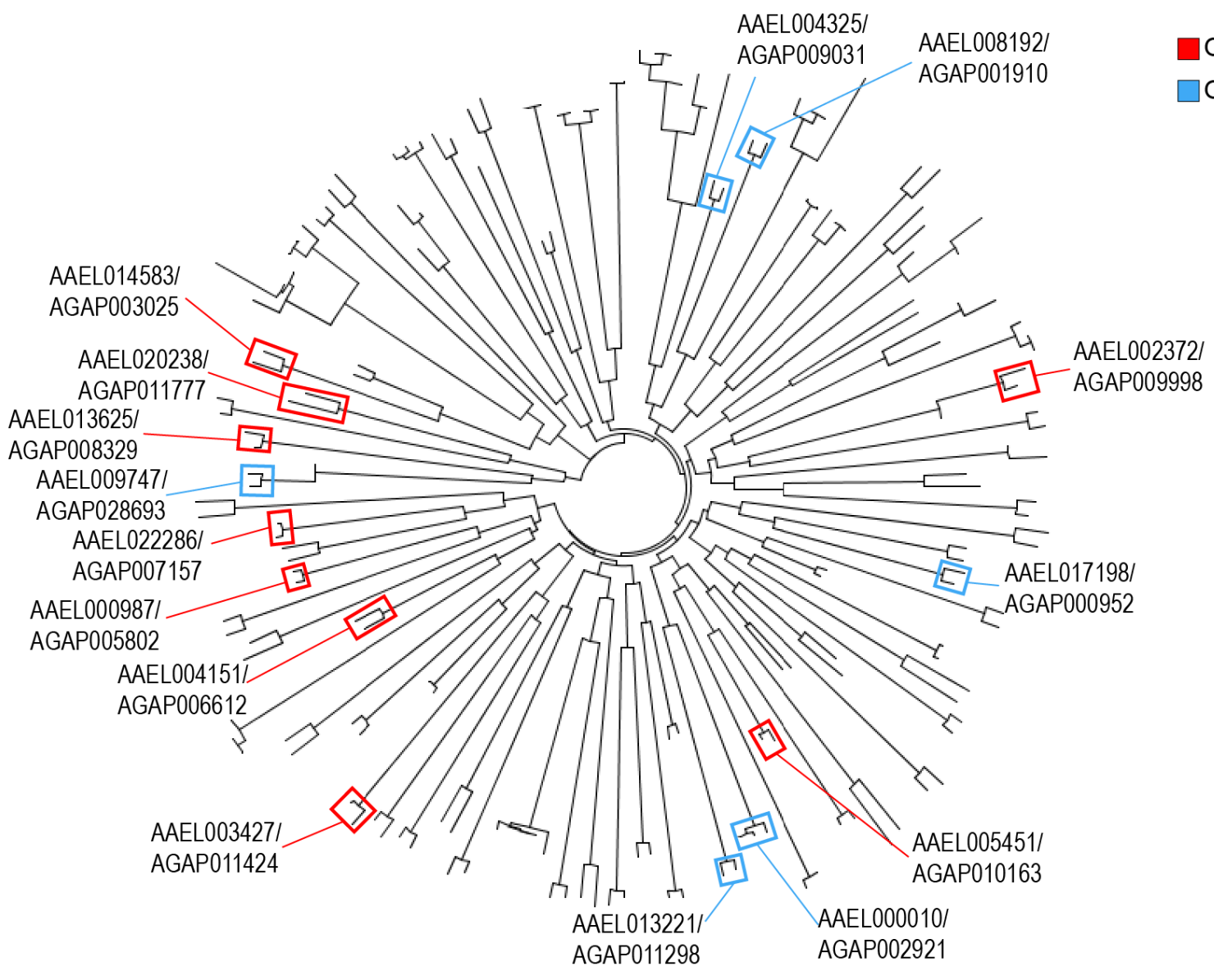

Orthogroup higher in Aedes

Orthogroup higher in Anopheles 
bioRxiv preprint doi: https://doi.org/10.1101/2021.12.19.473372; this version posted December 21, 2021. The copyright holder for this preprint (which was not certified by peer review) is the author/funder, who has granted bioRxiv a license to display the preprint in perpetuity. It is made available under aCC-BY 4.0 International license.

A
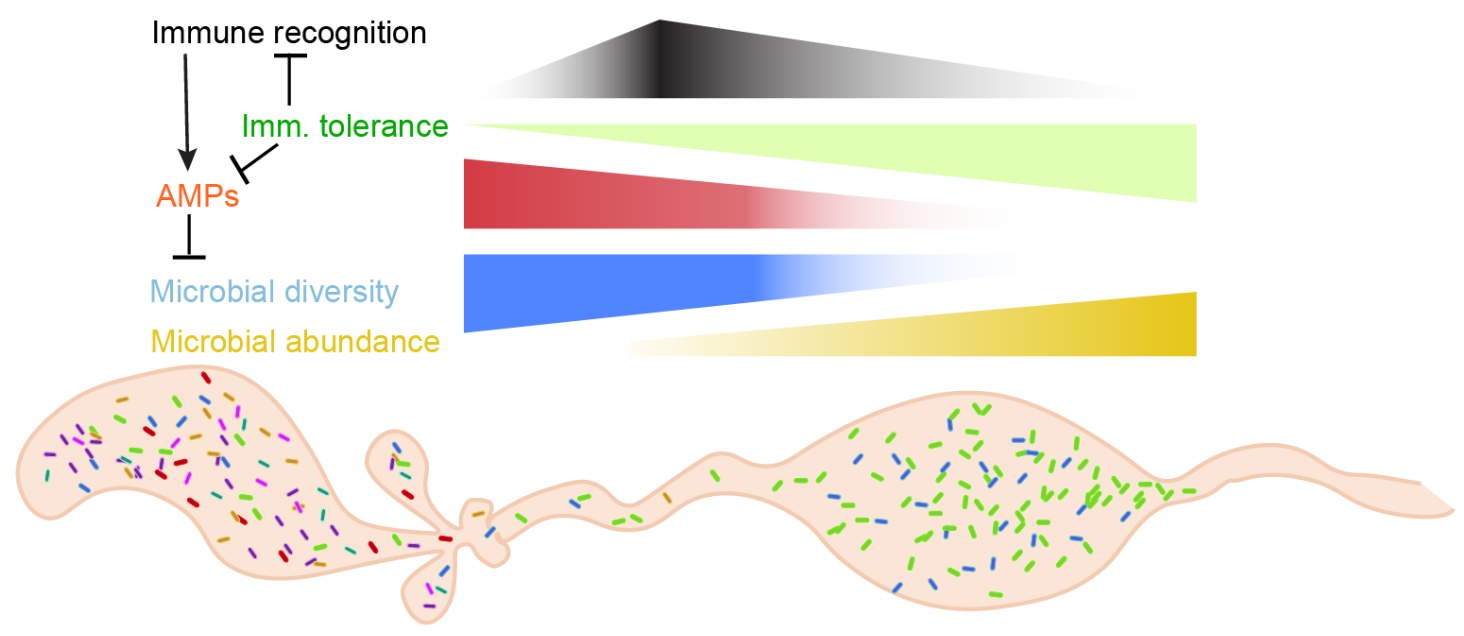